\title{
CU-ICAR HYDROGEN INFRASTRUCTURE FINAL REPORT
}

\author{
September 2011
}

\section{PREPARED BY}

Robert Leitner

David Bodde

Dennis Wiese

John Skardon

Bethany Carter

\section{PREPARED FOR}

Department of Energy

Golden Field Office

\section{Award No.}

DE-FG36-08G088115

\section{DOE PROJECT OFFICER}

James Alkire

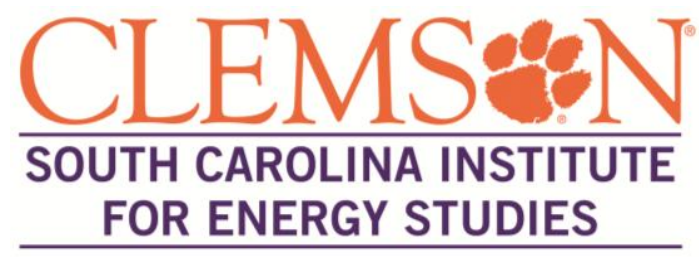




\section{Disclaimer}

This report was prepared as an account of work sponsored by an agency of the United States Government. Neither the United States Government nor any agency thereof, nor any of their employees, makes any warranty, expressed or implied, or assumes any legal liability or responsibility for the accuracy, completeness, or usefulness of any information, apparatus, product, or process disclosed, or represents that its use would not infringe privately owned rights. Reference herein to any specific commercial product, process, or service by trade name, trademark, manufacturer, or otherwise does not necessarily constitute or imply its endorsement, recommendation, or favoring by the United States Government or any agency thereof. The views and opinions of the authors expressed herein do not necessarily state or reflect those of the United States Government or any agency thereof.

\section{Acknowledgements}

The authors would like to acknowledge the following significant contributions to this project:

- Innovation Center Study - Mr. Manmohan Pozhickal performed the early study of innovation center attributes.

- AutoVenture Forum - The American Society of Mechanical Engineers (ASME) provided both financial and staff support to the planning and execution of the AutoVenture Forum. Mr. Ethan Byler managed the ASME efforts. Ms. Patti Jo Snyder of ASME managed the logistical arrangements for the first forum. The AVF team would also like to acknowledge the support provided by USCAR in organizing and hosting the many planning meetings and the encouragement offered by numerous auto industry executives.

- Test Vehicle Conversion - Conversion of the test vehicles was performed by the Mechanical Engineering senior design class and graduate students from the Clemson University International Center for Automotive Research (Frank Richardson, Dave Anderson, Neeraj Chirmulay, and Harish Kohli).

- Fuel System Controller - Grafton Standifer, a student in the Department of Electrical and Computer Engineering, performed the design and fabrication of the demonstration fuel system controller.

- Liquid Carrier and Reactor Testing - Dr. David Bruce and graduate student, Ha Nguyen, of the Department of Chemical and Biomolecular Engineering provided assistance with all aspects of the liquid carrier portion of the project. 


\section{Table of Contents}

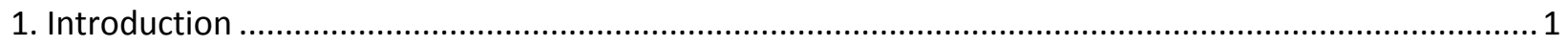

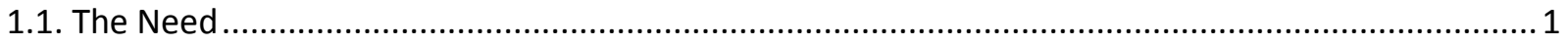

1.2. Project Objective

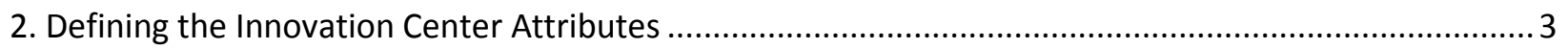

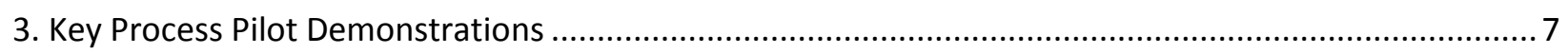

3.1. Industry-Wide Open Innovation Process Demonstration........................................................ 7

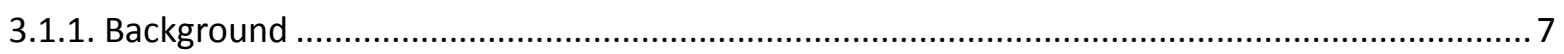

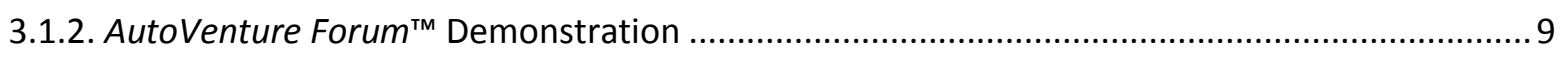

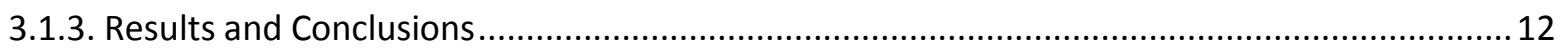

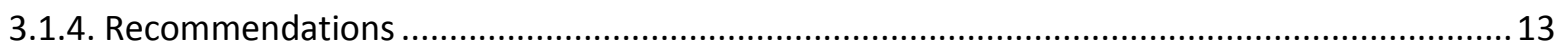

3.2. Technology Demonstration and Validation Process .............................................................. 15

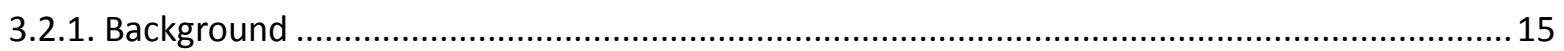

3.2.2. Hydrnol Prototype Fuel System Demonstration ................................................................. 17

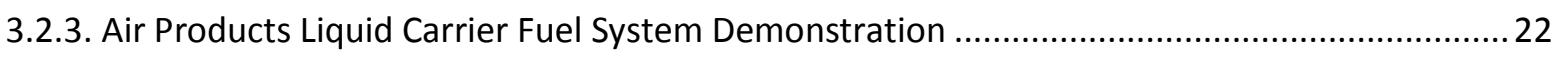

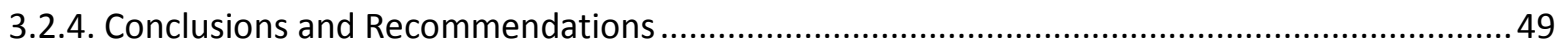

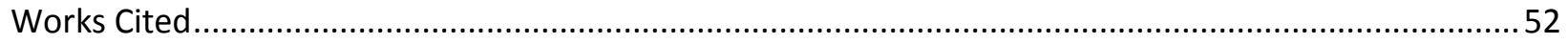

\section{List of Figures}

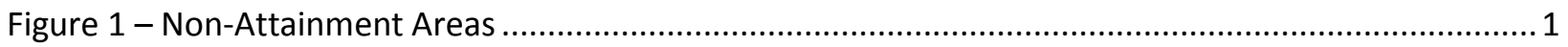

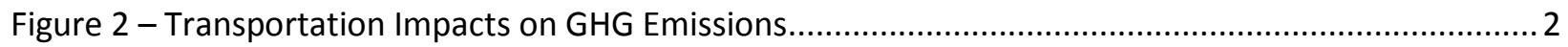

Figure 3 - Functions Performed by University Based Innovation Centers ............................................... 4

Figure 4 - Functions Performed by Community Based Non-Profit Innovation Centers .............................. 4

Figure 5 - Characteristics of University Based Innovation Centers ......................................................... 5

Figure 6 - Characteristics of Community Based Non-Profit Innovation Centers........................................ 5

Figure 7 - Electric Vehicle Powertrain Business Model Convergence ....................................................... 8

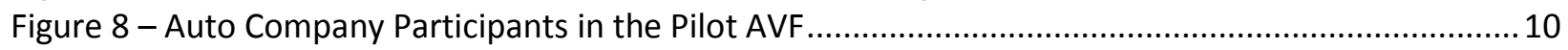

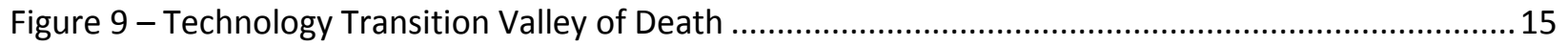

Figure 10 - Liquid Carrier Molecules Used For Prototype Fuel System Demonstration ........................... 17

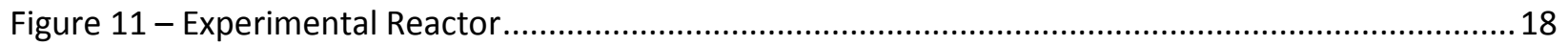

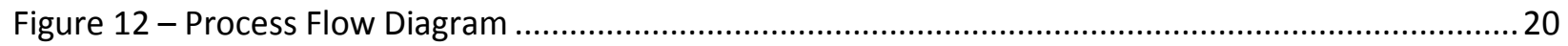

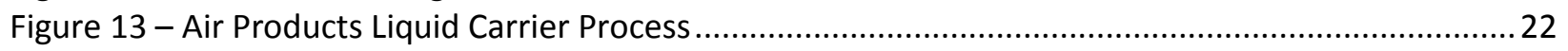

Figure 14 - Gas Chromatogram After 9 Hours Reaction Time...............................................................2 23

Figure 15 - 2,3,4,4a,9,9a-hexahydro-1H-Fluorene Partial Hydrogenation Byproduct .............................24

Figure 16 - Gas Chromatogram After 15 Hour Reaction Time ............................................................. 25

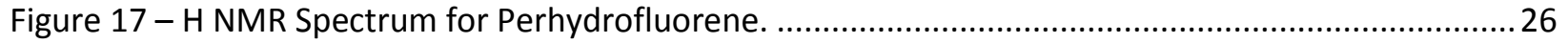

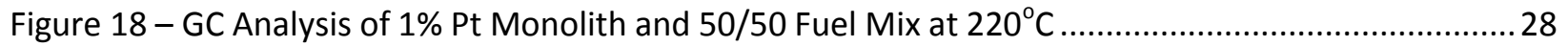

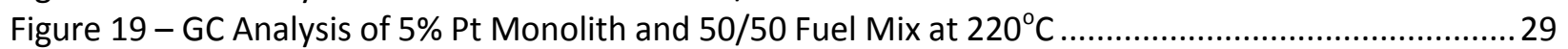

SOUTH CAROLINA INSTITUTE 
Figure 20 - Reaction Products for 5\% Pt Monolith and 50/50 Fuel Mix at $220^{\circ} \mathrm{C}$...................................30

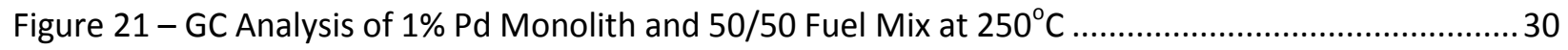

Figure 22 - Reaction Products for 1\% Pd Monolith and 50/50 Fuel Mix at $250^{\circ} \mathrm{C}$.................................. 31

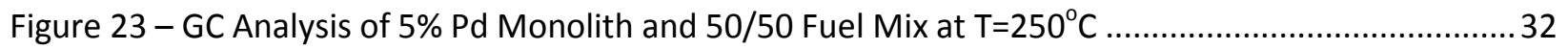

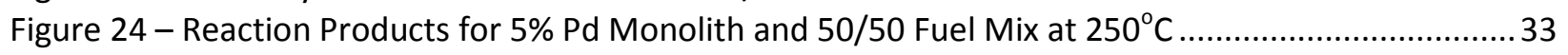

Figure25 - Comparison of Fluorene Production Results for Three Monoliths ....................................... 33

Figure 26 - GC Analysis of 5\% Pd Monolith Reactor with Neat Fuel ................................................... 34

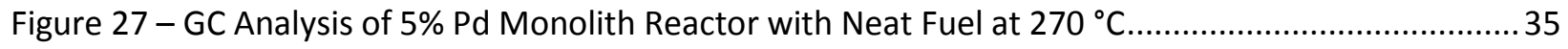

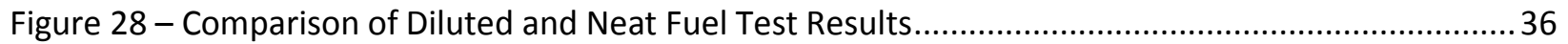

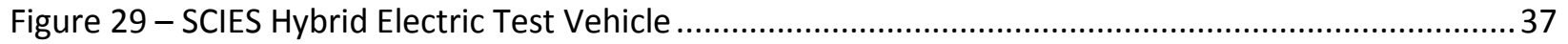

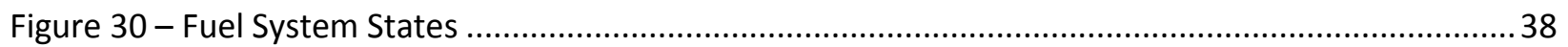

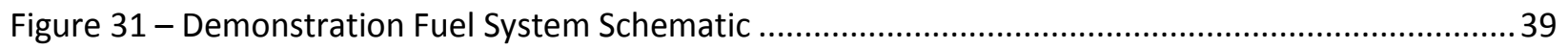

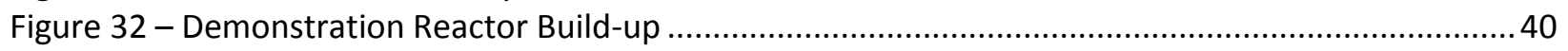

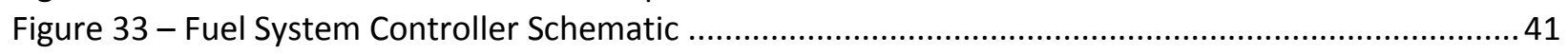

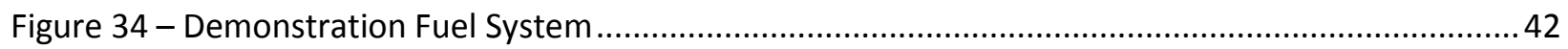

Figure 35 - Demonstration Fuel System Test Installation .................................................................. 43

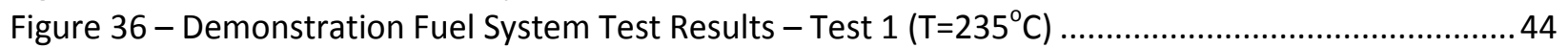

Figure 37 - Demonstration Fuel System Test Results - Test $2\left(T=250^{\circ} \mathrm{C}\right)$...............................................4 44

Figure 38 - Comparison of Experimental and Demonstration Reactor Test Results $\left(\mathrm{T}=250^{\circ} \mathrm{C}\right) \ldots \ldots \ldots \ldots \ldots . . . . .45$

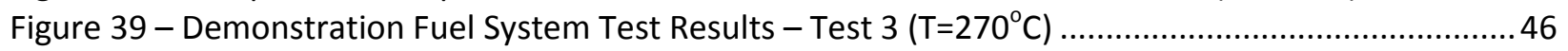

Figure 40 - Comparison of Experimental and Demonstration Reactor Test Results $\left(T=270^{\circ} \mathrm{C}\right) \ldots \ldots \ldots \ldots \ldots . . . . .46$

Figure 41 - Demonstration Fuel System Test Results - Test 4 (Fanfold)..............................................47

Figure 42 - Comparison of Demonstration Fuel System Test Results ....................................................4 48

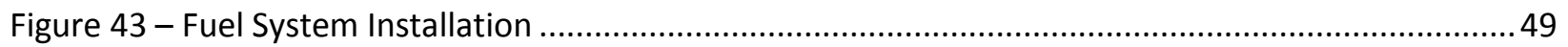

\section{List of Tables}

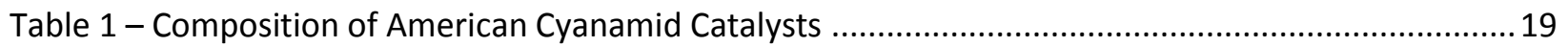

Table 2 - Dehydrogenation results for HDS-20A Catalyst (07July2010) ...............................................19

Table 3 - Dehydrogenation results for HDS-20A Catalyst (08July2010) ............................................... 19

Table 4 - Dehydrogenation results for HDS-2A Catalyst .......................................................................20

Table 5 - Dehydrogenation results for HDS-2A Catalyst with Reactor Bypass.........................................2

Table 6 - Dehydrogenation Results for In-house Catalyst with Reactor Bypass ......................................2 21

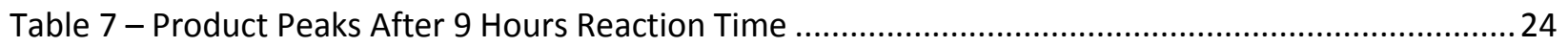

Table 8 - Product Peaks After 15 Hour Reaction Time .........................................................................25

Table 9 - Product Peaks for $1 \%$ Pt Monolith and 50/50 Fuel Mix at $220^{\circ} \mathrm{C}(\mathrm{T}=15 \mathrm{~min})$.............................28

Table 10 - Product Peaks for $5 \%$ Pt Monolith and 50/50 Fuel Mix at $220^{\circ} \mathrm{C}$ ( $\left.\mathrm{T}=90 \mathrm{~min}\right)$..........................29

Table 11 - Product Peaks for $1 \% \mathrm{Pd}$ Monolith and 50/50 Fuel Mix at $250^{\circ} \mathrm{C}(\mathrm{T}=0 \mathrm{~min})$............................. 31

Table 12 - Product Peaks for $5 \%$ Pd Monolith and 50/50 Fuel Mix at $\mathrm{T}=250^{\circ} \mathrm{C}$ ( $\left.\mathrm{T}=30 \mathrm{~min}\right) \ldots \ldots \ldots \ldots \ldots \ldots . . . . . . . . . .32$

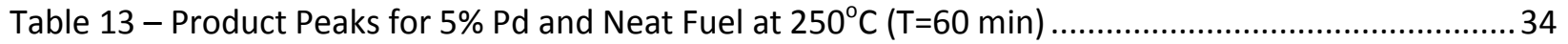

Table 14 - Product Peaks for $5 \%$ Pd Monolith Reactor at $270^{\circ} \mathrm{C}(\mathrm{T}=0 \mathrm{~min})$............................................. 35

Table 15 - Effect of Temperature on Reactor Performance................................................................. 36 


\section{Introduction}

\subsection{The Need}

Automobiles and trucks, powered by internal combustion engines and fueled by abundant, low cost petroleum, have served as the foundation for the prosperity and growth of our geographically dispersed, yet highly interconnected nation for the past century. However, recently, the negative impacts of this mode of transportation on our society have become more apparent. These impacts include:

- $\quad$ AIR QUALITY AND PUBLIC HEALTH. The US Environmental Protection Agency (EPA) uses six "criteria pollutants" as indicators of air quality, and has established a maximum concentration for each of them based on human health concerns. Vehicles are a major source of several criteria pollutants, including particulate matter, carbon monoxide and ozone. Despite large reductions in vehicle emissions, approximately 300 counties across the US, shown in Figure 1, are non-attainment areas today.

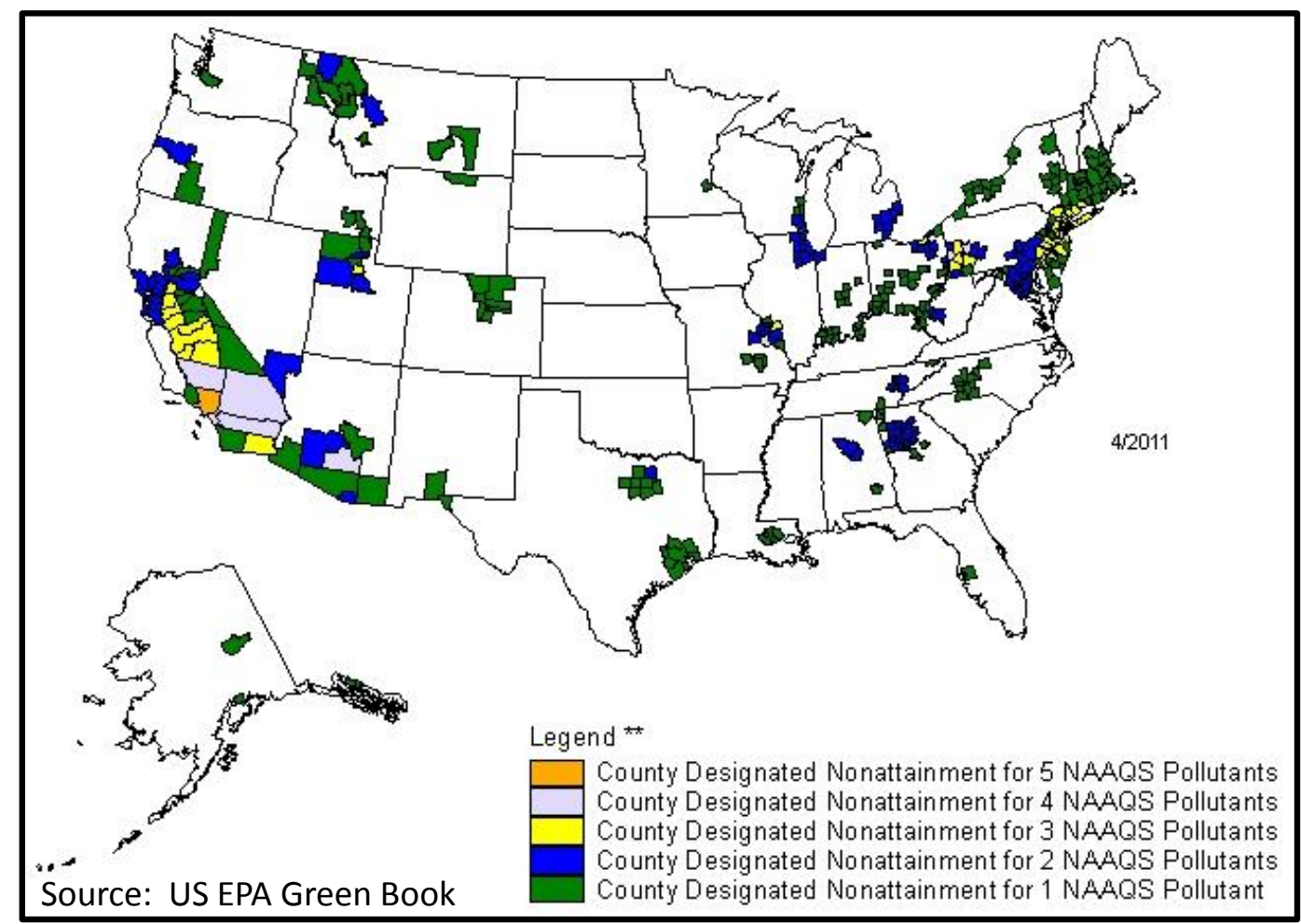

Figure 1 - Non-Attainment Areas

- CLIMATE CHANGE. The transportation sector is the second largest source of Greenhouse Gas (GHG) emissions in the US, and with substantial increases in vehicle demand in large developing nations, such as China, it is one of the fastest growing sources globally, as shown in Figure 2. 


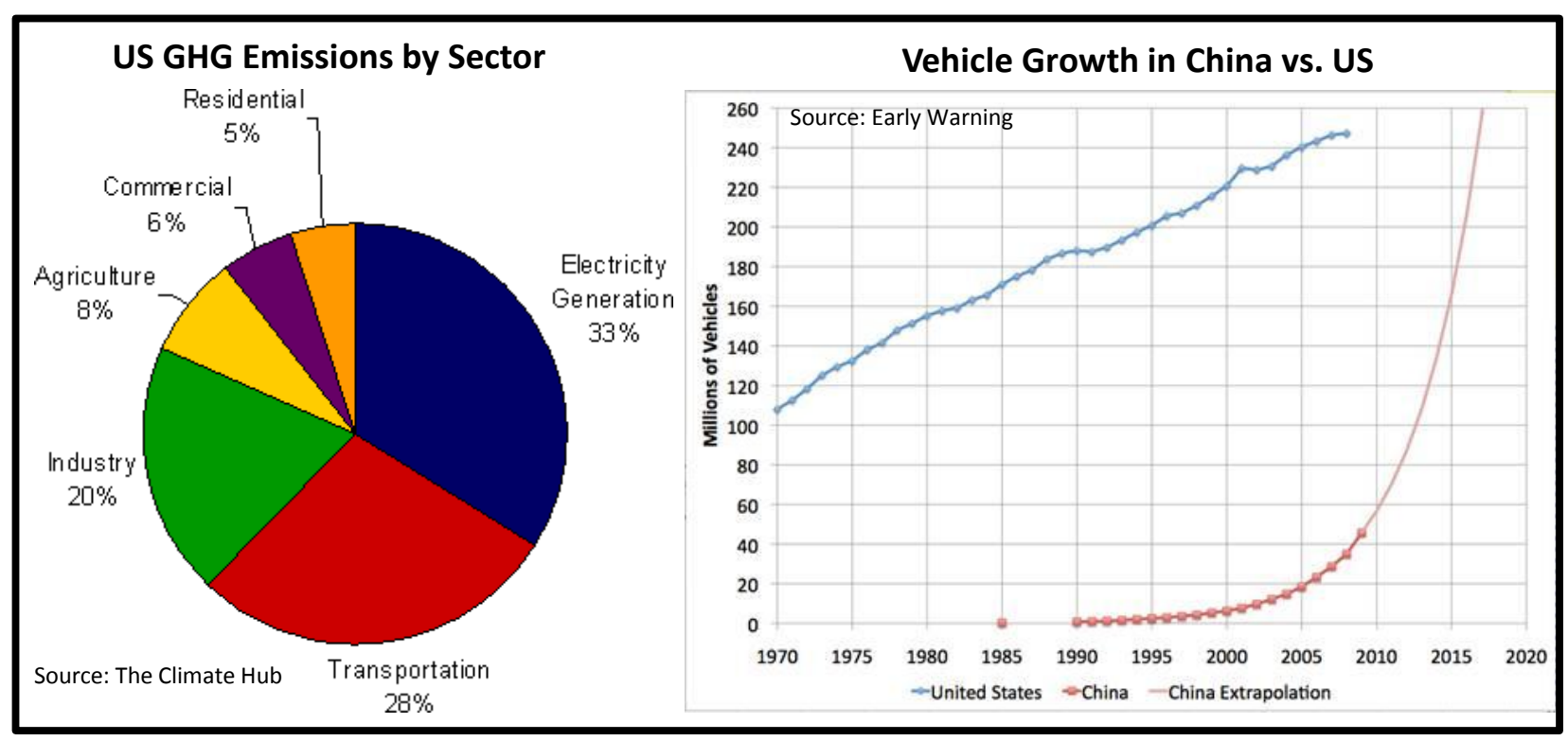

Figure 2 - Transportation Impacts on GHG Emissions

- ENERGY AND ECONOMIC SECURITY. The United States imports more than $60 \%$ of its petroleum, leaving the economy vulnerable to price fluctuations and supply disruptions on the global market. In 2009, the US petroleum trade deficit topped $\$ 200$ billion, more than $40 \%$ of its total trade deficit. (1) In addition, increased demand from large developing countries, such as China and India, coupled with finite supplies of petroleum that are increasingly more difficult to recover, will place growing pressure on prices and availability.

The need is clear. The automotive and fuel industries must transition to a more sustainable fuel source that reduces GHG and pollutant emissions and that enhances our nation's economic and energy security. This transition must be rapid, affordable, and not disruptive to the US economy which depends so heavily on vehicular transportation. The goal of this project is to support and enhance this transition.

\subsection{Project Objective}

The original project objective established in 2008 was to demonstrate a pilot innovation center that would support the Bush Administration's goal of accelerating the transition to a "hydrogen economy" consisting of hydrogen fueled vehicles and fueling infrastructure. With the change in Administrations and the move toward vehicle technologies with earlier commercialization opportunities, such as battery electric vehicles and plug-in hybrid electric vehicles, the objective of the project was adjusted to support this change in emphasis. The revised objective was to demonstrate key innovation processes for more rapidly and cost effectively transitioning to more sustainable technologies, including but not limited to hydrogen, in the automotive sector. 


\section{Defining the Innovation Center Attributes}

Initial efforts focused on collecting information on existing innovation centers and incubators to determine the key functions that they perform and key center characteristics. Two basic types of innovation centers were identified; those connected to or sponsored by a university and community based non-profit centers. Data on a total of 35 centers, listed below, were collected and analyzed.

\section{University Innovation Centers}

1. William J. von Liebig Center at UCSD

2. Deshpande Center at MIT

3. UC Davis Innovation Access

4. The Madison Gas \& Electric (MGE) Innovation Center at University of Wisconsin Madison

5. The Innovation Center at Rogers State University

6. Ohio University Innovation Center

7. Collaborative Innovation Center $(\mathrm{CIC})$ at Carnegie Mellon

8. The Technology Innovation Center, the University of lowa

9. Wisconsin Innovation Service Center at University of Wisconsin Whitewater

10. The Boulder Innovation Center, University of Colorado

11. Rutgers Food Innovation Center

12. The Austin Technology Incubator and Clean Energy Incubator, University of Texas at Austin

13. University of Central Florida Incubation Program

14. Arizona Center for Innovation

\section{Community Based Non-Profit Innovation Centers}

1. The Rocky Mountain Innovation Initiative

2. Southwest Michigan Innovation Center

3. Ben Craig Center at UNC Charlotte

4. Technology Innovation Center at Illinois

5. Gwinnett Innovation Park

6. The Advanced Technology Development Center

7. The Seminole Technology Business Incubation center

8. Delaware Technology Park

9. The Business Technology Center of Los Angeles County

10. Mid-Michigan Innovation Center

11. BizTech

12. CleanStart

13. The Enterprise Center of Johnson County

14. Environmental Business Cluster

15. IGNITE

16. Technology Research and Development Authority Business Innovation Center

17. Technology Ventures Corporation

18. Bessemer Business Incubation System

19. The Center for Entrepreneurial Excellence at Alabama

20. The Nussbaum Center for Entrepreneurship

21. Ny Designs 
Figure 3 summarizes the various functions that are performed by university sponsored innovation centers, and the percentage of the 14 centers which were surveyed that perform these functions. Figure 4 provides similar information for the 21 non-profit community based centers.

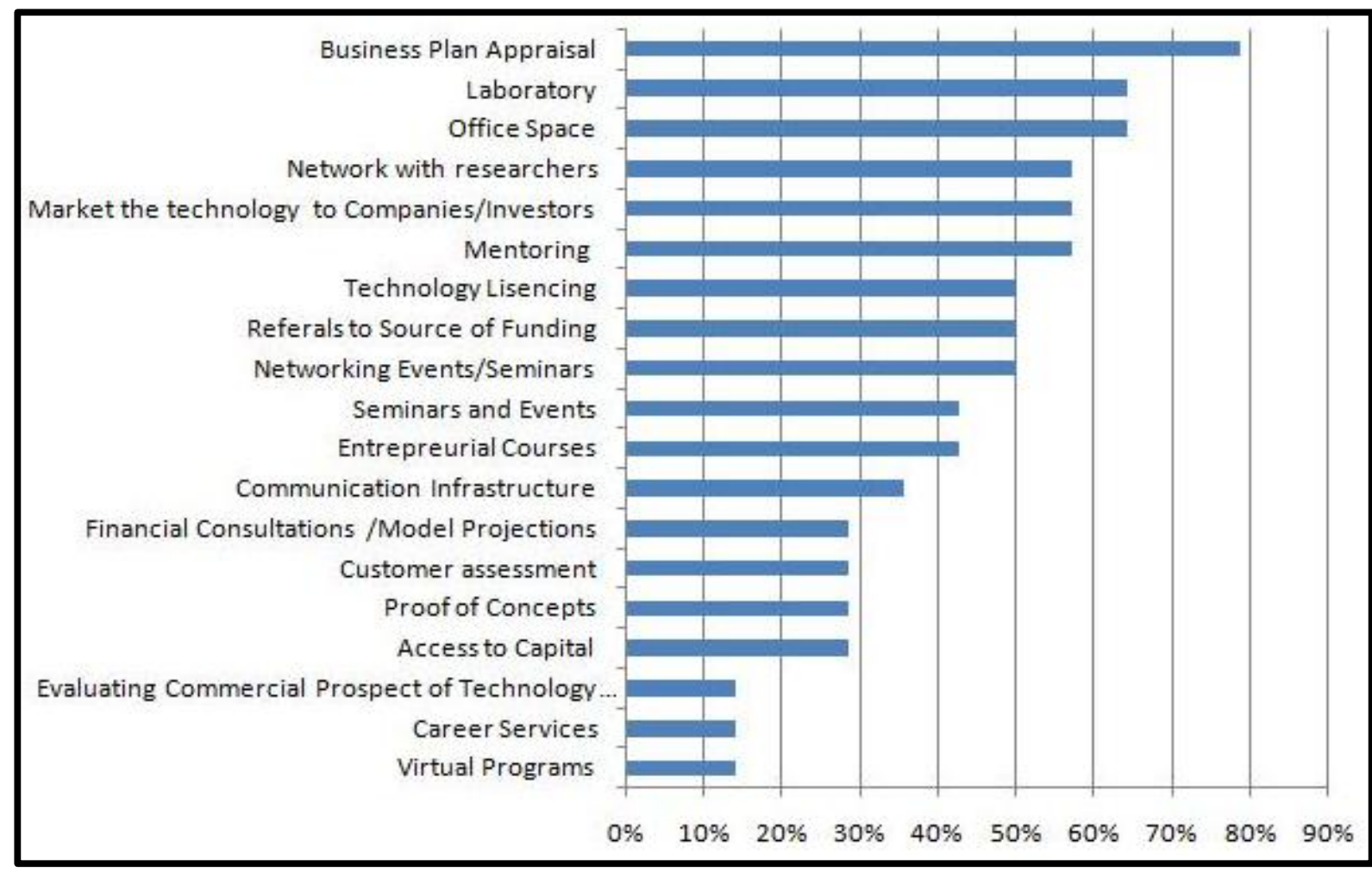

Figure 3 - Functions Performed by University Based Innovation Centers

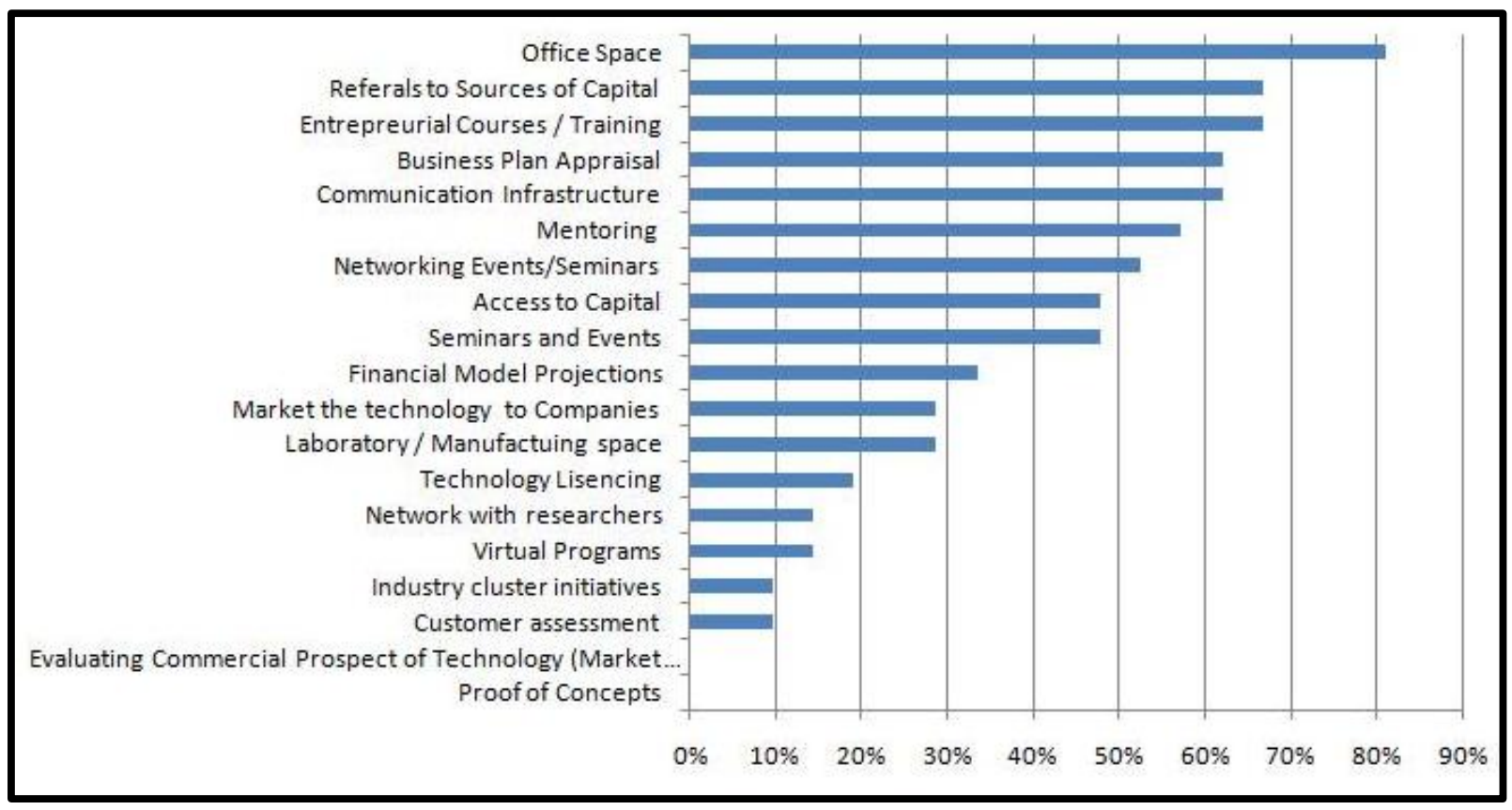

Figure 4 - Functions Performed by Community Based Non-Profit Innovation Centers 
In addition to identifying key functions performed by innovation centers, key center characteristics also were identified. These characteristics are summarized in Figures 5 and 6.

Located inside main campus Market Focus

Multi disciplinary

Well defined Client entrance and exit strategy Paid Advisors from Business Community Attorney referals

Database for easy access to technology and talents

Alumini involvement

Events to showcase the technology

Equity Partnership

Highlights Tax Break Advantage

Presence of established Companys Volunteers from Business Community

Sustained a decade of operation

Proximity to Local Businesses Non Residential Clients

Staff with Business/ Entrepreneurial experience

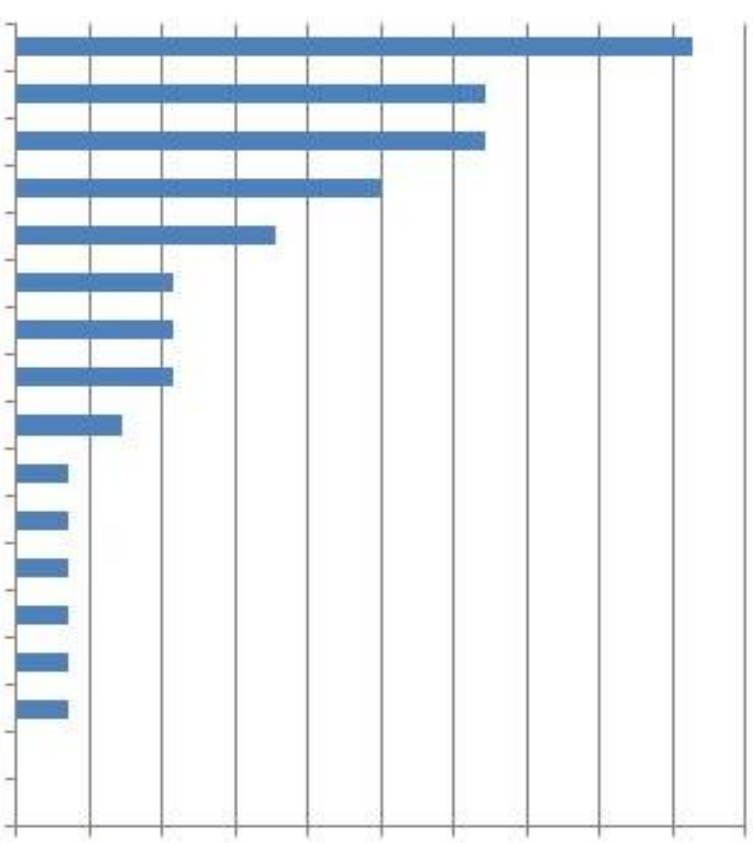

$0 \% \quad 10 \% \quad 20 \% \quad 30 \% \quad 40 \% \quad 50 \% \quad 60 \% \quad 70 \% \quad 80 \% \quad 90 \% 100 \%$

Figure 5 - Characteristics of University Based Innovation Centers

Well defined Client entrance and exit strategy

Marketing Focus

Paid Advisors from Business Community

Proximity to Local Businesses

Multi disciplinary

Staff with Business/ Entrepreneurial experience

Attorney referals

Intern Program

Sustained a decade of operation

Non Residential Clients

University Relations

Highlights Tax Break

External Clients Affiliates

Presence of established Companys

Volunteers from Business Community

Events to showcase the technology

Database for easy access to technology and talents

Alumini involvement

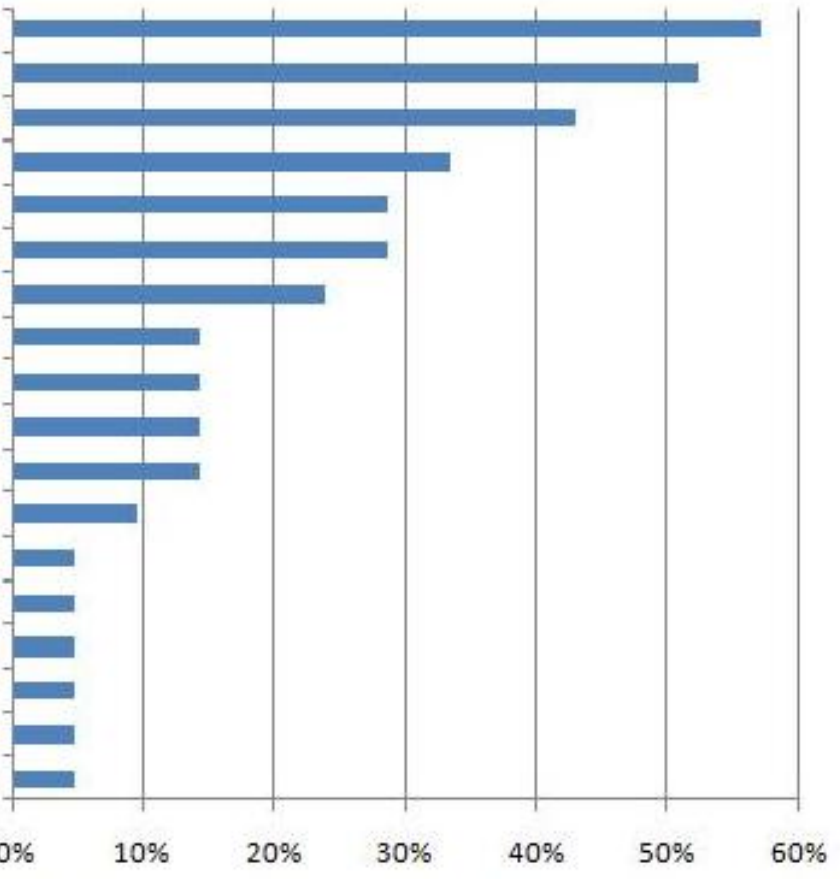

Figure 6 - Characteristics of Community Based Non-Profit Innovation Centers 
Based on these data and a review of the literature, two process areas were identified that offered potentially high payoff for the auto and fuels industries and were not duplicative of capabilities already in widespread use within innovation centers. These two process areas were:

1. An industry-wide open innovation process

2. Prototype demonstration and validation

The objective of our project was to develop and demonstrate the potential of these two processes in accelerating the transition of the auto and fuels industries to more sustainable, environmentally responsible, and secure vehicles and fuels. 


\section{Key Process Pilot Demonstrations}

\subsection{Industry-Wide Open Innovation Process Demonstration}

\subsubsection{Background}

The innovation process that has served the auto industry well for over 100 years is evolving in response to persistent, external stresses, (2) including:

- The impact of auto emissions on air quality and climate change;

- The price and future availability of motor fuels;

- Federal requirements for increased fuel economy; and,

- Intense international competition.

These stresses have produced rapid shifts in the types of vehicles demanded by the public and fragmentation of the market into electric, compressed natural gas, and propane powered vehicles, as well as electric, hydraulic, and pneumatic hybrids (in addition to improved gasoline and diesel engines and flex fuel designs). Clearly, a faster and less costly approach to innovation in this transition period would be beneficial.

At the same time, new business models derived from the convergence of microprocessors, telecommunications, and software have emerged to offer information services to drivers - navigation, safety, information, entertainment and even vehicle operation. Consider, for example, the internet and phone applications that have been developed to tell electric vehicle drivers where the nearest charging stations are, what type of charging is available, and if the charger is in use or has been reserved.

In addition, new competitors have arisen from an increasingly diverse set of technology suppliers around the globe. Some of these technology suppliers, especially in developing countries, have integrated forward into vehicle production. Consider BYD, for example, the Chinese battery manufacturer that is integrating into electric vehicles with investment from Warren Buffett. Thus, the scope of opportunity and the breadth of competitive threats have multiplied. Over the last 10 years, automakers around the world have responded to such pressures by opening their once verticallyintegrated innovation processes to include selected suppliers.

The next logical step in this progression is to include the entrepreneurial sector-the proliferation of new ventures with innovative technologies seeking markets, strategic development partners, and investors. Much evidence suggests that the strategic engagement of entrepreneurs, widely known as open innovation, can yield competitive advantage for individual companies. At Proctor and Gamble, for example, a strategy of open innovation that was begun in 2002 now yields over 1/3 of the company's innovations. (3) Other industry leaders have established open innovation business models in a variety of contexts. (4) What has yet to be accomplished is the application of open innovation at the industry level rather than the company level, a strategy most appropriate when a common industry-wide solution is beneficial to the public - as is the case with vehicles and fuels.

Throughout history, revolutionary technologies from steam to microelectronics have been launched by entrepreneurs and not by industry incumbents. Indeed, evidence suggests that this tendency has increased in recent times. A study of patents by the U.S. Small Business Administration found that small firm patents are twice as likely as those from large firms to be among the 1 percent most frequently 
cited. (5) And a subsequent study (6) showed that small companies have recently become the majority of those considered "most innovative."

Nevertheless, the large industry incumbent remains essential for many economically meaningful innovations. (7) In the case of the auto and fuels industries, entrepreneurial innovations need industry incumbents for three reasons. First, entrepreneurial innovations must scale up to become economically meaningful. In a rapidly changing market with many competitors and imitators, rapid scale up is key to success. However, rapid scale-up requires large-scale investment and manufacturing knowhow. Second, for complex assembled products like autos, the integration of the innovation into the larger system becomes a task that can only be accomplished by the systems integrator-in most cases the industry incumbent. (8) And finally, incremental improvements to the original entrepreneurial innovation can accumulate to become a significant source of performance growth, while incremental improvements in the production process simultaneously reduce cost. (9) Such improvements tend to be the domain of the established company.

The electric powertrain vehicle, which is currently being promoted by governments around the globe as a solution to environmental and fuel security problems, is a good example of where industry-wide open innovation has payoff. Three traditional and formerly distinct business models converge around the electric vehicle powertrain. These traditional business models (illustrated in Figure 7) include:

- $\quad$ Auto companies, once vertically integrated, now requiring innovation by suppliers at all tiers, but still lacking systematic connections with entrepreneurs and new ventures;

- Energy companies, traditionally commodity energy providers, but increasingly facing competition from "smart" electricity and renewable electricity generated from distributed sources; and

- Information and communication companies, offering smart devices and systems that manage electric energy onboard vehicles, among energy-using devices, and within smart grids.

Entrepreneurs are especially active at the interface among these traditional business models because the most attractive opportunities to accelerate the pace of change reside there.

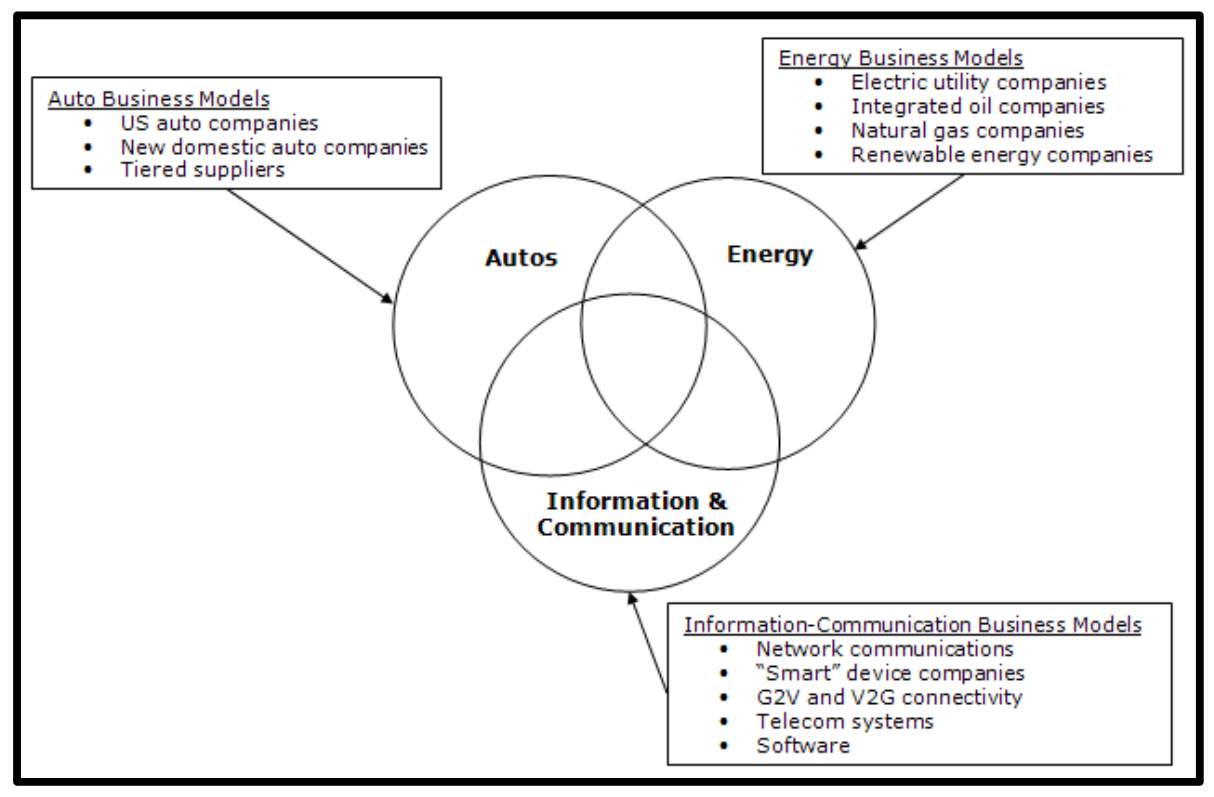

Figure 7 - Electric Vehicle Powertrain Business Model Convergence 
Within this convergence of business models can be found game-changing opportunities that would accelerate the pace of change. (10) For example, consumers could realize more value from their plug-in hybrid or all-electric vehicles if they had the opportunity to recharge at any place and time. That would extend the electric range of these vehicles independent of the pace of battery improvements. Further, the energy supplied to the recharging stations could be derived, at least in part, from distributed and renewable sources. And because the renewable energy could be stored on vehicles at the higher value of transportation fuel rather than the lower price of grid electricity, the cost of energy storage, a formidable barrier to renewable electricity, would not inhibit its use. And with smart grid technology, (11) any parking lot so equipped could become a marketplace where vehicles exchange electric energy with each other, with the grid, and with local renewable electric generation.

\subsubsection{AutoVenture Forum $^{\mathrm{TM}}$ Demonstration}

To better understand how open innovation could be applied to an entire industry, Clemson University and the American Society of Mechanical Engineers (ASME) undertook a proof-of-concept industry-wide, open-innovation network demonstration. We called this first step the AutoVenture Forum ${ }^{\mathrm{TM}}$ (AVF), and its purpose was to accelerate sustainable mobility innovation by linking the fresh ideas and perspectives of entrepreneurs with the technology base, systems integration, manufacturing, and market channels of the established auto industry. The AVF sought to augment, not replace, the current innovation processes of the auto industry. The demonstration AVF, a one-day meeting in which new venture companies presented their technologies to the industry, served as the point of departure for building an industry-wide open innovation service.

The AutoVenture Forum was begun with the hypothesis that an open industry-wide innovation network can both increase the number of innovations that are commercialized as well as the speed of commercialization by linking entrepreneurial companies that have developed relevant new innovations with the systems capabilities, manufacturing capacity and market channels of the industry incumbents. A network innovation process can bypass the limitations of the more vertically integrated innovation models to realize opportunities like these. And in doing so, network innovation can accelerate the transition to sustainable mobility.

At the beginning, we set out several principles for the open innovation network, which we applied rigorously to the demonstration AVF. These principles were derived from the experience of research consortia such as Sematech and the auto industry collaborative FreedomCAR. The AutoVenture Forum serves as an impedance matching network between the disparate cultures of the entrepreneurial venture and that of the established industries. Its aim is to drive deal flow, the progression of opportunities, for the industry participants and for the entrepreneurs. History and experience suggest that five principles should guide operations:

1. Neutrality. The open innovation network must remain pre-competitive, a good-faith broker for all partners. It must be a catalyst for opportunity, but not become involved in deals between partners. Here, fact and perception must align well.

2. Leverage. The network should reinvent nothing, but rather adapt success from experiences gained elsewhere.

3. Learning. The business model and value proposition will surely evolve over time, and so continual learning and adaptation are essential.

4. Partnership. The value of a network is proportional to the number of active members. Thus, the network should attract a variety of participants and remain open to new members whose presence can add value. 
5. Service. Designing and delivering useful, cost-effective services is essential to attract entrepreneurial ventures. A healthy deal flow of partnering opportunities provides the greatest value for the industry participants.

Securing auto industry participation in the pilot AVF proved to be a daunting task. However, after extensive meetings and discussions, eighteen auto companies agreed to participate. These companies are listed in Figure 8. A second area of considerable discussion was the focus of the AVF. Ultimately, the companies agreed that a narrow focus, which would ensure that they had the right technical experts at the forum, was the best approach. The auto companies requested that the pilot AVF focus on vehicle connectivity (often referred to as "V2X") - the set of sensor, communication, microelectronic, and software technologies that link a vehicle to: (a) other vehicles, (b) entertainment and information, (c) supporting infrastructures like fueling or road; and (d) emergency services. (12)

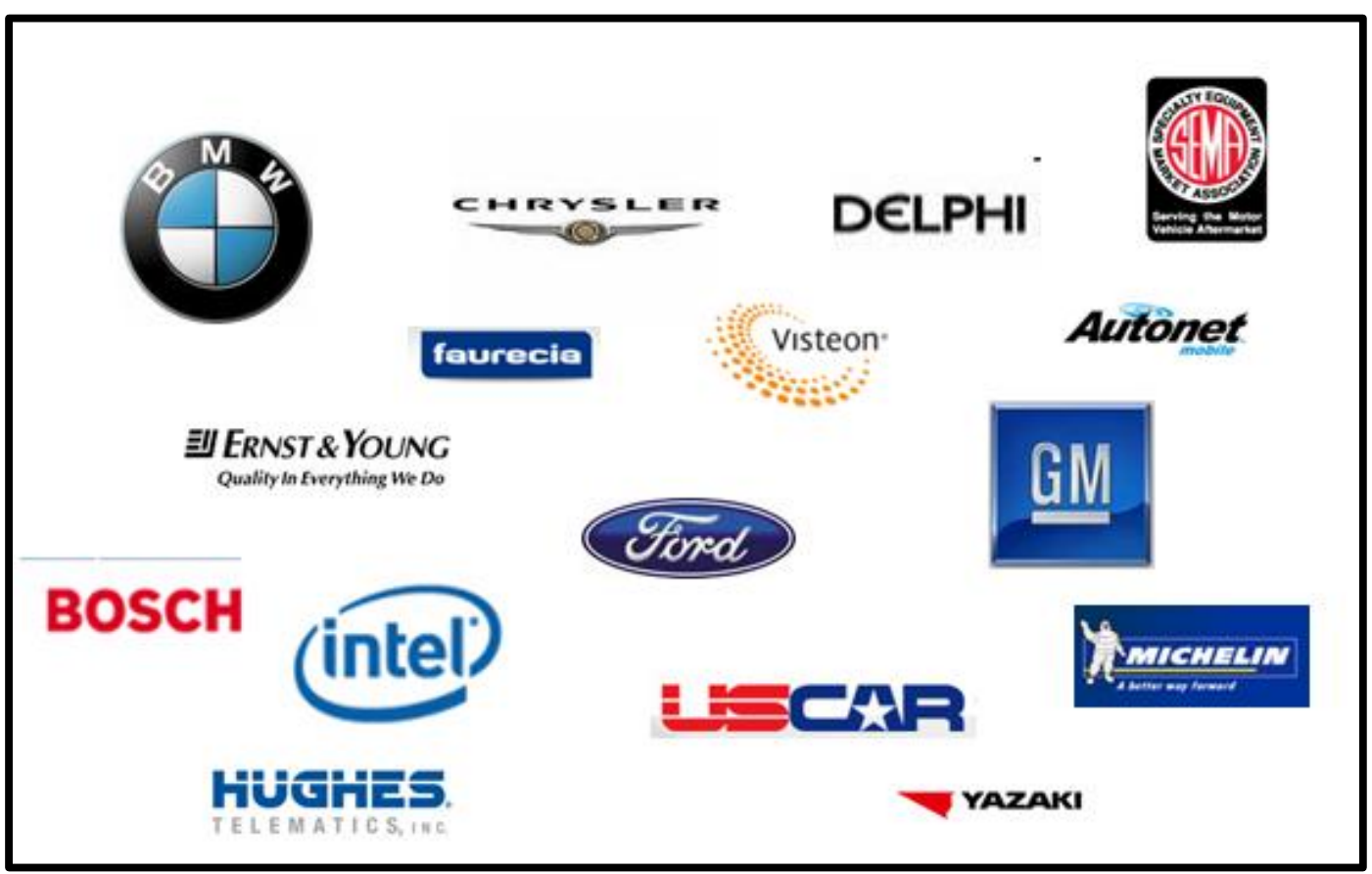

Figure 8 - Auto Company Participants in the Pilot AVF

The entrepreneurial companies were selected through an intensive 6-month search in cooperation with venture capital associations like the Angel Capital Association, state entrepreneur support organizations like the State Science and Technology Institute, and professional societies like the Connected Vehicle Trade Association. The AVF team set out four key criteria for inclusion in the Forum:

1. Participating new ventures must have at least one round of professional venture capital investment, either from a state agency, angel investors, or an established VC firm. This provided an essential external validation: that professionals acting in their self-interest had put their own money into the venture.

2. The new ventures must have a clearly articulated idea of the value they bring to the auto sector. 
3. The new ventures must have a clear idea of what they are seeking in an auto industry partner - product sales, R\&D partnership, product development partnership, investment, and so forth.

4. The new ventures must set out the experience and qualifications of the management team.

Over 30 new venture companies applied to participate in the first AVF, of which 12 were invited after undergoing an extensive screening process based on the four criteria above. The 12 companies selected were:

- Aha Mobile - developer of an online platform that uniquely enables automotive manufacturers to incorporate Web content safely in their vehicles and future proof those vehicles to work with the latest Web content years into the future without ever requiring a software update

- Audible Auto - a developer of multi-faceted audio infotainment technologies across a variety of platforms that will allow drivers to personalize their driving experience just as users of smartphones, iPads and laptops can customize their interactions with their respective electronic devices

- Carma Systems, Inc. - develops and markets an integrated $\mathrm{m} 2 \mathrm{~m}$ telematics vehicle diagnostics monitoring, as well as environmental engine performance hardware and software, device

- Celadon Applications - a software development company that focuses on developing software solutions for unmet telematics and infotainment niches for the hybrid and electric vehicle market

- Centrafuse - a provider of embedded software tools and feature bundles that enables any auto manufacturer to capitalize on the Connected Car trend

- DriveCast - developer of a web-based media manager that solves the GUI/HMI issue of managing multimedia contents for the car

- Monarch Antenna, Inc. - has invented "game changing" technology in smart antennas for the entire spectrum of applications and frequencies

- Motolingo - provides a complete solution to dangerous driving and vehicle management that works out of the box on mobile phones and PCs

- Power Tagging - a smart grid technology company dedicated to improving grid intelligence, as well as improved grid energy efficiency and grid stability as new uses for power emerge

- Rajant Corporation - a leading provider of wireless mesh network solutions

- SensorTech - an advanced materials company commercializing "smart plastic" sensors and switches that make other products more intelligent

- Zipit Wireless - develops device software and operates network services for some of the largest technology companies in the world that market and distribute connected and managed wireless devices

All twelve were given extensive briefings by the AVF team on how to present their company to the industry attendees in 15 minutes - and absolutely no more.

The demonstration AutoVenture Forum, a one-day event, was held on 22 September in Novi, Michigan, a suburb of Detroit. Over 90 people attended from the 18 auto companies (OEMs and suppliers) and the 12 new venture companies. 


\subsubsection{Results and Conclusions}

The response of those participating in the demonstration AVF was overwhelmingly positive. Soon after the forum, the AVF team sent a brief e-mail survey to all the participants, simply to test immediate reactions. Of those responding, 77 percent ranked the AVF either "high" or "very high" in quality, and 40 percent held the event to be absolutely unique. In addition, early responses from the entrepreneurs and comments from the industry participants affirm the value of the connections made.

To be sure, the longer-term consequences for the automotive innovation cycle remain to be proven. It simply takes time for the relationships that were begun in AVF to bear fruit in the form of private deals, e.g. research partnerships, product sales, and the like. But the preliminary and anecdotal results obtained thus far affirm that this proof will be worth the effort to obtain it.

The most important findings from the design, startup, and execution of the AutoVenture Forum are:

\section{Central Role of Supply Chain in Automotive Innovation}

Evidence suggests that the auto industry is evolving toward a community of innovation and away from its formerly vertically integrated structure. The full integration of the entrepreneurial community into this community of innovation is the next logical step. However, this logic does not imply that entrepreneur integration should occur primarily with the OEM. To the contrary, OE suppliers could offer a more logical connection, because they relieve two key concerns for the OEM:

- Production Scale-up. OEMs are concerned with the ability of a new venture to increase production quickly enough to match the pace of new-vehicle introduction. A new venture affiliated with an OE supplier would help ensure reliable scale-up.

- System Integration. For the OEM, integration of much new technology now takes place at the level of major systems and sub-systems rather than individual components.

This logic implies that the OE suppliers must play a key role in any future AVF. The OEM senior managers with whom we have worked support this view.

\section{AVF as an Engine of Job Creation}

Job creation in the domestic supply chain could become an accompanying economic benefit of AVF. Much evidence suggests that in some industries -- microelectronics, for example -- the innovation occurs in the U.S. but the scale-up in manufacturing occurs offshore. (13) While innovation creates wealth, scale-up creates the jobs now needed in our economy. By making connections between domestic $\mathrm{OE}$ suppliers and new ventures, AVF can encourage scale-up and hence job creation within the North American market.

\section{Quality Deal Flow}

The heart of value-added for an industry-level mediator like AVF derives from the quality of the entrepreneurial ventures that it attracts. If this activity were to be continued in the future, ongoing relationships would have to be established with a network of venture investors, entrepreneur support institutions, and professional associations to encourage new ventures relevant to automotive markets and drive deal flow.

Industry Leadership: Continuing Toward Open Innovation

A sustainable business model for open innovation in the auto space would combine industry leadership with four essential features: 
- An industry champion. Some credible, professional institution must become the locus of the initiative. This cannot be one of the competing companies, nor an outsider like a university or professional society.

- A management platform. Professional management will be required, though not necessarily occupied full time with AVF.

- Effective channels to entrepreneurial companies. The uniqueness of AVF derives from its ability to generate a high-quality flow of deal-ready new ventures. Equally important, the AVF team must be able to coach new venture managements on how and what to present at the actual Forum.

- Public-private support. Proving the value of the AVF model requires a demonstration period long enough for the economic results to be realized, rather than merely anticipated as they are now. In addition, an experimental period will be required to establish the price points for private company participation.

\subsubsection{Recommendations}

The AutoVenture Forum demonstration project makes a strong case that an industry-level open innovation model is both feasible and desirable. However, such enterprises cannot be well done by universities or professional societies. The next step forward would be for industry leadership to complete the job.

It seems reasonable to conclude that much value was created by the AVF. Whether or not the AVF can become self-supporting remains in question. Thus, a demonstration of the "revenue model" for AVF will be required before the AVF can accomplish its mission of building a cheaper, faster, better innovation cycle. In the following, we propose a strategy for demonstrating the revenue model-the strategic next steps for AVF.

- Industry leadership. University-based leadership for AVF is unlikely to provide the management structure and operational capabilities that can deliver sustainable results. And in any case, the auto industry must come to own the AVF if it is to achieve its major purpose. Therefore, a transition process to industry management will be required. At this time, USCAR appears to offer the most suitable platform for AVF management. The first step is to explore this with USCAR.

- ASME/Clemson role. If the auto industry provides leadership and a management structure, ASME and Clemson can add value by serving as a neutral channel for the entrepreneurial community. During the pilot AVF, the ASME/Clemson team built: (a) the network of contacts, channel partners, and credibility to recruit the new ventures; and (b) the experience to work efficiently with them to provide entrepreneur coaching. Thus, the second step is to explore the conditions under which ASME/Clemson could participate.

- Government support. Securing federal support for a demonstration of the AVF revenue model becomes the third step. The DoE and/or DoD should be contacted to explore a demonstration project, jointly funded with the industry and of about 3 years duration. A cheaper, better, faster innovation cycle serves the public interest because:

- The auto industry has gained strategic economic interest in the U.S. and overseas, and improved innovation is essential for its competitive survival;

- The national security problems arising from heavy dependence on imported oil arise chiefly from road transportation; and, 
- Governments around the world are seeking to reduce the climate change issues posed by petroleum consumption in autos.

The AutoVenture Forum sought to demonstrate how a network innovation process could accelerate innovation at the industry level. In the road mobility industry, such acceleration is needed to serve national goals of energy security, environmental protection, and economic growth. Hence, the lessons learned in this pioneering effort can assist the Department of Energy in its own policy development and implementation efforts. And, any continuation of AVF beyond the 22 September pilot could materially assist the Department of Defense in reducing the use of petroleum fuels in combat operations. 


\subsection{Technology Demonstration and Validation Process}

\subsubsection{Background}

One of the greatest obstacles in transitioning a new discovery or invention to a commercial product is the demonstration and validation phase, where the technology moves from a simple proof of concept article in the lab to a prototype with near final form, fit, and function that can be tested in a realistic environment and integrated into a system to verify its performance prior to committing to commercialization. This phase has been called the Valley of Death (14) (15) because of the large number of innovators that have been unable to secure the higher amounts of funding needed and that lacked the expertise and equipment necessary to perform component and system level verifications. The prototype demonstration and validation phase corresponds roughly to Technology Readiness Levels in the range of four to six.

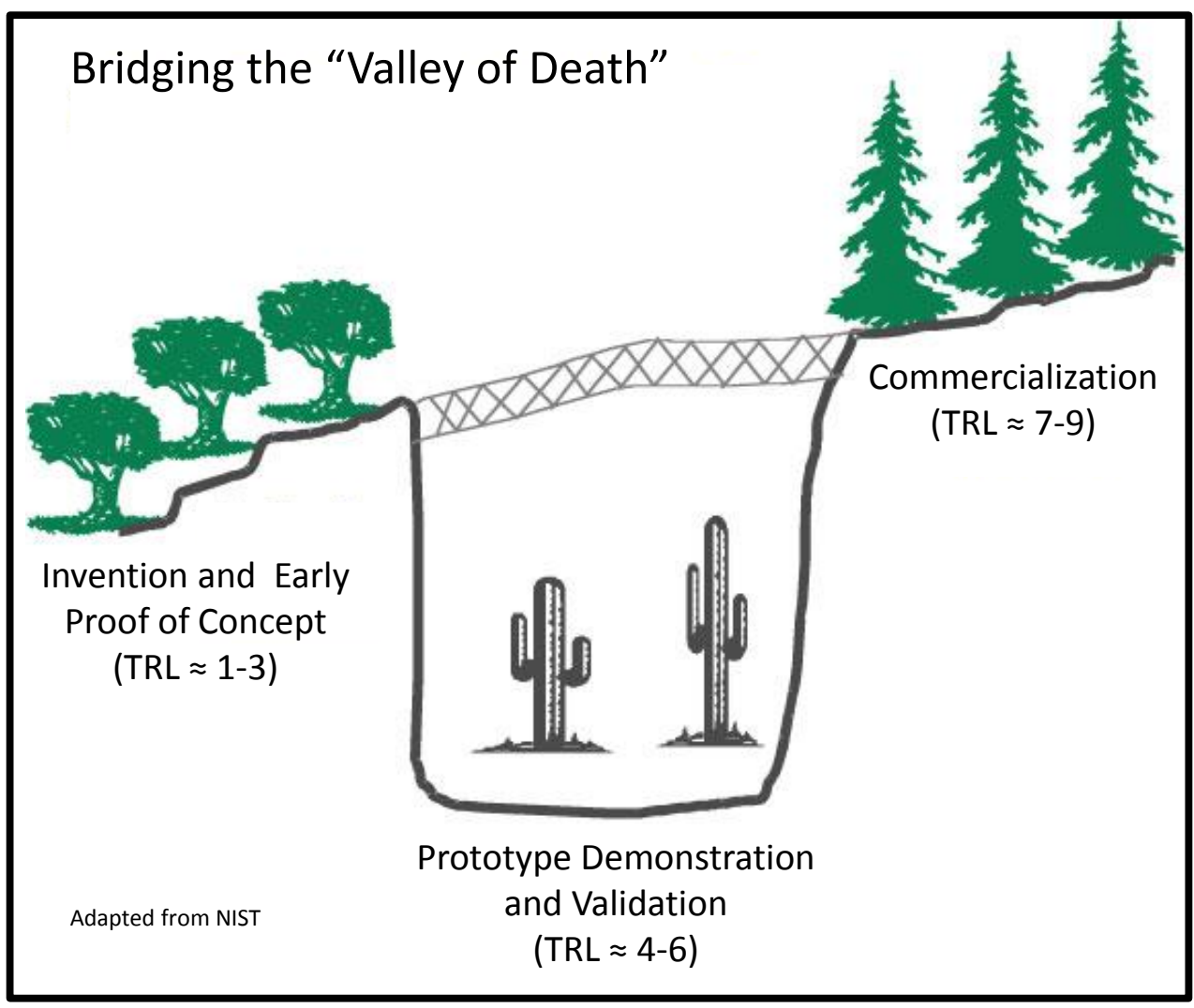

Figure 9 - Technology Transition Valley of Death

For this project, our objective was to assess the potential of universities to perform rapid, low cost prototype demonstration and validation efforts in support of small, entrepreneurial firms. This is a step beyond the normal university role of basic research, however, if successful, this would provide additional opportunities for innovators to obtain the information needed to take the final step to commercialization. Our focus for this project was on technologies that would support the transition to a hydrogen fueled transportation sector. 
Four broad problem areas have been identified as roadblocks to the introduction of hydrogen in the transportation sector. These are:

- Production - A low cost method of producing hydrogen, other than from natural gas, is needed

- Distribution - A low cost, high volume method of transporting hydrogen from the production facility to the fueling station is required

- On-board Storage - A low cost, light weight, low volume method of storing hydrogen on the vehicle is needed

- Power Generation - Lower cost fuel cells or other methods of converting the hydrogen fuel to vehicle power are required.

Key among these problems is the problem of distribution. It is estimated that it would take several hundred billion dollars to create a hydrogen infrastructure of pipelines, rail and truck transports, and fueling stations comparable in capacity, number, and geographic distribution to today's gasoline stations. Therefore, our initial efforts focused on identifying technologies in the early stages of development that offered potential solutions to the distribution problem.

One of the most promising technology areas identified was hydrogen liquid carriers. Liquid carriers are molecules composed of a large weight percentage of hydrogen, which are liquid within the normal range of operating temperatures. These molecules can undergo reversible hydrogenationdehydrogenation reactions, giving off hydrogen and transforming into a "spent" liquid that can be rehydrogenated into the original carrier molecule at low cost. The most promising liquid carriers can be handled and transported like petroleum fuels, making it possible to use much of the existing petroleum infrastructure, thus substantially reducing the cost of distribution. These liquids also provide dense, low volume storage of hydrogen without the need for cryogenic cooling and super-insulated tanks or special high pressure vessels for gaseous storage. Liquid carriers can be stored in conventional fuel tanks that can be conformally mounted, thus simplifying their integration into the vehicle.

A review of current research on liquid carriers found a promising technology in the early stages of development. This technology was being developed by Asemblon, a small company in Redmond, Washington. Asemblon had just received $\$ 2.9 \mathrm{M}$ as the first installment of its Series $\mathrm{C}$ round of financing. This brought the total investment funds raised by the company to $\$ 11 \mathrm{M}$. As with the AutoVenture Forum, we used Asemblon's ability to secure private venture funding as a strong indication that their claims about the technology were sound.

Asemblon's expertise is in a surface chemistry nanotechnology called self-assembling monolayers. They had used this expertise to develop a family of liquid carrier molecules called Hydrnol ${ }^{\mathrm{TM}}$. While the chemistry itself is proprietary, the three molecules in the family were expected to be capable of reversibly releasing $6.7 \%, 8.8 \%$, and $10.8 \%$ hydrogen by weight.

Through a series of meetings with Asemblon, it was agreed that SCIES would develop an integrated fuel system for an Internal Combustion Engine (ICE) test vehicle that would demonstrate the feasibility of using Hydrnol as a fuel source for small, ICE powered vehicles. This demonstration would assist Asemblon in its plans to penetrate a variety of small engine vehicle markets. In addition, this fuel system could be used as the hydrogen source for larger engines that use a small quantity of hydrogen to enhance the combustion process. 
Demonstration of a prototype fuel system using the Asemblon liquid carrier technology was an ideal fit to the objectives of this project. As a small company, with limited resources and a narrow, highly specialized expertise, the company was ill equipped to demonstrate its technology at the vehicle level, which was a key requirement for commercialization. SCIES had ready access to the specialized resources needed for this project, including the personnel and equipment of the Chemical and Mechanical Engineering Departments at Clemson University, as well as Clemson University's International Center for Automotive Research, making it possible to conduct a rapid, low cost vehicle demonstration effort. Therefore, a prototype fuel system demonstration of the initial $6.7 \mathrm{wt} \% \mathrm{Hydrnol}$ liquid carrier molecule was chosen as our pilot project.

\subsubsection{Hydrnol Prototype Fuel System Demonstration}

The $6.7 \mathrm{wt} \%$ Hydrnol molecule is commonly known as propylamine $\left(\mathrm{C}_{3} \mathrm{H}_{9} \mathrm{~N}\right)$. Its structure is shown in Figure 10. Asemblon had performed limited demonstrations of the ability to dehydrogenate propylamine to propionitrile $\left(\mathrm{C}_{3} \mathrm{H}_{5} \mathrm{~N}\right)$ in a gas phase reaction. While propylamine did not have the ultimate performance needed for vehicle applications, Asemblon felt that much of the work on catalyst selection, reactor design, and fuel system development for this molecule would be directly applicable to the higher hydrogen weight percent molecules that they were formulating at that time. Therefore, our prototype fuel system demonstration work focused on propylamine.

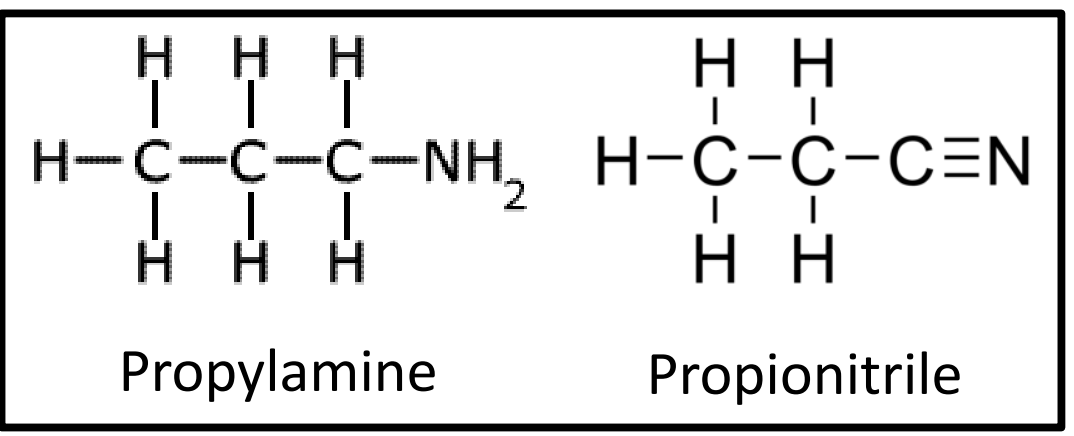

Figure 10 - Liquid Carrier Molecules Used For Prototype Fuel System Demonstration

\section{Experimental Reactor Design}

The first step toward building the Hydrnol fuel system was to select the reactor components, in particular the catalyst, and collect reactor performance data that would allow accurate sizing of the prototype system. The experimental reactor that was fabricated to obtain this information, shown in Figure 11, consisted of a 24 -inch long, $1 / 2$-inch diameter stainless steel tube fitted at the bottom with a type K thermocouple and sealed with Swagelok fittings. Glass wool was placed in the end of the reactor tube and $1500 \mu \mathrm{m}$ diameter glass beads were added on top of the glass wool. The height of the glass beads in the reactor tube was such that the beads covered the bottom thermocouple. Approximately 0.5 grams of cobalt catalyst was added to the reactor tube. The 0.5 grams of catalyst was evenly split into two aliquots and poured into the reactor tube. Each aliquot of catalyst was sandwiched between two layers of glass wool. Additional glass beads were poured on top of the catalyst, with a height in the reactor tube such that a second thermocouple at the top of the reactor tube was within the glass beads. Once the reactor tube was packed with catalyst it was mounted inside an oven, which allowed for temperature control of the dehydrogenation reaction. 


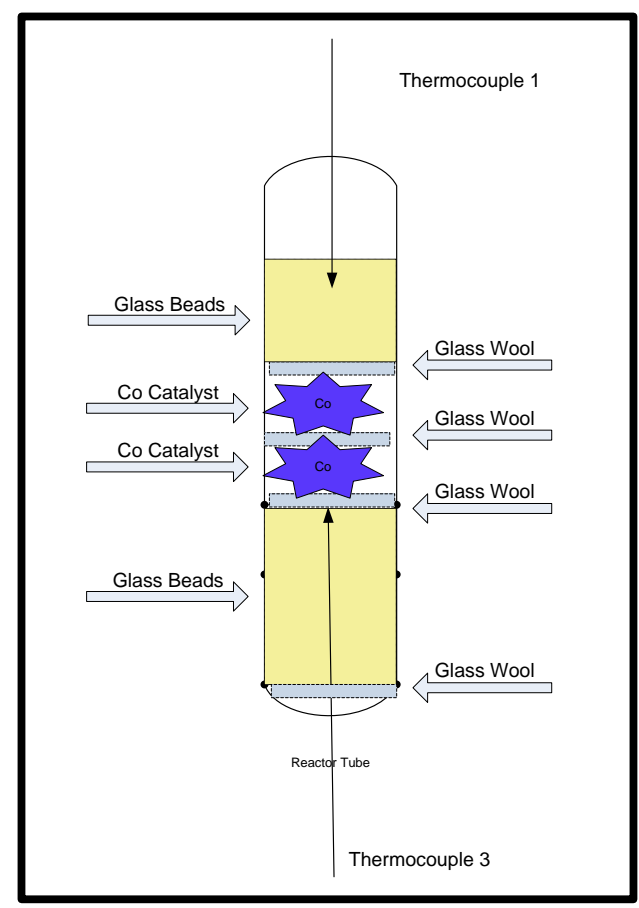

Figure 11 - Experimental Reactor

The dehydrogenation reaction of propylamine to propionitrile and hydrogen was carried out in a gas phase reaction, where the propylamine was sent to the reactor tube using nitrogen as an inert carrier gas. Once in the reactor tube the propylamine was dehydrogenated over the solid cobalt oxide catalyst. The gas stream was then sent to the Gas Chromatograph (GC) or to a trap located on the side of the reactor assembly.

Using this process flow, the percent conversion was calculated from equation (1),

$$
\mathrm{N}_{\mathrm{PA}}=\mathrm{N}_{\mathrm{PA}_{\mathrm{o}}}\left(1-\mathrm{X}_{\mathrm{PA}}\right)
$$

where $\mathrm{N}_{P A}$ is the number of moles of propylamine after the dehydrogenation reaction, $\mathrm{N}_{\mathrm{PAO}}$ is number of moles of propylamine before the dehydrogenation reaction, and $X_{P A}$ is the conversion of propylamine. Without any way of bypassing the reactor there was no way to determine the number of moles of propylamine before the reaction takes place. Therefore, the number of moles of propylamine before the reaction was approximated by adding the number of moles of propylamine and propionitrile after the reaction as determined by the GC. This is an approximation made under the assumption that no byproducts will be formed in the reaction, which later was determined was not the case.

\section{Experimental Reactor Test Results}

The gas phase dehydrogenation of propylamine to propionitrile was performed by feeding a gaseous mixture of nitrogen and propylamine through the packed bed reactor loaded with one of two commercially available hydrodesulfurization catalysts from American Cyanamid (HDS-20A and HDS-2A). Their compositions are presented in Table 1. 


\begin{tabular}{cccc} 
& \multicolumn{3}{c}{ Composition (weight percent) } \\
\cline { 2 - 4 } Catalyst & $\underline{\mathrm{MoO}}_{3}$ & $\underline{\text { CoO }}$ & Alumina \\
HDS-20A & 16.2 & 5.0 & 78.8 \\
HDS-2A & 15.0 & 3.2 & 81.8
\end{tabular}

Table 1 - Composition of American Cyanamid Catalysts

Dehydrogenation reactions were run under varying conditions of temperature, pressure, and flow rate. The dehydrogenation reaction and products formed were then monitored through the use of an Agilent Technologies 7890A Gas Chromatograph equipped with a Flame Ionization Detector (FID). Five calibration standards of known concentration were prepared in acetonitrile for both propylamine and propionitrile. The standards were injected into the GC using an Agilent 7683B injector. A relation between known concentrations and peak area was obtained from the calibration curve, thus allowing for determination of reaction conversion.

Experiments were performed to determine the effect of temperature change on reaction conversion over the range of $513 \mathrm{~K}-573 \mathrm{~K}$ for both catalysts. The reactor was held at a pressure of $11.5 \mathrm{psig}$, and the mass flow rate was held at $30 \%$ of the maximum controller flow rate.

Using the HDS-20A catalyst, the calculated percent conversion of propylamine to propionitrile from two duplicate test runs was extremely low even after the reaction temperature was increased from $513 \mathrm{~K}$ to 573K, as shown in Tables 2 and 3, despite the endothermicity of the dehydrogenation reaction.

\begin{tabular}{|c|c|c|c|c|c|}
\hline $\begin{array}{c}\text { \%Conversion } \\
\text { Propylamine }\end{array}$ & $\begin{array}{c}\text { Flow Rate } \\
\text { (cm3/min) }\end{array}$ & Temperature (K) & Pressure (psig) & $\begin{array}{c}\text { Residence Time in } \\
\text { Reactor } \text { (min) }\end{array}$ & $\begin{array}{c}\text { Residence time } \\
\text { Exit to GC } \\
\text { (min) }\end{array}$ \\
\hline $\mathbf{0 . 1 1 9}$ & 144 & 513 & 11.5 & 0.044 & 1.127 \\
\hline $\mathbf{0 . 1 5}$ & 149 & 533 & 11.5 & 0.042 & 1.127 \\
\hline $\mathbf{0 . 1 7 2}$ & 155 & 553 & 11.5 & 0.041 & 1.127 \\
\hline $\mathbf{0 . 1 1 4}$ & 161 & 573 & 11.5 & 0.039 & 1.127 \\
\hline $\mathbf{0 . 1 1 9}$ & 161 & 573 & 11.5 & 0.039 & 1.127 \\
\hline
\end{tabular}

Table 2 - Dehydrogenation results for HDS-20A Catalyst (07July2010)

\begin{tabular}{|c|c|c|c|c|c|}
\hline $\begin{array}{c}\text { \%Conversion } \\
\text { Propylamine }\end{array}$ & $\begin{array}{c}\text { Flow Rate } \\
\text { (cm3/min) }\end{array}$ & Temperature (K) & Pressure (psig) & $\begin{array}{c}\text { Residence Time in } \\
\text { Reactor }\end{array}$ (min) & $\begin{array}{c}\text { Residence time } \\
\text { Exit to GC } \\
\text { (min) }\end{array}$ \\
\hline $\mathbf{0 . 0 1 8}$ & 144 & 513 & 11.5 & 0.044 & 1.127 \\
\hline $\mathbf{0 . 0 2 4}$ & 149 & 533 & 11.5 & 0.042 & 1.127 \\
\hline $\mathbf{0 . 0 4 7}$ & 155 & 553 & 11.5 & 0.041 & 1.127 \\
\hline $\mathbf{0 . 2 5 9}$ & 161 & 573 & 11.5 & 0.039 & 1.127 \\
\hline
\end{tabular}

Table 3 - Dehydrogenation results for HDS-20A Catalyst (08July2010)

The dehydrogenation of propylamine to propionitrile was repeated under the same reaction conditions, using the second catalyst, HDS-2A. The percent conversion of propylamine to propionitrile increased with this catalyst for all temperatures, relative to the HDS-20A results, suggesting that increasing the amount of cobalt in the catalyst might be beneficial. However, the percent conversions at all temperatures were still low, as shown in Table 4. 


\begin{tabular}{|c|c|c|c|c|c|}
\hline $\begin{array}{c}\text { \%Conversion } \\
\text { Propylamine }\end{array}$ & $\begin{array}{c}\text { Flow Rate } \\
\text { (cm3/min) }\end{array}$ & Temperature (K) & Pressure (psig) & $\begin{array}{c}\text { Residence Time in } \\
\text { Reactor }\end{array}$ (min) & $\begin{array}{c}\text { Residence time } \\
\text { Exit to GC } \\
\text { (min) }\end{array}$ \\
\hline $\mathbf{0 . 0 3 2}$ & 144 & 513 & 11.5 & 0.044 & 1.127 \\
\hline $\mathbf{0 . 1 8 8}$ & 149 & 533 & 11.5 & 0.042 & 1.127 \\
\hline $\mathbf{1 . 2 8 8}$ & 155 & 553 & 11.5 & 0.041 & 1.127 \\
\hline $\mathbf{5 . 3}$ & 161 & 573 & 11.5 & 0.039 & 1.127 \\
\hline
\end{tabular}

\section{Table 4 - Dehydrogenation results for HDS-2A Catalyst}

To eliminate the assumption that no byproducts are formed during the dehydrogenation reaction, a bypass of the reactor was incorporated into the process allowing for the determination of the initial moles of propylamine before any reaction occurs. The process flow diagram, shown in Figure 12, depicts how the flow of the nitrogen-propylamine mixture was regulated through the use of mass flow controllers and three four-way valves. The first four-way valve sends the inert carrier gas to either the propylamine, which was located on the side of the reactor assembly in a Teflon bubbler (at ambient conditions), or bypasses the propylamine. The gas stream is then sent through the second four-way valve which either sends the gas to the reactor or bypasses the reactor. The gas stream is then sent by the third four-way valve to the gas chromatograph or to a trap.

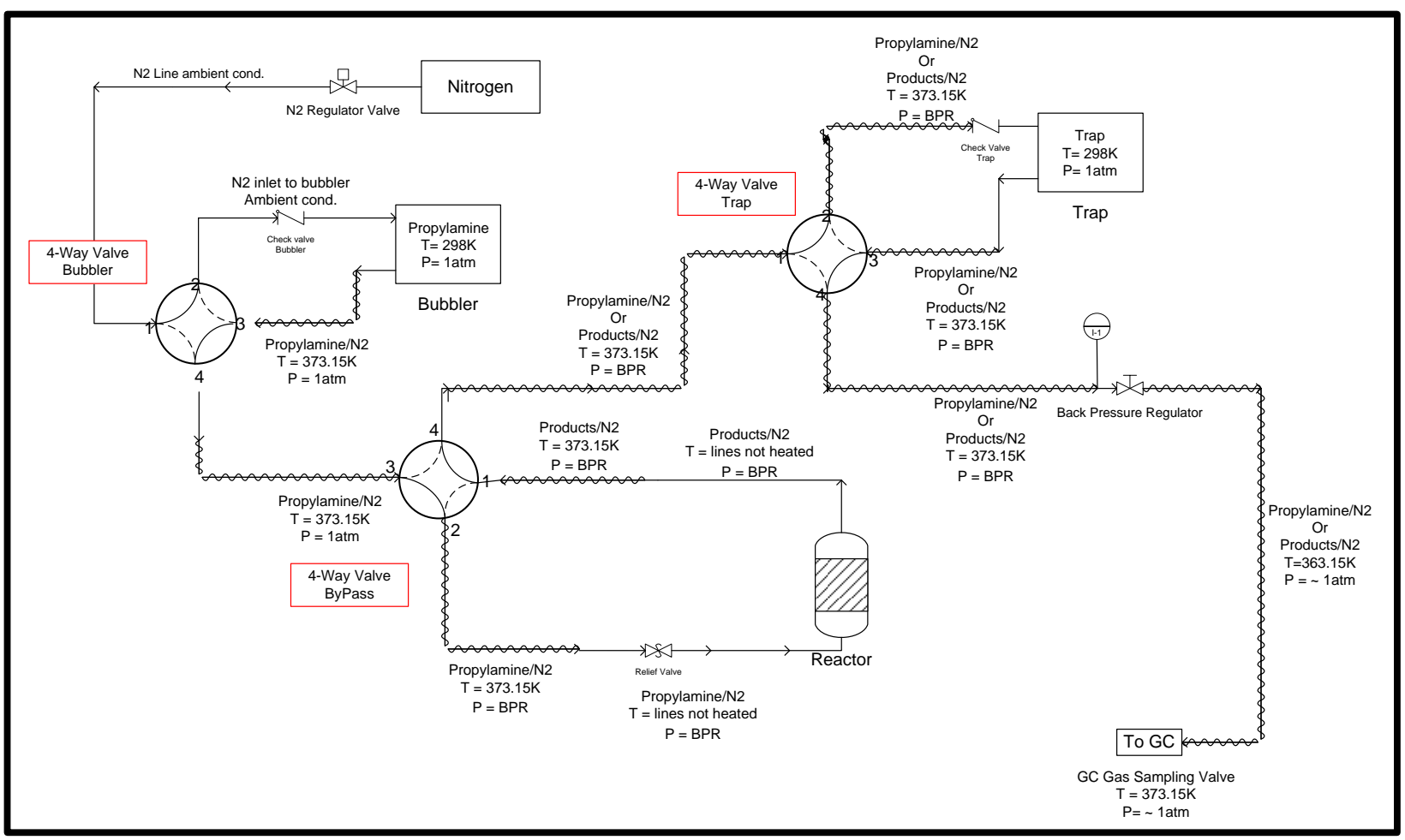

Figure 12 - Process Flow Diagram

Once the reactor bypass was installed, the conditions shown in Table 4 for the HDS-2A catalyst were repeated. Table 5 shows a substantial increase in the actual percent conversion of propylamine compared to the conversion estimates in Table 4, however, the percent yields of propionitrile were still extremely low, indicating that a significant percentage of the propylamine was being converted into undesired products. 


\begin{tabular}{|c|c|c|c|c|c|c|}
\hline $\begin{array}{c}\text { \% Conversion } \\
\text { Propylamine }\end{array}$ & \% Yield Propionitrile & $\begin{array}{c}\text { Flow Rate } \\
\text { (cm3/min) }\end{array}$ & Temperature (K) & Pressure (psig) & $\begin{array}{l}\text { Residence Time } \\
\text { Reactor }\end{array}$ (min) & $\begin{array}{l}\text { Residence Time } \\
\text { Exit to GC (min) }\end{array}$ \\
\hline 10.95 & 0.03 & 132 & 513 & 11.5 & 0.048 & 1.15 \\
5.85 & 0.51 & 137.15 & 533 & 11.5 & 0.046 & 1.15 \\
6.44 & 0.73 & 142.3 & 553 & 11.5 & 0.045 & 1.15 \\
16.06 & 2.66 & 147.44 & 573 & 11.5 & 0.043 & 1.15 \\
\hline
\end{tabular}

Table 5 - Dehydrogenation results for HDS-2A Catalyst with Reactor Bypass

Asemblon had planned to perform a systematic study of catalysts to select the catalyst that would be used for the experimental reactor parametric studies and in the prototype fuel system. Unfortunately, with the Federal Government's move away from hydrogen as a transportation fuel, Asemblon had been unable to secure the remaining $\$ 3.6 \mathrm{M}$ of Series $\mathrm{C}$ financing and therefore, had been unable to perform the necessary catalyst studies. Without a catalyst that could provide high reaction rates, conversion efficiency, and selectivity, the planned prototype fuel system would not achieve the performance needed to support a transition to a commercial product. After discussions with Asemblon, it was decided that we would try one final catalyst, based on our test results with the two Cyanamid catalysts.

The Cyanamid catalyst test results suggested that increasing the cobalt content would have a beneficial effect on conversion efficiency. Therefore, a catalyst of higher weight percent cobalt was prepared inhouse by depositing cobalt(II) nitrate hexahydrate on alumina pellets. The blank alumina pellets were initially dried at $423 \mathrm{~K}$ for thirty minutes and stored in a glass desiccator. The cobalt(II) nitrate hexahydrate salt was melted slowly on a hot plate. The molten salt was slowly added to the dried alumina support pellets. Once the cobalt salt was applied uniformly to the alumina support, the pellets were calcined in air at $673 \mathrm{~K}$ for four hours and then allowed to cool. A second coating of cobalt(II) nitrate hexahydrate was added to the calcined pellets to increase the cobalt metal loading. The catalyst pellets were then calcined a second time at $673 \mathrm{~K}$ for four hours.

Table 6 shows percent conversion of propylamine and percent yield of propionitrile from the dehydrogenation reaction using the in-house cobalt catalyst. The dehydrogenation reaction was performed at a pressure of 100 psig and $50 \%$ of the maximum controller flow rate. Temperature was varied from $473 \mathrm{~K}$ to $573 \mathrm{~K}$.

\begin{tabular}{|c|c|c|c|c|c|c|}
\hline $\begin{array}{c}\% \\
\text { Conversion } \\
\text { Propylamine }\end{array}$ & $\begin{array}{c}\% \\
\text { Yield } \\
\text { Propionitrile }\end{array}$ & $\begin{array}{c}\text { Flow Rate } \\
\text { (cm3/min) }\end{array}$ & Temperature (K) & Pressure (psig) & $\begin{array}{c}\text { Residence Time } \\
\text { in Reactor } \\
\text { (min) }\end{array}$ & $\begin{array}{c}\text { Exit to GC } \\
\text { (min) }\end{array}$ \\
\hline 39.5 & 0.02 & 23.33 & 473 & 100.0 & 0.11 & 0.66 \\
7.9 & 0.19 & 25.30 & 513 & 100.0 & 0.10 & 0.66 \\
37.3 & 4.18 & 27.27 & 553 & 100.0 & 0.09 & 0.66 \\
38.9 & 9.03 & 28.25 & 573 & 100.0 & 0.09 & 0.66 \\
\hline
\end{tabular}

Table 6 - Dehydrogenation Results for In-house Catalyst with Reactor Bypass

Table 6 confirms that a catalyst with higher cobalt loading will increase conversion efficiency, even with the short residence time. However, the selectivity of the reaction, while better, remained low. One concern was that some of the unwanted byproducts might be cyanide gas, a common product of a propylamine reaction.

While the initial results with the in-house catalyst showed promise in terms of conversion efficiency, without substantial additional catalyst screening, the level of reaction selectivity could not be achieved, 
and the potential for producing hazardous byproducts existed. A catalyst screening effort was beyond the scope of the funds available and our agreement with Asemblon, therefore, further efforts to develop a Hydrnol fuel system were stopped pending Asemblon's ability to obtain the additional funding needed to perform the catalyst screening.

\subsubsection{Air Products Liquid Carrier Fuel System Demonstration}

As a result of Asemblon's inability to secure its remaining Series C investment funding, the demonstration and validation of the Hydrnol technology was placed on hold. However, the rationale for selecting liquid carriers as a demonstration area remained valid. Therefore, the search for an alternative liquid carrier was initiated. A second promising liquid carrier, developed by Air Products (AP) under DOE funding, was identified. (16) (17) (18) (19) (20) (21) Like the Hydrnol technology, the AP liquid carrier was in the early stages of development. Air Products had initiated work on this technology near the end of its DOE funded efforts, and no additional work was planned due to lack of funding. Therefore, a demonstration and validation effort was established, in an effort to move this technology to the next stage of commercialization.

The AP liquid carrier was novel in two respects:

- The reaction occurred with the carrier in the liquid phase, providing advantages in terms of the reaction temperature and the ability to separate the hydrogen gas from the liquid fuel

- The carrier was autothermal, meaning that in addition to the dehydrogenation reaction it could undergo a second exothermic oxidation reaction that could produce much of the heat needed to drive the endothermic dehydrogenation reaction

The overall process is shown in Figure 13. In an off-board reaction, fluorenone $\left(\mathrm{C}_{13} \mathrm{H}_{8} \mathrm{O}\right)$ is hydrogenated to produce the perhydrofluorene $\left(\mathrm{PHF}, \mathrm{C}_{13} \mathrm{H}_{22}\right.$ ) liquid carrier. The PHF undergoes a dehydrogenation reaction on-board the vehicle to produce hydrogen and fluorene $\left(\mathrm{C}_{13} \mathrm{H}_{10}\right)$. The fluorene is capable of undergoing a further exothermic oxidation-dehydrogenation reaction, which can produce a substantial portion of the heat required to drive the primary dehydrogenation reaction. The resulting reaction product is fluorenone, which is collected from the vehicle and returned for re-hydrogenation. For this project, our goal was to demonstrate a fuel system based on just the dehydrogenation reaction of PHF to fluorene, with the heat of reaction supplied by an external source.

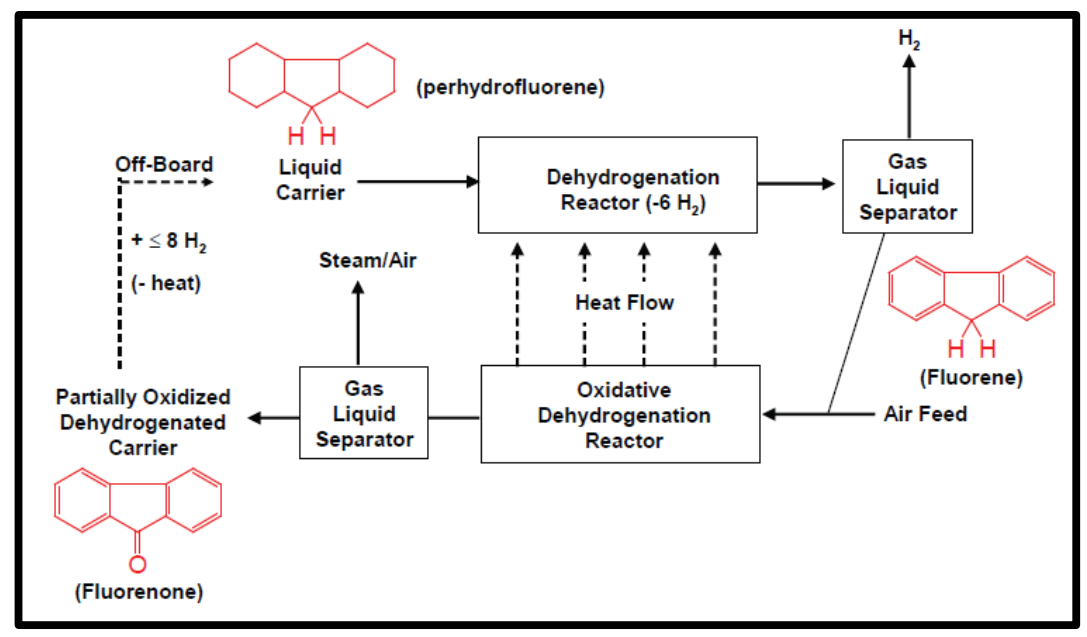

Figure 13 - Air Products Liquid Carrier Process 


\section{Production of Perhydrofluorene}

Due to the high cost and limited availability of Perhydrofluorene (PHF), more readily available fluorene was purchased and hydrogenated to perhydrofluorene. Initially, a saturated solution of fluorene was desired for the hydrogenation reactions in order to maximize the amount of fluorene hydrogenated. The solubility limit of fluorene in tetrahydrofuran (THF) was determined by adding small, incremental, weighed amounts of fluorene to a known volume of THF until no further fluorene would dissolve. This saturated solution was then used in the hydrogenation process. In later hydrogenation experiments, adding fluorene in excess of the solubility limit in THF was found to be as effective as the saturated solution, and resulted in higher total yields. The hydrogenation procedure in which fluorene was added in excess is described below.

The hydrogenation of fluorene to perhydrofluorene was performed in a two liter batch Parr reactor equipped with a heating jacket for controlling temperature and a motor driven magnetic stirrer for continuous agitation, using a commercially available $5 \%$ ruthenium on alumina catalyst, under temperature and pressure conditions contained in the literature. For a two liter batch hydrogenation reaction 375 grams of fluorene, $1000 \mathrm{ml}$ of THF, and 60 grams of the catalyst were added to the vessel. After the initial six hour hydrogenation reaction, the products were concentrated by removing any residual THF solvent via rotary evaporation. In subsequent hydrogenation reactions the catalyst was reused. It was found that catalytic activity decreased with time. Given this result, longer reaction time was needed as well as increased amounts of the catalyst for many of the subsequent hydrogenations. The amount of time and catalyst varied depending on the amount of fluorene to perhydrofluorene as well as the presence of any partially hydrogenated intermediates.

A Hewlett Packard G1530A gas chromatograph equipped with a split-splitless injector and HP 5973 Mass Spectrometer (MS) with El ion source (70 eV ionization energy) and quadrupole detector was used to analyze the reaction products. Chromatographic separation of perhydrofluorene, residual fluorene, and any partially hydrogenated intermediates was done using a DB-WAXetr capillary column $(30.0 \mathrm{~m}, 0.25$ $\mathrm{mm}, 0.25 \mu \mathrm{m}$ Agilent Technologies). Figure 14 and Table 7 show results for the hydrogenation reaction after 9 hours.

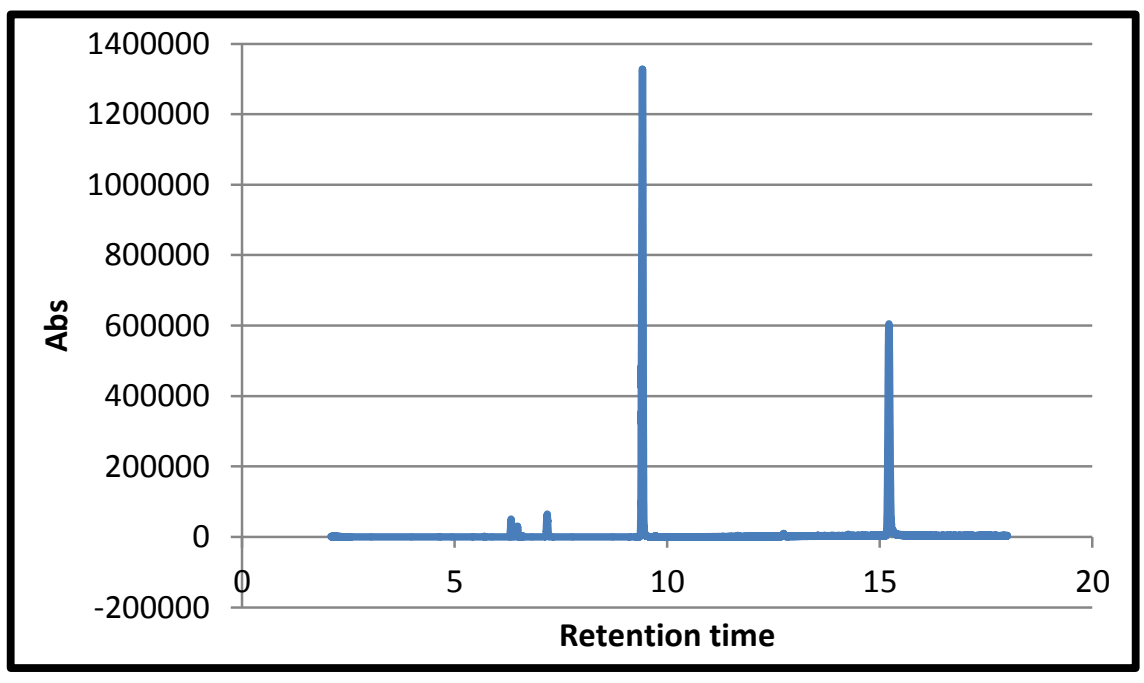

Figure 14 - Gas Chromatogram after 9 Hours Reaction Time 


\begin{tabular}{|c|r|r|r|r|}
\hline Peak & $\begin{array}{c}\text { Retention } \\
\text { Time }\end{array}$ & \multicolumn{1}{c|}{$\begin{array}{c}\text { Peak } \\
\text { Area }\end{array}$} & $\begin{array}{c}\text { Percent } \\
\text { Max }\end{array}$ & \multicolumn{1}{c|}{$\begin{array}{c}\text { Percent } \\
\text { Total }\end{array}$} \\
\hline 1 & 6.33 & 826569 & 2.85 & 1.619 \\
2 & 6.478 & 483645 & 1.67 & 0.947 \\
3 & 7.179 & 1236010 & 4.26 & 2.421 \\
4 & 9.42 & 29011429 & 100 & 56.832 \\
5 & 12.743 & 161302 & 0.56 & 0.316 \\
6 & 14.26 & 122282 & 0.42 & 0.24 \\
7 & 15.216 & 19206361 & 66.2 & 37.624 \\
\hline
\end{tabular}

Table 7 - Product Peaks after 9 Hours Reaction Time

Perhydrofluorene eluted off the column at a retention time of 7.2 minutes. The two peaks in greatest abundance were a partially hydrogenated byproduct species (at 9.4 minutes) and fluorene (at 15.2 minutes). The identification of fluorene was based on GC-MS analysis of a known fluorene standard. The partially hydrogenated byproduct species is believed to be 2,3,4,4a,9,9a-hexahydro-1H-Fluorene, or an isomeric variation, shown in Figure 15. It is hypothesized that the peaks present at 6.33 and 6.47 minute retention times are partially hydrogenated products with perhaps only one double bond; the mass spectrum indicates an $\mathrm{m} / \mathrm{z}$ of 176 for those two peaks, suggesting one double bond. These byproducts were not identified.

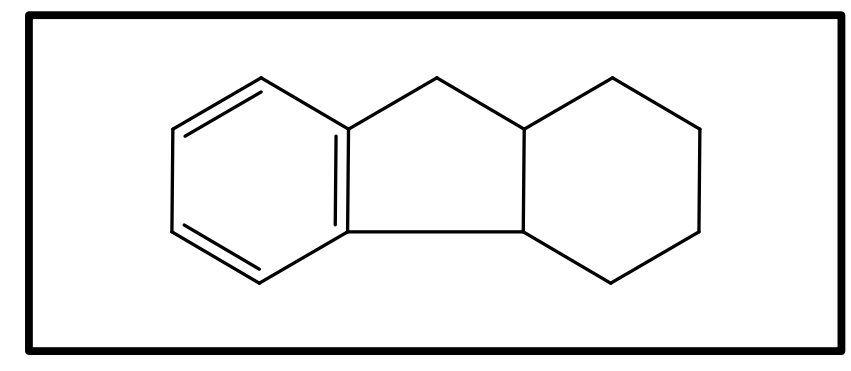

Figure 15 - 2,3,4,4a,9,9a-hexahydro-1H-Fluorene Partial Hydrogenation Byproduct

To reduce the amount of partially hydrogenated species and any residual fluorene, the reaction time was increased. The same batch that was hydrogenated for nine hours was hydrogenated for an additional six hours, resulting in increased conversion of fluorene to perhydrofluorene. Figure 16 and Table 8 show gas chromatography results for the 15 hour hydrogenation. 


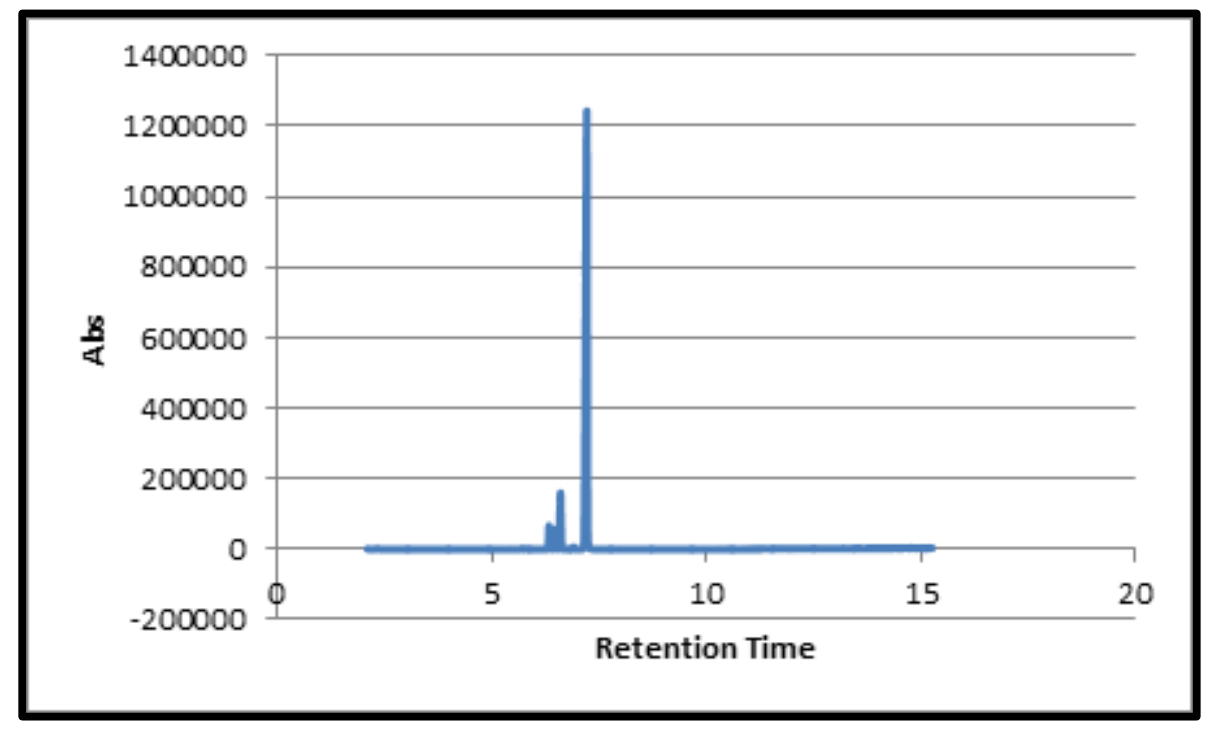

Figure 16 - Gas Chromatogram after 15 Hour Reaction Time

\begin{tabular}{|c|r|r|r|r|}
\hline Peak & $\begin{array}{c}\text { Retention } \\
\text { Time }\end{array}$ & \multicolumn{1}{c|}{$\begin{array}{c}\text { Peak } \\
\text { Area }\end{array}$} & $\begin{array}{c}\text { Percent } \\
\text { Max }\end{array}$ & $\begin{array}{c}\text { Percent } \\
\text { Total }\end{array}$ \\
\hline 1 & 5.702 & 39162 & 0.12 & 0.107 \\
2 & 5.775 & 21250 & 0.07 & 0.058 \\
3 & 6.332 & 1010980 & 3.22 & 2.759 \\
4 & 6.424 & 10765 & 0.03 & 0.029 \\
5 & 6.474 & 1031017 & 3.29 & 2.814 \\
6 & 6.598 & 3057673 & 9.74 & 8.345 \\
7 & 6.902 & 89993 & 0.29 & 0.246 \\
8 & 7.212 & 31381422 & 100 & 85.643 \\
\hline
\end{tabular}

Table 8 - Product Peaks after 15 Hour Reaction Time

The results indicate that $85.6 \%$ of the fluorene was hydrogenated into perhydrofluorene. After 15 hours of hydrogenation no residual fluorene was detected. The other three peaks in low abundance (6.332 and 6.474 minutes retention time) were believed to be other byproducts resulting from incomplete hydrogenation of fluorene, different from that of 2,3,4,4a,9,9a-hexahydro- $1 \mathrm{H}$-Fluorene, which had a retention time of 9.4 minutes. Peaks present at 6.598 minutes and 6.902 minutes are hypothesized to be other isomers of perhydrofluorene, since the ion molecular weight is 178 and the fragmentation patterns of the MS are similar to that of perhydrofluorene. These byproducts were not identified.

Proton Nuclear Magnetic Resonance Spectroscopy was used to further confirm the hydrogenation product as primarily perhydrofluorene. 1H NMR Analysis was done using a Bruker $300 \mathrm{MHz}$ proton NMR. Figure 17 shows the $1 \mathrm{H}$ NMR spectrum for perhydrofluorene, which compares closely with the perhydrofluorene $1 \mathrm{H}$ NMR shown on the Sigma-Aldrich website. 


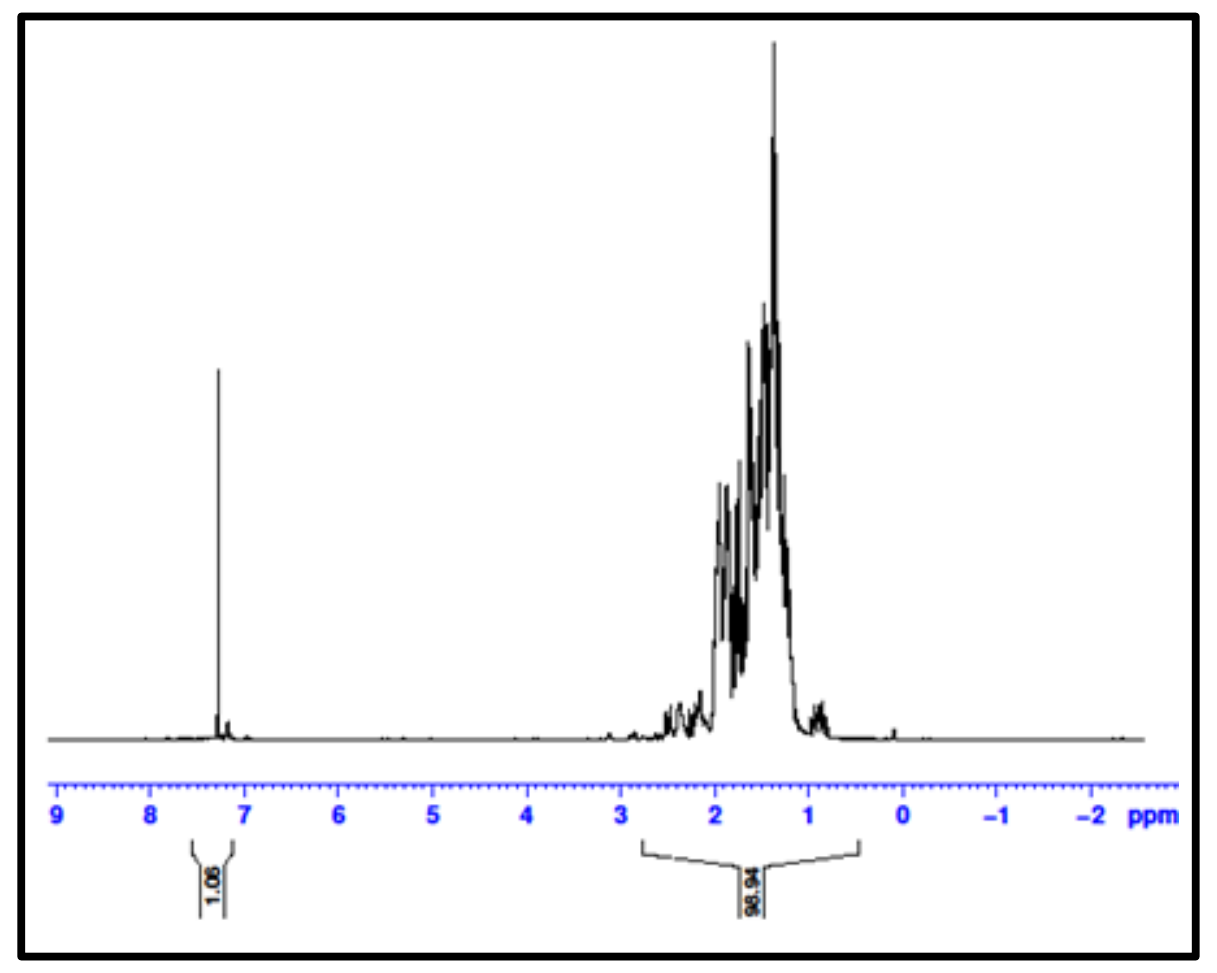

Figure 17 - H NMR Spectrum for Perhydrofluorene.

The PHF produced was used in both the experimental reactor testing done for catalyst selection and in the demonstration fuel system testing.

\section{Experimental Reactor Efforts}

Prior to building the demonstration fuel system, a small, experimental reactor was constructed to aid in selecting the best catalyst and to optimize the reaction conditions. Based upon Air Products' recommendation, a monolith configuration was selected for the reactor. The monolith chosen was a 400 cell per inch (cpi) corrugated Fecralloy material that was wash coated with the catalyst, then rolled and inserted into the reactor tube.

Based upon the literature, two commercially available catalysts, platinum on alumina and palladium on alumina, were selected for testing. In addition, two catalyst loadings, $1 \%$ and $5 \%$, were chosen for both the platinum and palladium catalysts to assess their impact on reaction rate and, in turn, the elimination of a potential problem identified by Air Products in their research. (16) AP found that catalyst efficiency degraded with reactor length, possibly due to the large volume of hydrogen gas produced (approximately $98 \%$ by volume). It was hypothesized that this large volume of gas might form a gas film on the catalyst surface, preventing the liquid from making contact and inhibiting further reaction. By reducing the catalyst loading, and therefore the rate of reaction per unit volume of reactor, it was hoped that this surface "unwetting" phenomena might be mitigated.

An experimental reactor was constructed from a one inch diameter, three inch long stainless steel tube. The one inch wide monolith sheets were rolled into a cylindrical form and inserted into the reactor tube. Thermocouples were inserted at the entrance and exit to the monolith. A thermocouple was also placed on the exterior wall of the reactor. The reactor cylinder was wrapped with heat tape and 
insulation. The heat tape was connected to a thermal controller, which was used to maintain the reactor set point temperature. A positive displacement piston pump was used to accurately control the flow rate of the fuel into the reactor. The objective of this testing was to determine the best catalyst material and loading, as well as to establish reaction conditions for the demonstration system reactor. Test conditions included a range of flow rates and reactor temperatures.

A 50/50 volume percent solution of the perhydrofluorene fuel (approximately 85\% pure) in toluene was pumped through each of the four monolith reactors to compare catalytic activity as well as selectivity. The perhydrofluorene was diluted with toluene to help prevent solidified fluorene (m.p. $=116-117^{\circ} \mathrm{C}$ ) from plugging the unheated tubing downstream of the reactor. The toluene present in the fuel mix helps dissolve any solid fluorene that is formed from the dehydrogenation reaction. The reactor testing was carried out at ambient pressure and set point temperatures of $220^{\circ} \mathrm{C}$ and $250^{\circ} \mathrm{C}$. Flow rates ranged from 50 to $400 \mathrm{ml} / \mathrm{hr}$. Samples of the dehydrogenation products were collected in fifteen-minute time intervals from a knock-out pot downstream of the monolith reactor. The knock-out pot was drained between sampling intervals.

A GC-MS system consisting of a Hewlett Packard G1530A gas chromatography equipped with a splitsplitless injector and HP 5973 mass spectrometer with El ion source (70 eV ionization energy) and quadrupole detector was used to analyze the reaction products. Chromatographic separation of perhydrofluorene, residual fluorene, and any partially hydrogenated intermediates was done using a DBWAXetr capillary column ( $30.0 \mathrm{~m}, 0.25 \mathrm{~mm}, 0.25 \mu \mathrm{m}$ Agilent Technologies).

Initial testing was done with the $1 \%$ platinum on alumina catalyst. The dehydrogenation reaction was carried out at a reactor set point temperature of $220^{\circ} \mathrm{C}$ and flow rates of $400 \mathrm{ml} / \mathrm{hr}$ and $200 \mathrm{ml} / \mathrm{hr}$. GC analysis results of the dehydrogenation products are presented in Figure 18. Table 1 shows the retention time and peak area data from the GC-MS analysis of the dehydrogenation products for the 15 minute collection time and $400 \mathrm{ml} / \mathrm{hr}$ flow rate, which had the highest conversion of perhydrofluorene to fluorene observed during this test. The Retention Times (RTs) of perhydrofluorene and fluorene were 7.2 minutes and 15.2 minutes, respectively. Other peaks to be noted are those at RTs of 6.3 minutes, 6.5 minutes, and 6.6 minutes. The peak at 6.6 minutes corresponds to an isomer of perhydrofluorene. The peaks at 6.3 minutes and 6.5 minutes are hypothesized to be partially hydrogenated byproducts. 


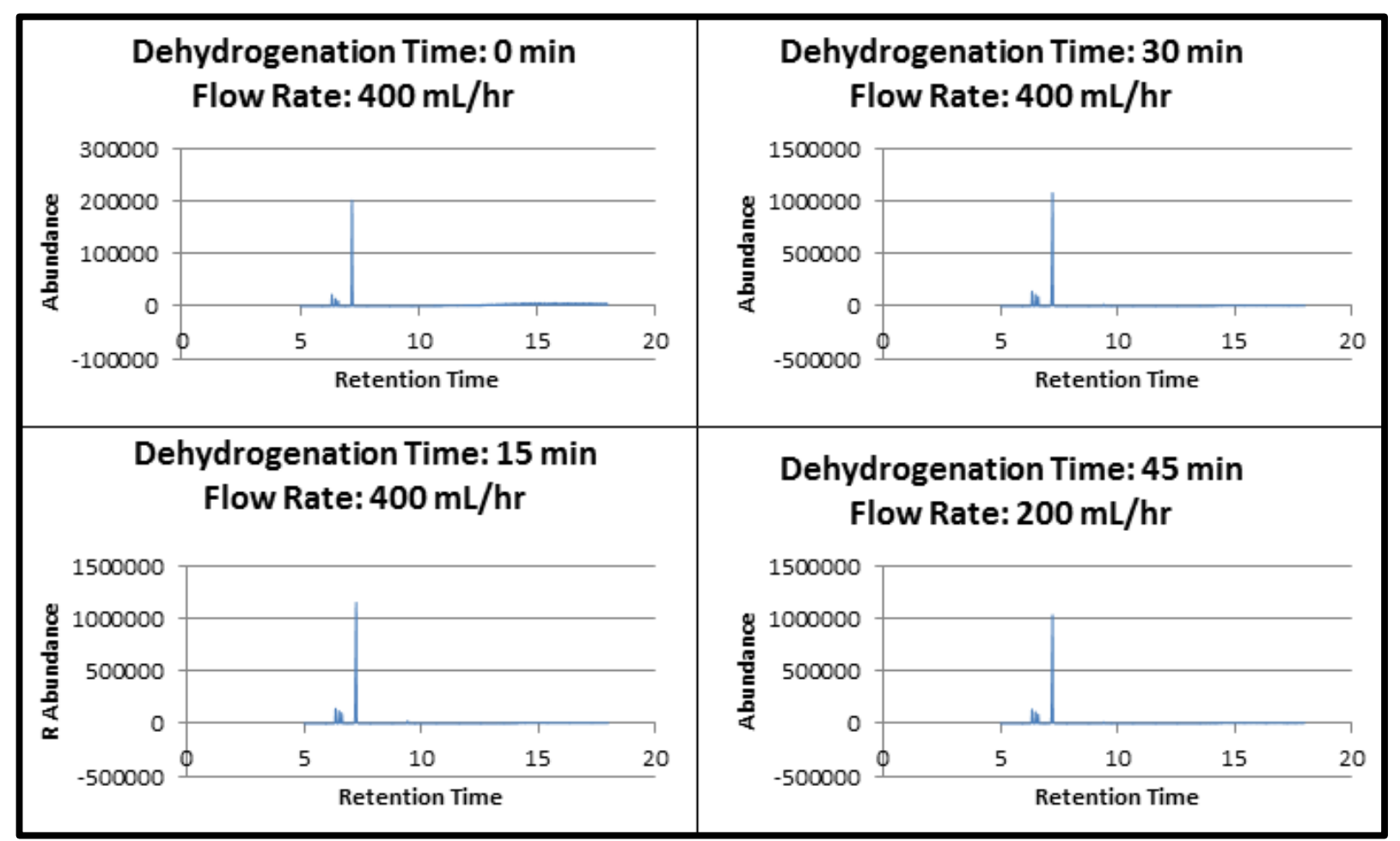

Figure 18 - GC Analysis of $1 \%$ Pt Monolith and $50 / 50$ Fuel Mix at $220^{\circ} \mathrm{C}$

\begin{tabular}{|c|r|r|r|}
\hline Peak & $\begin{array}{c}\text { Retention } \\
\text { Time }\end{array}$ & \multicolumn{1}{c|}{$\begin{array}{c}\text { Peak } \\
\text { Area }\end{array}$} & $\begin{array}{c}\text { Percent } \\
\text { Total }\end{array}$ \\
\hline 1 & 6.346 & 2598990 & 7.212 \\
2 & 6.494 & 2033670 & 5.643 \\
3 & 6.611 & 1801521 & 4.999 \\
4 & 6.925 & 92120 & 0.256 \\
5 & 7.228 & 28905956 & 80.211 \\
6 & 9.426 & 440764 & 1.223 \\
7 & 15.23 & 164277 & 0.456 \\
\hline
\end{tabular}

Table 9 - Product Peaks for $1 \%$ Pt Monolith and $50 / 50$ Fuel Mix at $220^{\circ} \mathrm{C}(\mathrm{T}=15 \mathrm{~min}$ )

The GC-MS analysis of the $1 \%$ Pt catalyst products indicated minimal conversion of PHF to fluorene. In comparing the peak areas of PHF and fluorene from the GC chromatographs, $79.6-80.2 \%$ of the reaction products were unconverted PHF, while only $0.2-0.5 \%$ of the reaction products were fluorene. This analysis further indicated little difference in conversion when comparing the two flow rates of $200 \mathrm{ml} / \mathrm{hr}$ and $400 \mathrm{ml} / \mathrm{hr}$. Therefore, testing shifted to the $5 \% \mathrm{Pt}$ monolith.

For testing of the $5 \% \mathrm{Pt}$ monolith, the PHF flow rate was reduced to $100 \mathrm{ml} / \mathrm{hr}$, then to $50 \mathrm{ml} / \mathrm{hr}$, to increase the residence time. The reactor temperature was held at $220^{\circ} \mathrm{C}$. GC analysis of the dehydrogenation products is presented in Figure 19. Note that for the sample at time equals zero, there is only a small by-product peak at RT $=9.4$, which increases with the other samples. Table 10 shows the 
retention time and peak area data for the sample collection time with the highest conversion of PHF to fluorene (90 minutes). Note that for this sample, there is a substantial byproduct (8.7\%) at RT=9.4.

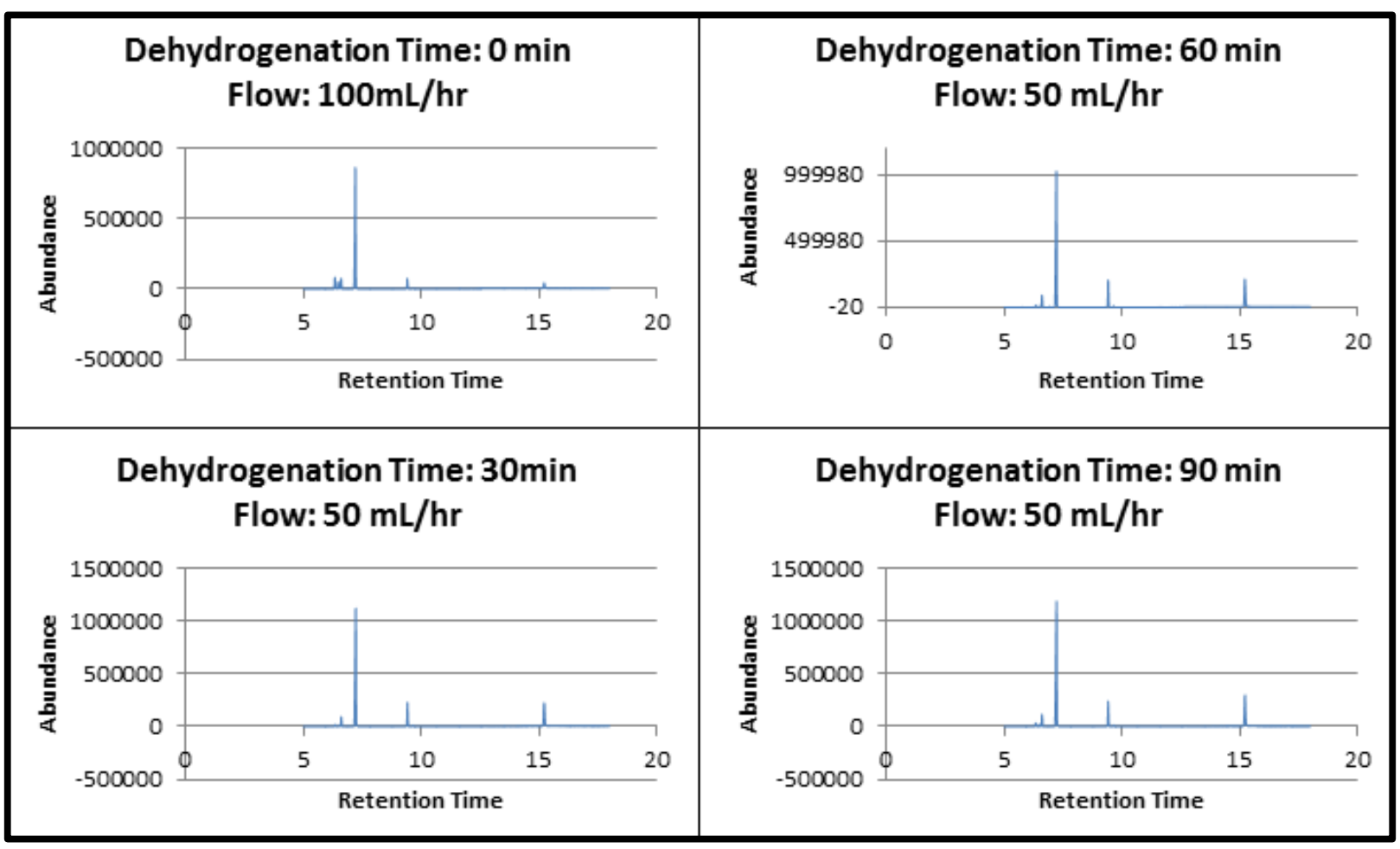

Figure 19 - GC Analysis of 5\% Pt Monolith and 50/50 Fuel Mix at $220^{\circ} \mathrm{C}$

\begin{tabular}{|c|r|r|r|}
\hline Peak & $\begin{array}{c}\text { Retention } \\
\text { Time }\end{array}$ & \multicolumn{1}{c|}{$\begin{array}{c}\text { Peak } \\
\text { Area }\end{array}$} & \multicolumn{1}{c|}{$\begin{array}{c}\text { Percent } \\
\text { Total }\end{array}$} \\
\hline 1 & 6.339 & 534734 & 1.149 \\
2 & 6.486 & 323868 & 0.696 \\
3 & 6.607 & 2062503 & 4.432 \\
4 & 7.227 & 30652941 & 65.874 \\
5 & 9.42 & 4062312 & 8.73 \\
6 & 15.231 & 8552868 & 18.38 \\
\hline
\end{tabular}

Table 10 - Product Peaks for 5\% Pt Monolith and 50/50 Fuel Mix at $220^{\circ} \mathrm{C}$ ( $\mathrm{T}=90 \mathrm{~min}$ )

Figure 20 shows the amount of unreacted PHF and the amount of fluorene produced in the reaction samples. The results for the $50 \mathrm{ml} / \mathrm{hr}$ flow rate are fairly constant, with the samples consisting of an average of $67.1 \%$ PHF and $17.5 \%$ fluorene. The increases or decreases in the amount of fluorene produced tend to mirror the decreases or increases, respectively, in the amount of PHF that remained in the sample, confirming the primary reaction that was occurring was PHF to fluorene, however, the production of the intermediate byproduct suggested that the Pt catalyst was not highly selective for this reaction at these test conditions, therefore, testing shifted to the palladium monoliths. 


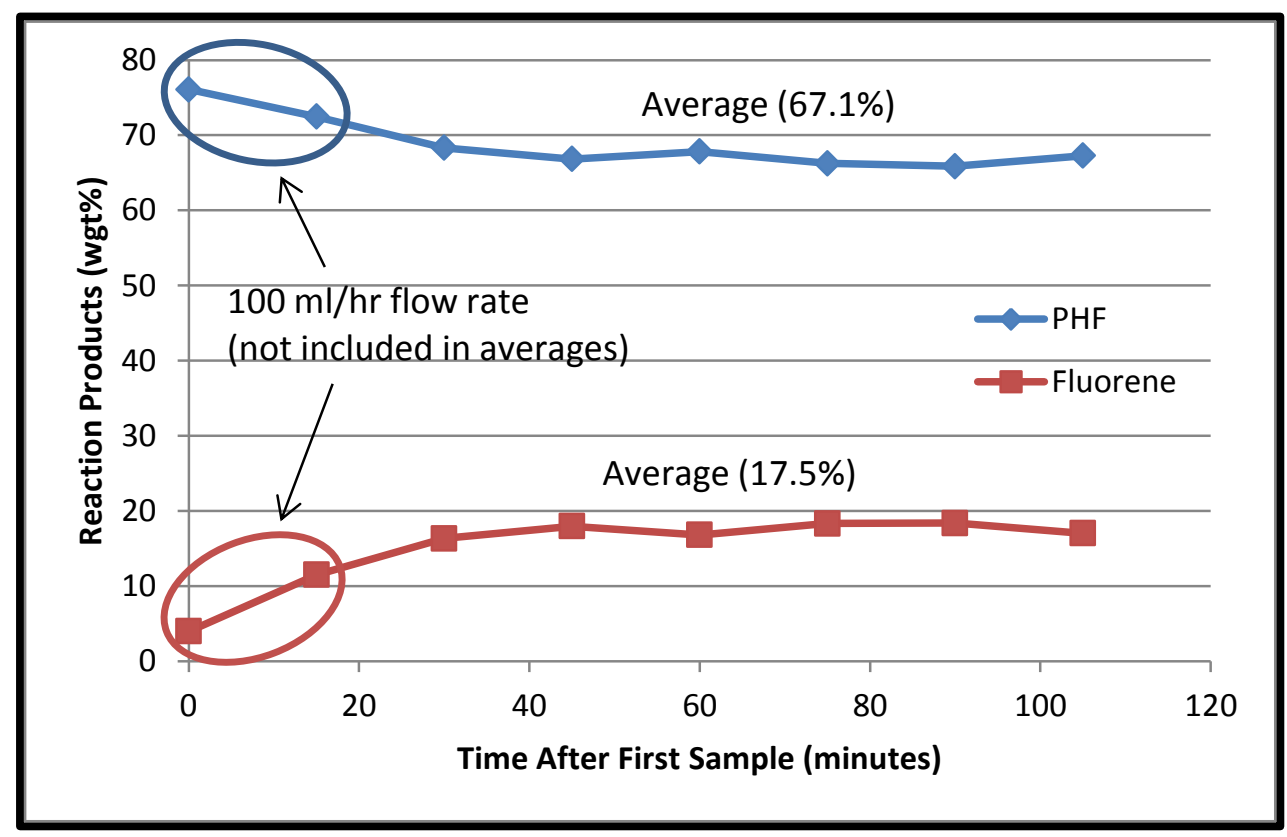

Figure 20 - Reaction Products for 5\% Pt Monolith and 50/50 Fuel Mix at $220^{\circ} \mathrm{C}$

The next catalyst tested was the $1 \% \mathrm{Pd}$ monolith at a reactor set point temperature of $250^{\circ} \mathrm{C}$ and flow rate of $50 \mathrm{ml} / \mathrm{hr}$. GC analysis of the reaction products is presented in Figure 21. Table 11 shows peak area and retention time data for the sample at Time $=0 \mathrm{~min}$, corresponding to the highest percentage of fluorene produced during this test (28.5\%). Note the absence of other peaks in the GC plots, indicating a highly selective conversion of PHF to fluorene.

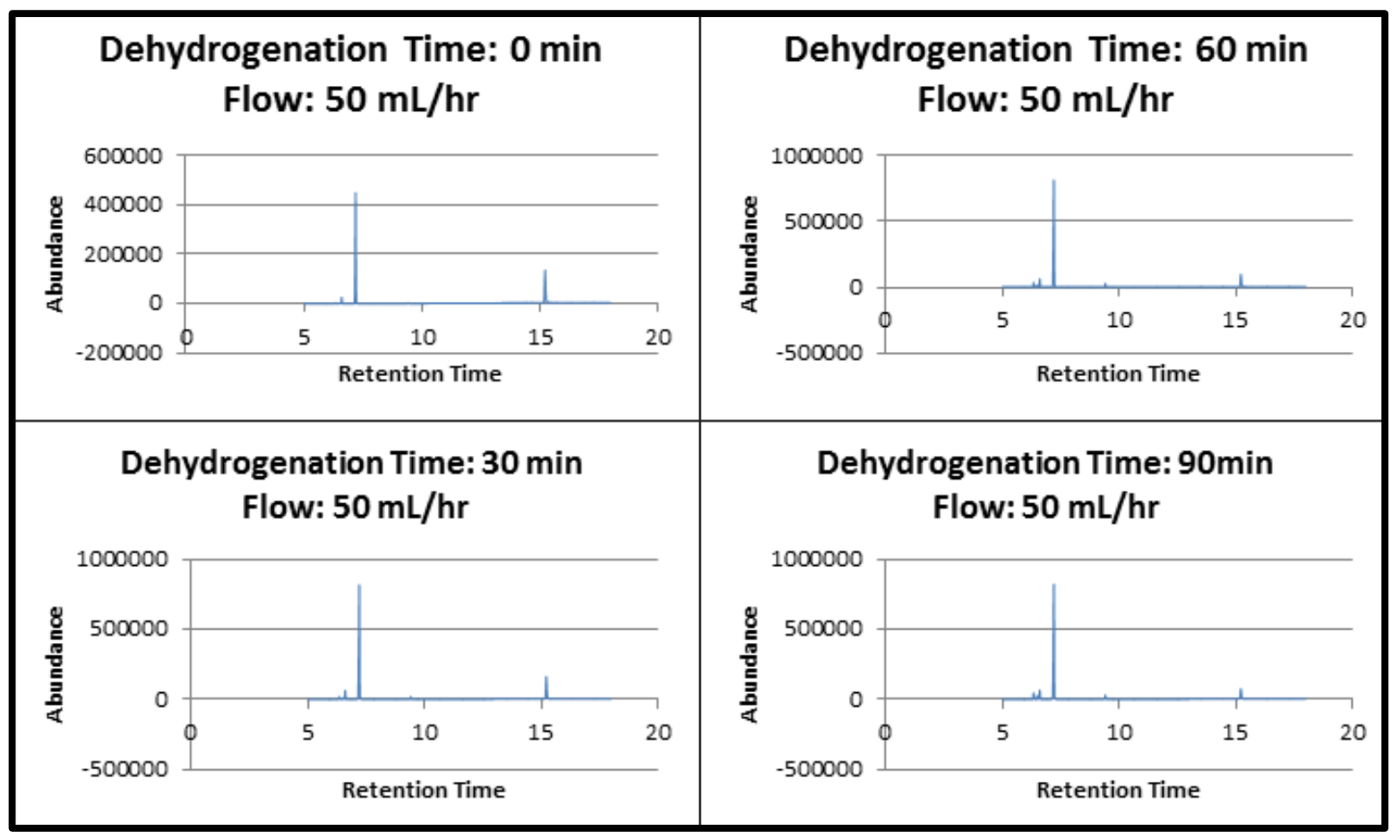

Figure 21 - GC Analysis of 1\% Pd Monolith and 50/50 Fuel Mix at $250^{\circ} \mathrm{C}$ 


\begin{tabular}{|c|r|r|r|}
\hline Peak & $\begin{array}{c}\text { Retention } \\
\text { Time }\end{array}$ & \multicolumn{1}{c|}{$\begin{array}{c}\text { Peak } \\
\text { Area }\end{array}$} & $\begin{array}{c}\text { Percent } \\
\text { Total }\end{array}$ \\
\hline 1 & 6.336 & 32059 & 0.243 \\
2 & 6.476 & 14836 & 0.113 \\
3 & 6.607 & 400919 & 3.041 \\
4 & 7.197 & 8924563 & 67.697 \\
5 & 9.415 & 49213 & 0.373 \\
6 & 15.226 & 3761459 & 28.533 \\
\hline
\end{tabular}

\section{Table 11 - Product Peaks for $1 \%$ Pd Monolith and 50/50 Fuel Mix at $250^{\circ} \mathrm{C}$ ( $\mathrm{T}=0 \mathrm{~min}$ )}

Figure 22 shows the amount of unreacted PHF and the amount of fluorene produced in the reaction samples. Note the continuous increase in unreacted PHF and the continuous decrease in the amount of fluorene produced. This reduction in the reaction was accompanied by an increase in the temperature difference between the thermocouple at the inlet to the monolith, which was used to set the reactor temperature, and the thermocouple at the exit to the reactor. By the end of the test, this temperature difference was $80^{\circ} \mathrm{C}$ (i.e. $250^{\circ} \mathrm{C}$ at the inlet and $330^{\circ} \mathrm{C}$ at the exit). Since the PHF-to-fluorene reaction is highly endothermic, this temperature difference is not unexpected, because the heat being added to the reactor is not being consumed by the reaction, resulting in an increase in the liquid temperature. This increase in temperature may also have resulted in some evaporation of the PHF (b.p. $=253^{\circ} \mathrm{C}$ ), reducing the residence time of the liquid in the reactor and resulting in less conversion of PHF to fluorene. A post-test inspection of this reactor showed dark deposits on the reactor walls, suggesting that some coking had occurred, likely due to the high temperatures in the reactor.

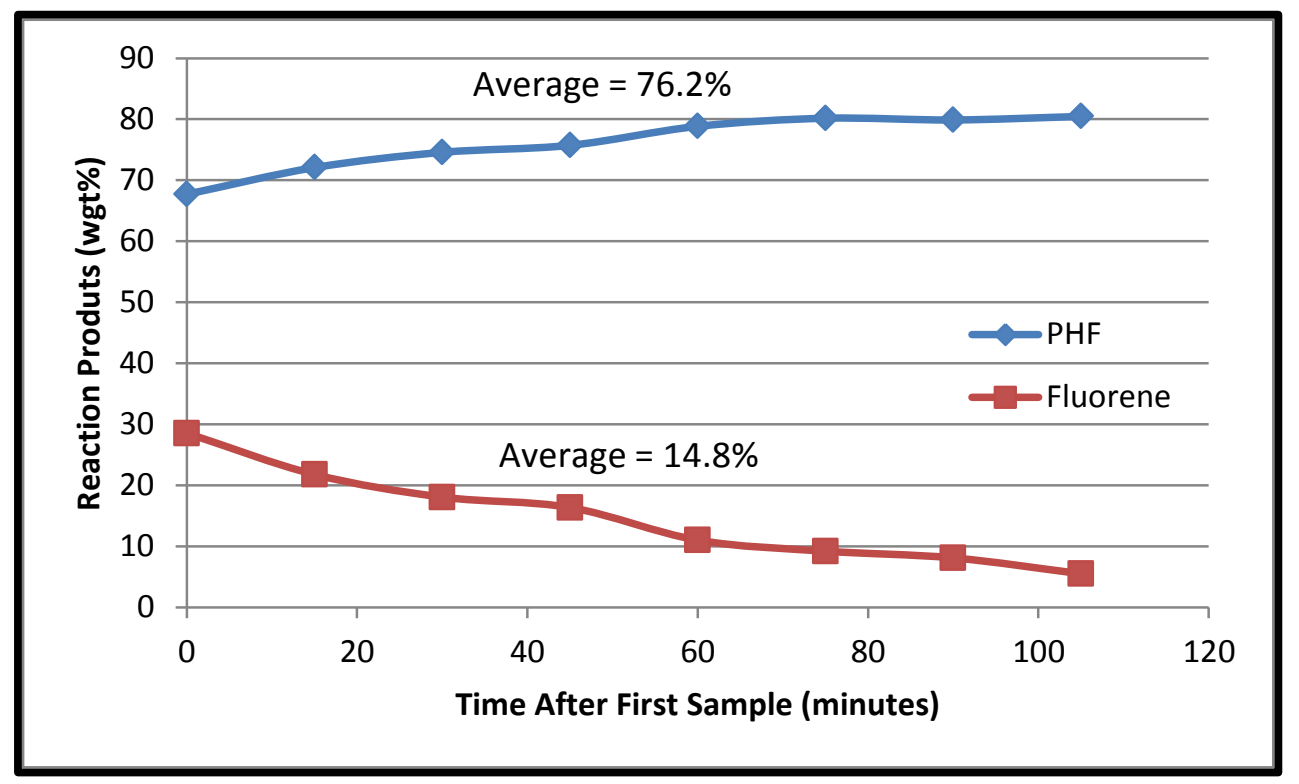

Figure 22 - Reaction Products for $1 \%$ Pd Monolith and 50/50 Fuel Mix at $250^{\circ} \mathrm{C}$

The final catalyst tested was $5 \%$ palladium on alumina. The reactor set point temperature was $250^{\circ} \mathrm{C}$, and a flow rate of $50 \mathrm{ml} / \mathrm{hr}$ was maintained for this test. GC analysis is presented in Figure 23. Retention time and peak area data are presented in Table 12 for the highest percent of fluorene observed, which was at the 30 minute sample collection time. The maximum amount of fluorene 
produced was $26.2 \%$ of the sample, with $68.4 \%$ of the sample being unconverted PHF. Unlike the $1 \%$ Pd catalyst, the results for the $5 \%$ Pd catalyst were consistent for the entire test run. Minimal secondary byproducts were observed.

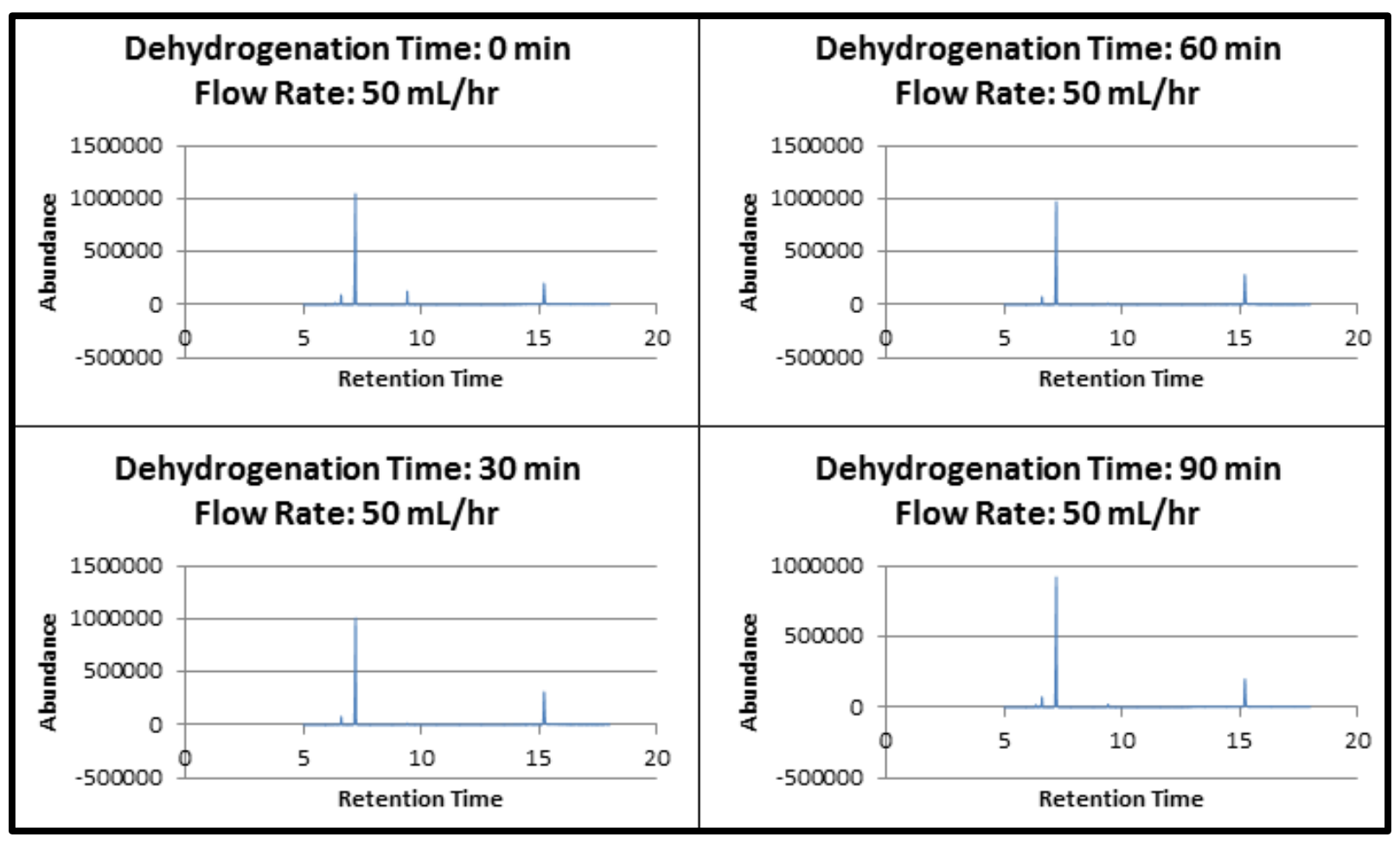

Figure 23 - GC Analysis of 5\% Pd Monolith and 50/50 Fuel Mix at $\mathrm{T}=250^{\circ} \mathrm{C}$

\begin{tabular}{|c|r|r|r|}
\hline Peak & $\begin{array}{c}\text { Retention } \\
\text { Time }\end{array}$ & \multicolumn{1}{c|}{$\begin{array}{c}\text { Peak } \\
\text { Area }\end{array}$} & $\begin{array}{c}\text { Percent } \\
\text { Total }\end{array}$ \\
\hline 1 & 6.343 & 84790 & 0.242 \\
2 & 6.483 & 40524 & 0.115 \\
3 & 6.608 & 1394681 & 3.975 \\
4 & 7.219 & 24006210 & 68.416 \\
5 & 9.419 & 219145 & 0.625 \\
6 & 15.223 & 9207702 & 26.241 \\
\hline
\end{tabular}

Table 12 - Product Peaks for 5\% Pd Monolith and 50/50 Fuel Mix at $\mathrm{T}=\mathbf{2 5 0}{ }^{\circ} \mathrm{C}$ ( $\mathrm{T}=\mathbf{3 0} \mathrm{min}$ )

Figure 24 shows the amount of unreacted PHF and the amount of fluorene produced in the reaction samples. The results are fairly steady over the test period, with an average of $21.4 \%$ production of fluorene and $71.2 \%$ of unreacted PHF remaining. No substantial difference in reactor inlet and outlet temperatures was observed during this test. 


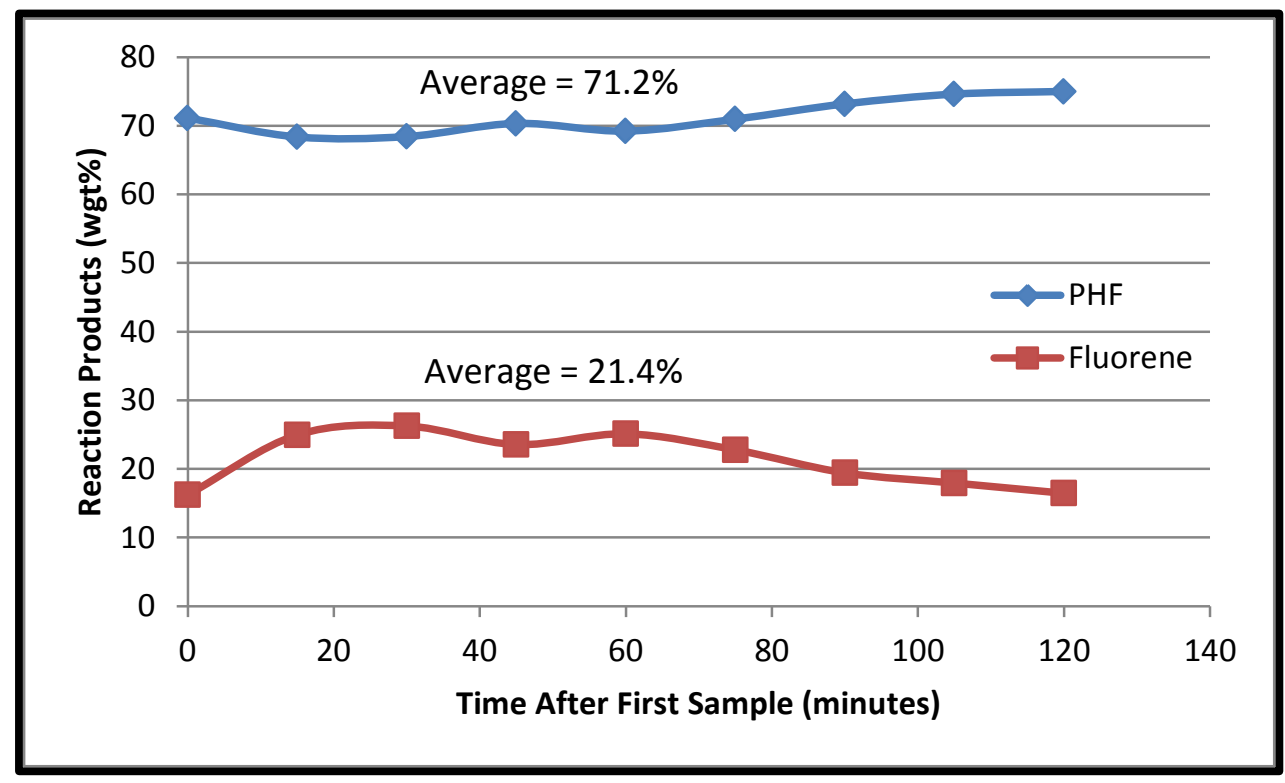

Figure 24 - Reaction Products for 5\% Pd Monolith and 50/50 Fuel Mix at $250^{\circ} \mathrm{C}$

A comparison of the fluorene production results for three of the monoliths tested is shown in Figure 25. Results for the $1 \%$ Pt monolith are not shown due to the low levels of fluorene produced (less than 1\%). Based upon the reasonably high level of fluorene production, coupled with the high selectivity of the reaction, the $5 \% \mathrm{Pd}$ monolith was selected for further testing and for use in the demonstration reactor system.

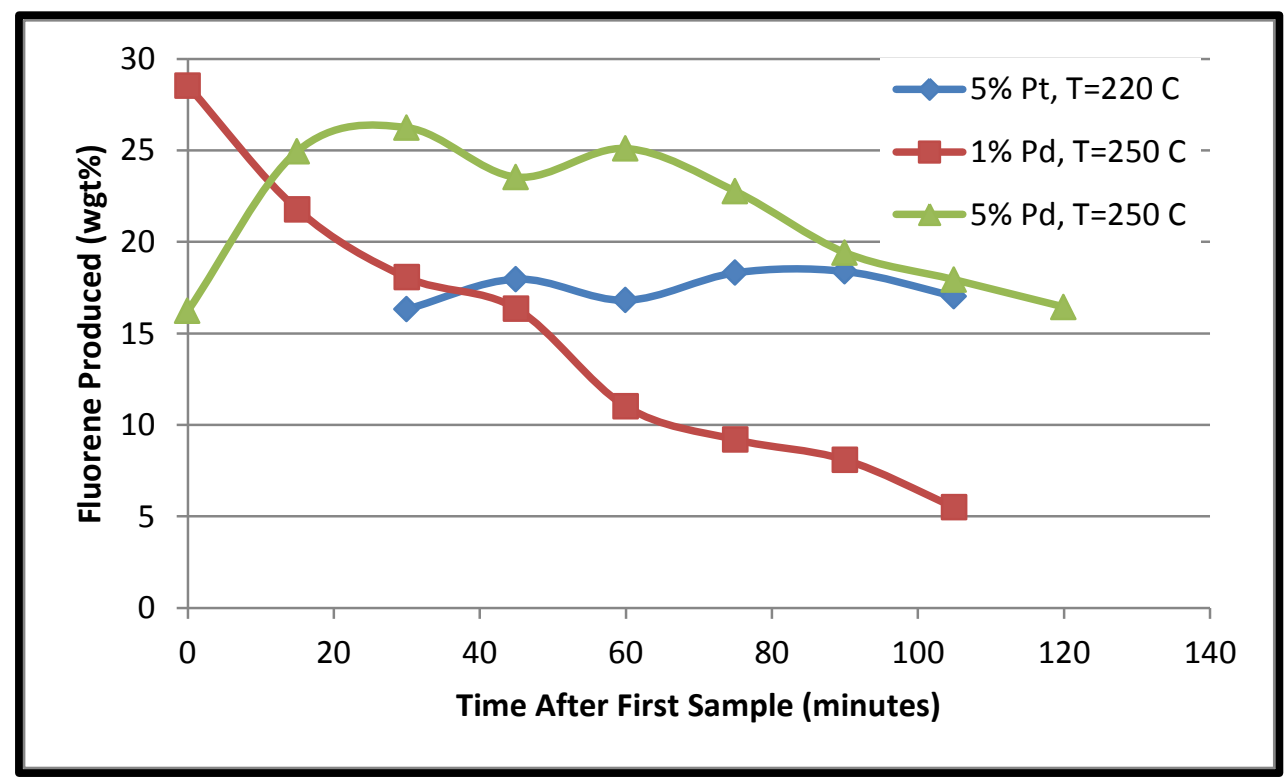

Figure 25 - Comparison of Fluorene Production Results for Three Monoliths

All of the testing performed to this point had been done with a 50/50 mix of toluene and the neat fuel. Therefore, the next round of testing focused on testing with neat fuel only. The first test in this round was conducted at atmospheric pressure, $250^{\circ} \mathrm{C}$ set-point temperature, and $50 \mathrm{ml} / \mathrm{hr}$ flow rate. These 
were the same experimental conditions as the 50/50 neat fuel/toluene tests. The dehydrogenation experiments with the diluted fuel versus the neat fuel were then compared to determine if the dilution of the fuel had any effect on the conversion of perhydrofluorene to fluorene. Dehydrogenation experiments were also conducted varying the set point temperature to investigate the effect of temperature on conversion.

GC analysis results for the dehydrogenation using the neat fuel and the 5\% Pd monolith reactor are presented in Figure 26. Table 13 shows retention time and peak area data corresponding to the highest percentage of fluorene observed at the 60 minute sample time.

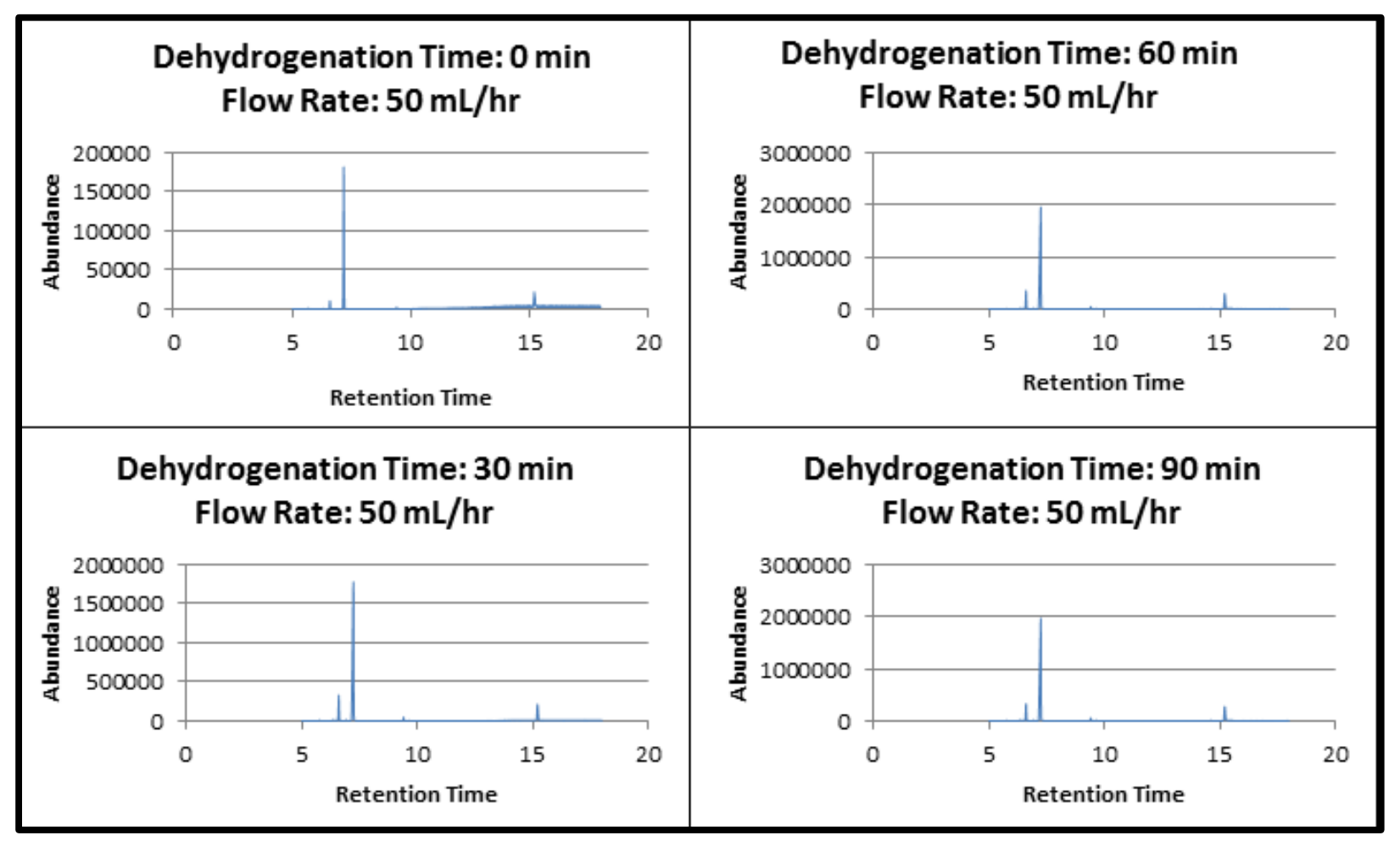

Figure 26 - GC Analysis of 5\% Pd Monolith Reactor with Neat Fuel

\begin{tabular}{|c|r|r|r|}
\hline Peak & $\begin{array}{c}\text { Retention } \\
\text { Time }\end{array}$ & \multicolumn{1}{c|}{$\begin{array}{c}\text { Peak } \\
\text { Area }\end{array}$} & $\begin{array}{c}\text { Percent } \\
\text { Total }\end{array}$ \\
\hline 1 & 6.333 & 243606 & 0.301 \\
2 & 6.481 & 271763 & 0.335 \\
3 & 6.606 & 6434871 & 7.942 \\
4 & 7.246 & 64022560 & 79.017 \\
5 & 9.416 & 740153 & 0.914 \\
6 & 15.213 & 8659420 & 10.688 \\
\hline
\end{tabular}

Table 13 - Product Peaks for $5 \% \mathrm{Pd}$ and Neat Fuel at $250^{\circ} \mathrm{C}(\mathrm{T}=60 \mathrm{~min}$ )

Results from the GC analysis of the neat fuel reaction samples indicate the maximum amount of fluorene produced was $\mathbf{1 0 . 7 \%}$, while $\mathbf{7 9 . 0 \%}$ of the sample was unreacted PHF. Compared to the test 
results for the 50/50 neat fuel/toluene mix, performed under the same conditions, the 50/50 blend showed significantly higher conversion to fluorene (26.2\% versus $10.7 \%)$. Two causes are suspected:

1) The toluene (b.p. $=110.6^{\circ} \mathrm{C}$ ) likely evaporated in the reactor, while the PHF remained liquid, essentially doubling the PHF residence time. The vapor may also have aided in pushing the hydrogen out of the reactor, providing more catalyst contact surface for the PHF.

2) Coking of the monolith may be a contributing factor in decreasing catalytic activity, thus reducing the conversion of PHF to fluorene. The same monolith was used for both the earlier neat fuel-toluene blend and this neat fuel only testing.

Further experiments were done to investigate the effects of temperature on reaction conversion. The dehydrogenation of the neat fuel was done using the same $5 \% \mathrm{Pd}$ monolith reactor at a $50 \mathrm{ml} / \mathrm{hr}$ flow rate and $270^{\circ} \mathrm{C}$ set point temperature. GC results are shown in Figure 27. Table 14 shows retention time and peak area data corresponding to the sample with the highest percent of fluorene observed.

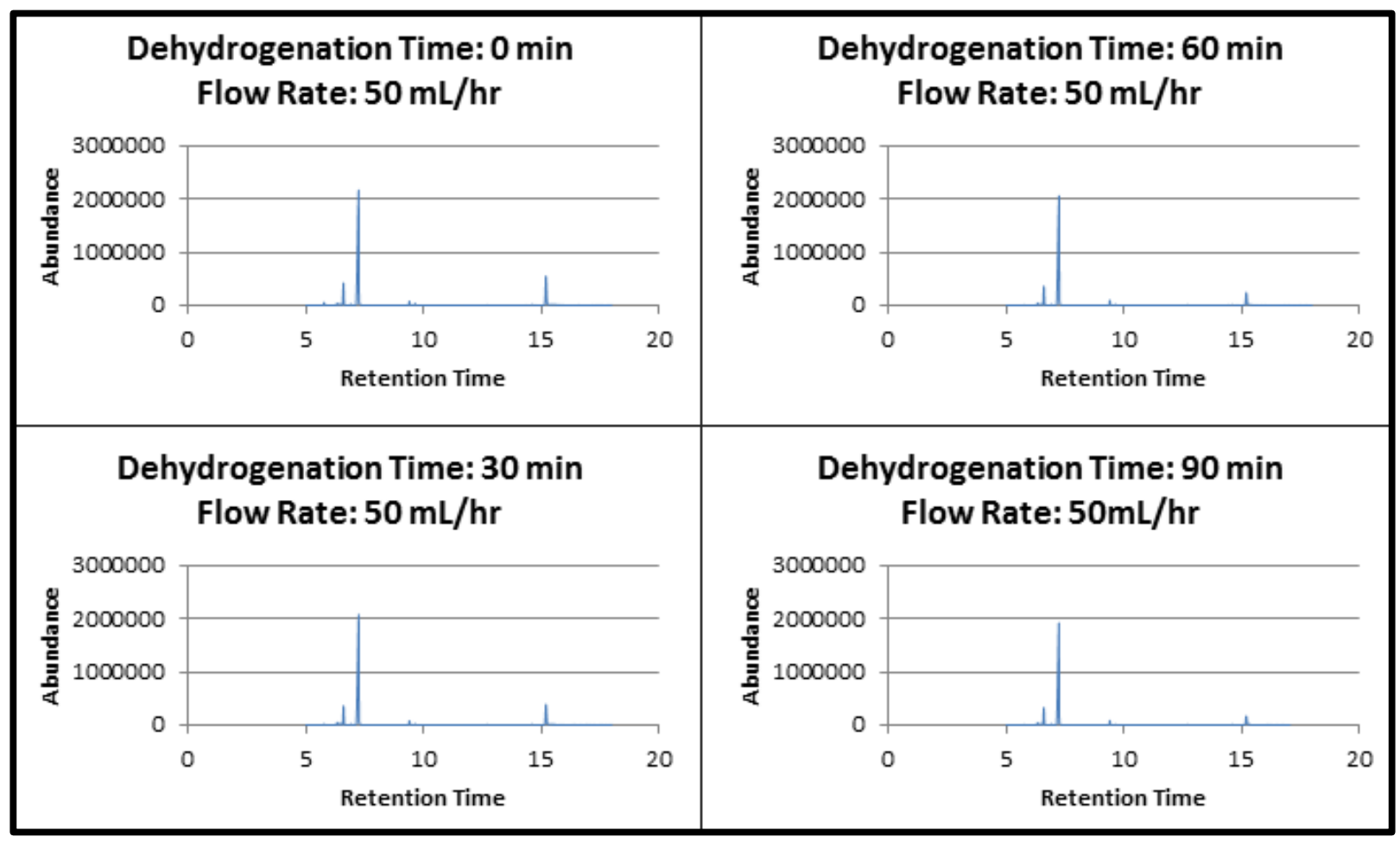

Figure 27 - GC Analysis of 5\% Pd Monolith Reactor with Neat Fuel at $270{ }^{\circ} \mathrm{C}$

\begin{tabular}{|c|r|r|r|}
\hline Peak & $\begin{array}{c}\text { Retention } \\
\text { Time }\end{array}$ & \multicolumn{1}{c|}{$\begin{array}{c}\text { Peak } \\
\text { Area }\end{array}$} & $\begin{array}{c}\text { Percent } \\
\text { Total }\end{array}$ \\
\hline 1 & 6.331 & 589606 & 0.551 \\
2 & 6.473 & 276255 & 0.258 \\
3 & 6.603 & 8585095 & 8.019 \\
4 & 7.246 & 78000871 & 72.857 \\
5 & 9.403 & 1251743 & 1.169 \\
6 & 15.206 & 16330495 & 15.254 \\
\hline
\end{tabular}

Table 14 - Product Peaks for $5 \%$ Pd Monolith Reactor at $270^{\circ} \mathrm{C}$ ( $\mathrm{T}=0 \mathrm{~min}$ ) 
The GC results indicate that initially higher conversion of perhydrofluorene to fluorene was observed for the dehydrogenation at $270^{\circ} \mathrm{C}$ when compared to the $250^{\circ} \mathrm{C}$ test. However, as Table 15 shows, while the results at $250^{\circ} \mathrm{C}$ are relatively constant for the duration of the test, the results at $270^{\circ} \mathrm{C}$ show a continuous decline, possibly due to monolith coking or PHF evaporation in the reactor, recondensing in the spent fuel tank.

\begin{tabular}{|c|c|c|c|c|}
\hline \multicolumn{5}{|c|}{$250^{\circ} \mathrm{C}$ set point temperature } \\
\hline Collection Time (min) & 0 & 30 & 60 & 90 \\
\hline PHF (\%) & 83.7 & 80.3 & 79.0 & 79.1 \\
\hline Fluorene (\%) & 11.4 & 8.5 & 10.7 & 10.1 \\
\hline \multicolumn{5}{|c|}{$270^{\circ} \mathrm{C}$ set point temperature } \\
\hline Collection Time (min) & 0 & 30 & 60 & 90 \\
\hline PHF (\%) & 72.9 & 75.8 & 80.0 & 81.5 \\
\hline Fluorene (\%) & 15.3 & 12.2 & 7.8 & 5.9 \\
\hline
\end{tabular}

Table 15 - Effect of Temperature on Reactor Performance

Figure 28 compares the neat fuel test results with the mixed fuel results. While the mixed fuel results were clearly superior, the adverse impact the toluene would have on the net weight of hydrogen produced per unit weight of the mixed fuel made this approach unattractive for vehicle applications. Therefore, neat fuel was chosen for use in the demonstration reactor, and the reactor was designed to provide increased residence time to offset the lower reaction rate of the neat fuel. Based upon these test results, a 5\% Pd, corrugated monolith was selected for use in the demonstration fuel system. The baseline operating temperature and pressure selected were $250^{\circ} \mathrm{C}$ and $1 \mathrm{~atm}$, respectively. A fanfold monolith configuration was also selected for testing in the demonstration fuel system to assess the potential benefits relative to gas film formation, which was suspected to be occurring in the small area triangular columns of the corrugated monolith.

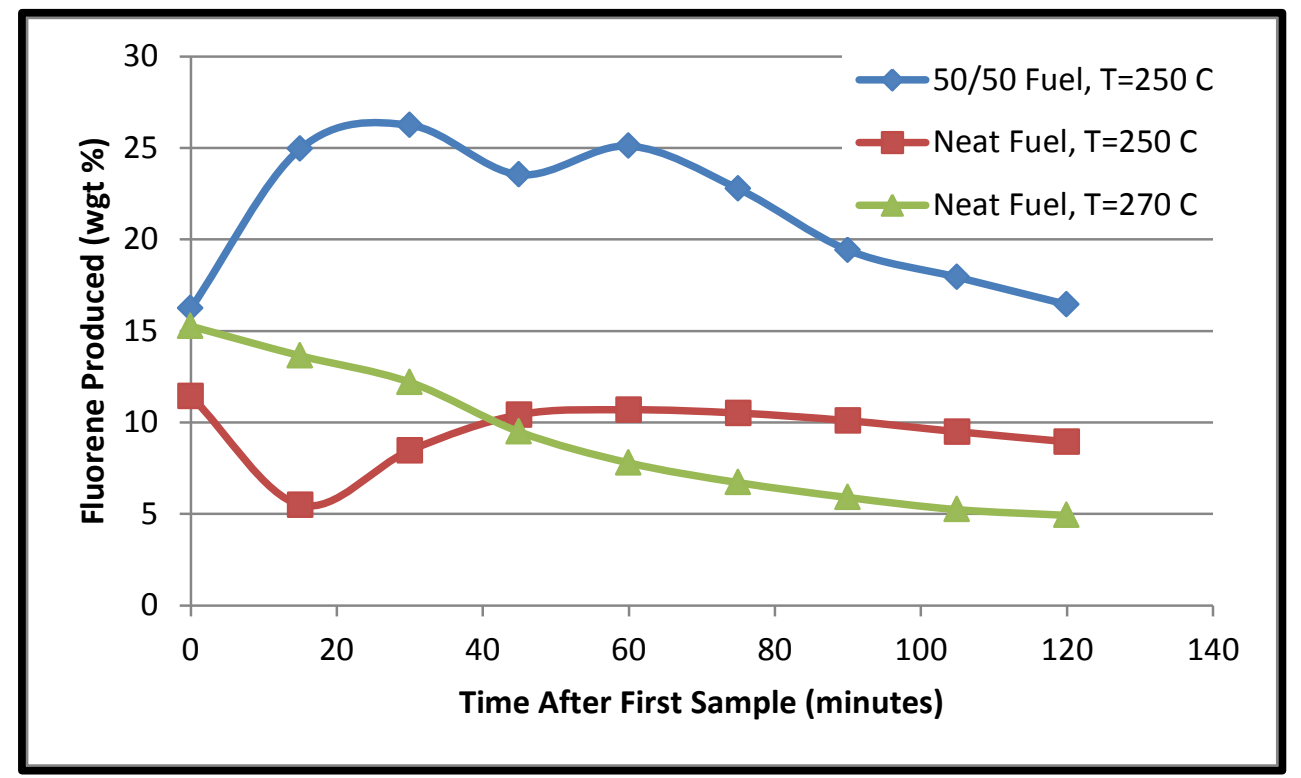

Figure 28 - Comparison of Diluted and Neat Fuel Test Results 


\section{Demonstration Fuel System}

While the experimental reactor testing was being conducted, work on the demonstration fuel system was begun in parallel. The functions of the fuel system were to:

- store the charged and spent liquids,

- separate the hydrogen from the liquid carrier, and

- deliver the hydrogen to the fuel cell at the required pressure, temperature and purity.

The system was designed to operate on SCIES' electric drive test vehicle. The vehicle, shown in Figure 29 , is an off-road vehicle that was converted by SCIES to a hybrid-electric configuration by replacing the internal combustion engine with a $4 \mathrm{hp}$ continuous, $17 \mathrm{hp}$ peak DC electric motor powered by three $12 \mathrm{~V}-110 \mathrm{AH}$ batteries and a $1 \mathrm{KW}$ PEM fuel cell, operating in a series configuration.

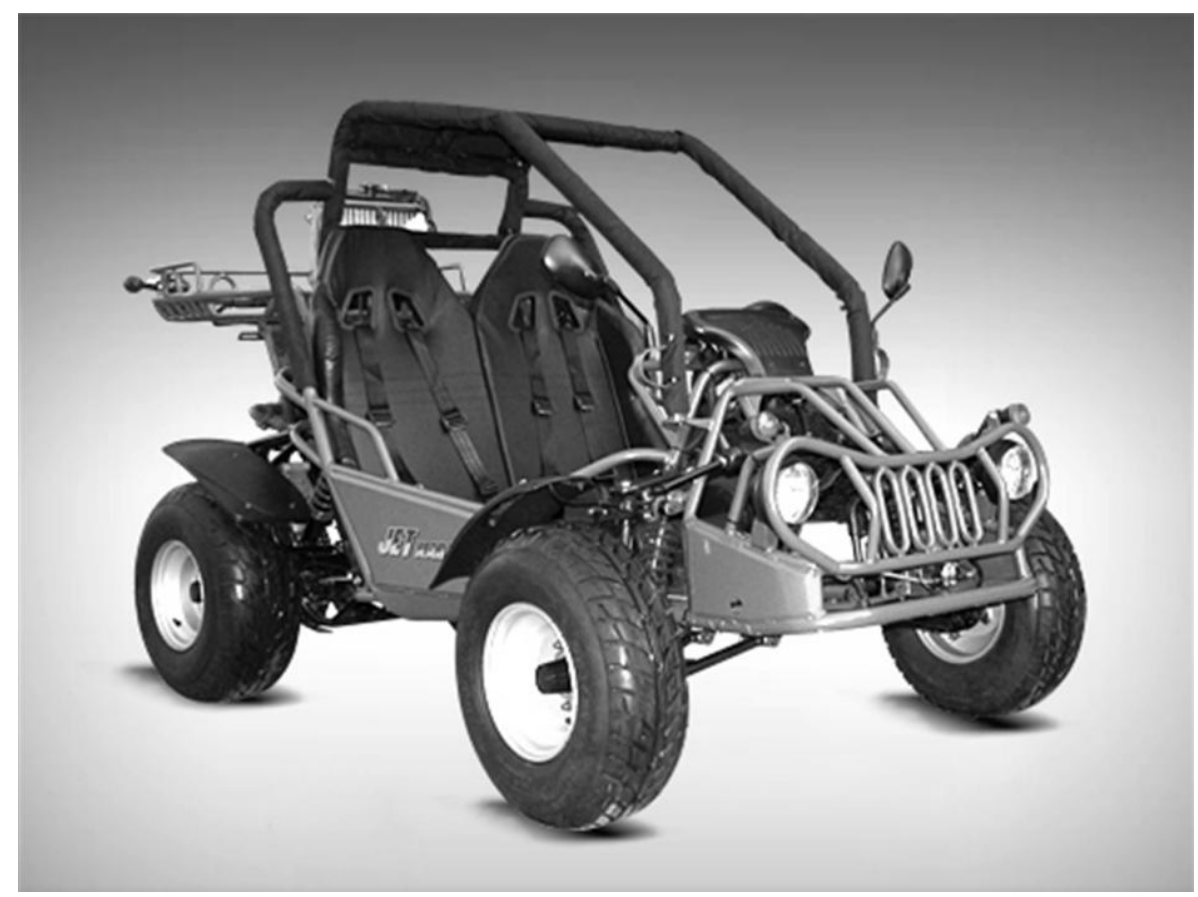

Figure 29 - SCIES Hybrid Electric Test Vehicle

As a series hybrid, the fuel cell functions strictly as a recharging system for the batteries. Therefore, the fuel system was designed to sense the State of Charge (SOC) of the batteries, and if the state of charge was less than $50 \%$ of full capacity, it would produce hydrogen for the fuel cell at a rate compatible with the fuel cell's demand, until the batteries reached a full state of charge. The fuel system was designed to operate in the following modes and states (shown in Figure 30):

- Off. The system is off and purged. SOC will be $100 \%$ unless the system was disabled prior to $100 \%$ SOC being reached.

- Start. The system is turned on. The reactor is being brought up to temperature, charged liquid is filling the reactor, and hydrogen is starting to reach the fuel cell. The SOC is $<50 \%$.

- Full. The system is on and running at full charging rate.

- Idle. The system is on and running at a rate that produces just enough hydrogen to maintain reactor temperature without depleting the batteries. No battery charging. 
- Purge._ The system is shut off, all liquid (charged and spent) in the reactor has been drained back to the spent fuel tank, and slightly pressurized hydrogen backfills the reactor.

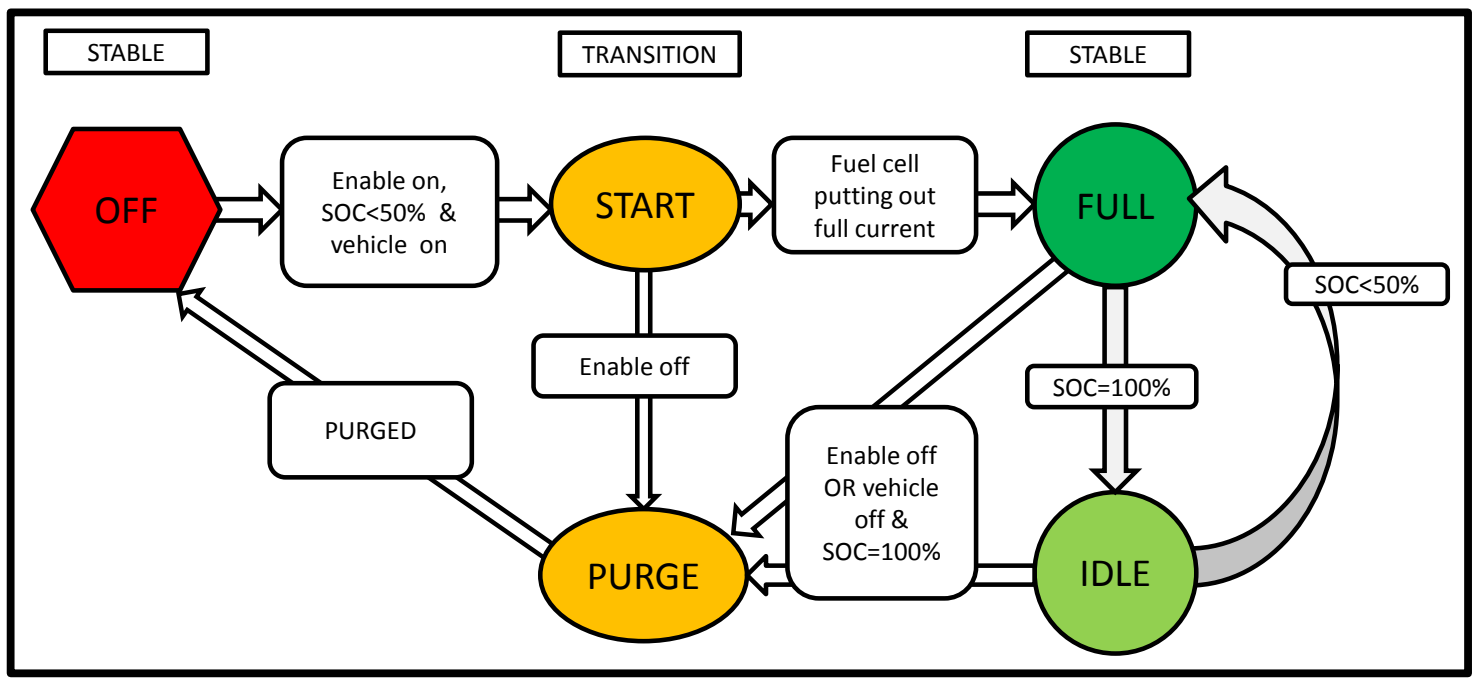

Figure 30 - Fuel System States

In addition, the fuel system was designed to operate in the following transitional states:

- Off to Start. The system will go to start if all of the following are true:

○ The battery state-of-charge is below $50 \%$

- The enable switch is on

$\circ$ The vehicle is on

- Start to Full. The system will go from Start to Full once fuel cell output current reaches maximum. (Note: The system will not go directly from Start to Idle because at Start the battery pack will have less than $50 \%$ full charge, thus restricting it from Idle.)

- Start to Purge. If the enable switch is turned off while in Start, the system will go into Purge to prepare the system to shut down.

- Full to Idle. The system will go to Idle after operating in Full, when the SOC has reached $100 \%$.

- Idle to Full. The system will go to Full when the SOC has dropped below $50 \%$ and the battery pack is discharging. The system will also go from Idle to Full if the vehicle is turned off while the SOC $<100 \%$. When the vehicle is turned off the fuel system will continue to run until the battery pack has reached $100 \%$ SOC using fuel cell current. If the system is turned off in Idle at less than $100 \%$ SOC, it will elevate to Full to charge the battery pack. If it is desired to conserve hydrogen, the enable switch may be shut off and the battery pack can be charged using wall current.

- Full to Purge. The system will go from Full to Purge if the enable switch is turned off, or if the vehicle is turned off while the SOC is $100 \%$.

- Idle to Purge. The system will go from Idle to Purge if the enable switch is turned off, or if the vehicle is turned off while the SOC is $100 \%$.

- Purge to Off. The system will automatically initiate a system purge after being turned off.

Requirements of the demonstration fuel system design were that it be:

- Capable of performing all of the system functions,

- Compatible in weight and size with mounting on the test vehicle, and

- Low cost. 
While the demonstration system was not intended to be representative of a production design, it should provide the basis from which a final design could be prepared.

A schematic of the prototype fuel system is shown in Figure 31. The fuel and spent tanks were simplyconstructed of PVC pipe. Sight glasses on both were made by LDI Industries. The fuel filter was a Flow Ezy 4ILA-03-25-F3-RD, whose purpose was to protect the pump and downstream components. The pump was a Fluid-o-Tech MG213XDD1PT stainless steel gear pump driven by a 12 volt direct current motor. A gear pump was selected for repeatability, controllability, and to provide high pressure if needed. Stainless steel was chosen for compatibility with the PHF. A 12 volt motor was chosen so that the pump could run from the on-vehicle battery. Downstream of the pump a Swagelok stainless steel one way valve prevented backflow from the reactor to the supply tank.

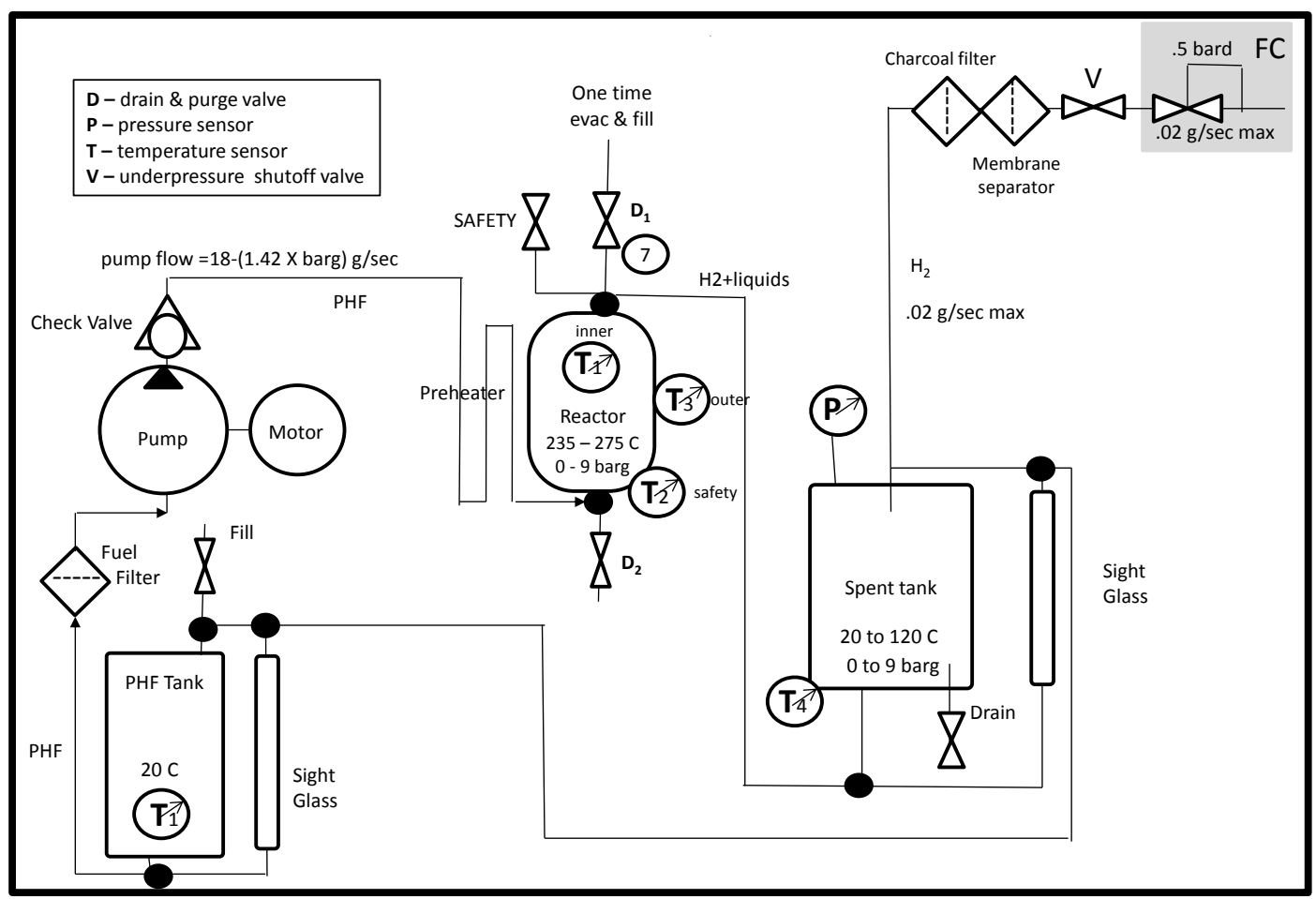

Figure 31 - Demonstration Fuel System Schematic

The reactor, shown in Figure 32, consisted of two concentric stainless steel pipes with threaded end caps, into which a catalyst-coated monolith was inserted. The inner and outer pipe diameters were chosen such that the distance to the center of the monolith core from the inside and outside walls was the same as the experimental reactor, resulting in similar heat transfer and temperature differences between the reactor walls and the monolith core. Heating cord was placed inside the inner pipe and wrapped around the outer pipe, then covered with two layers of two different types of insulation. The demonstration reactor was designed to provide about eight times the cross sectional area and five times the length of the experimental reactor, resulting in a demonstration reactor with forty times the volume of the experimental reactor. 


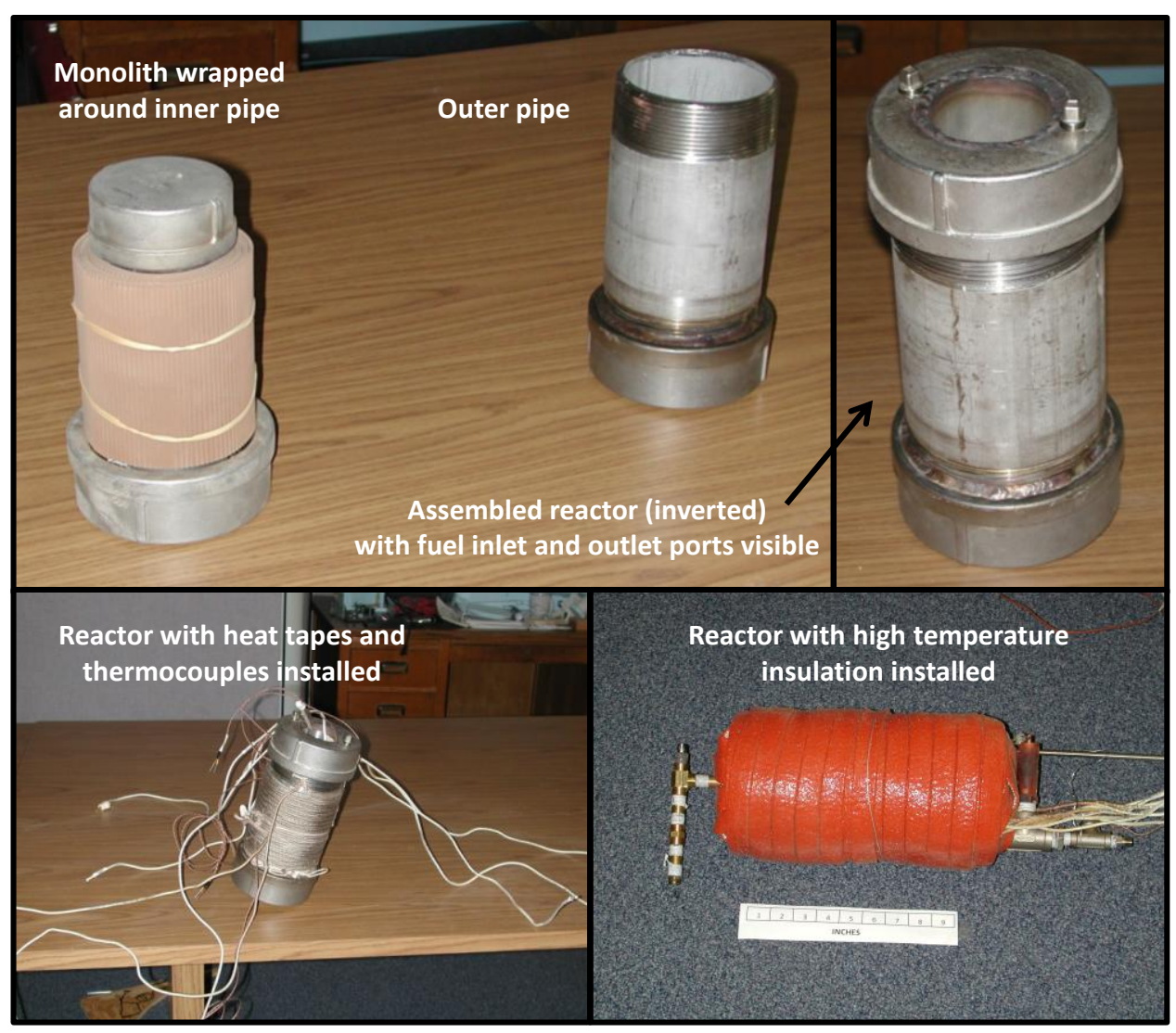

Figure 32 - Demonstration Reactor Build-up

Two monoliths were fabricated. One was made from the same $400 \mathrm{cpi}$ corrugated material used in the experimental reactor; the other was a fan fold configuration. The fan fold monolith had a lower surface area to volume ratio, which provided lower total reaction surface, but larger cell size, which was expected to reduce any problems with hydrogen gas film formation in the corners of the small triangular corrugated cells, that was thought to be occurring.

The fuel system controller is shown in Figure 33. The fuel system controller has responsibility for:

- Managing delivery of PHF to the reactor at the required flow rate

- Heating the reactor and controlling it at a set temperature

- Reading and logging data

- Setting alarms and shutting the system down if necessary

- Determining the current and commanded modes and controlling the transition between them 


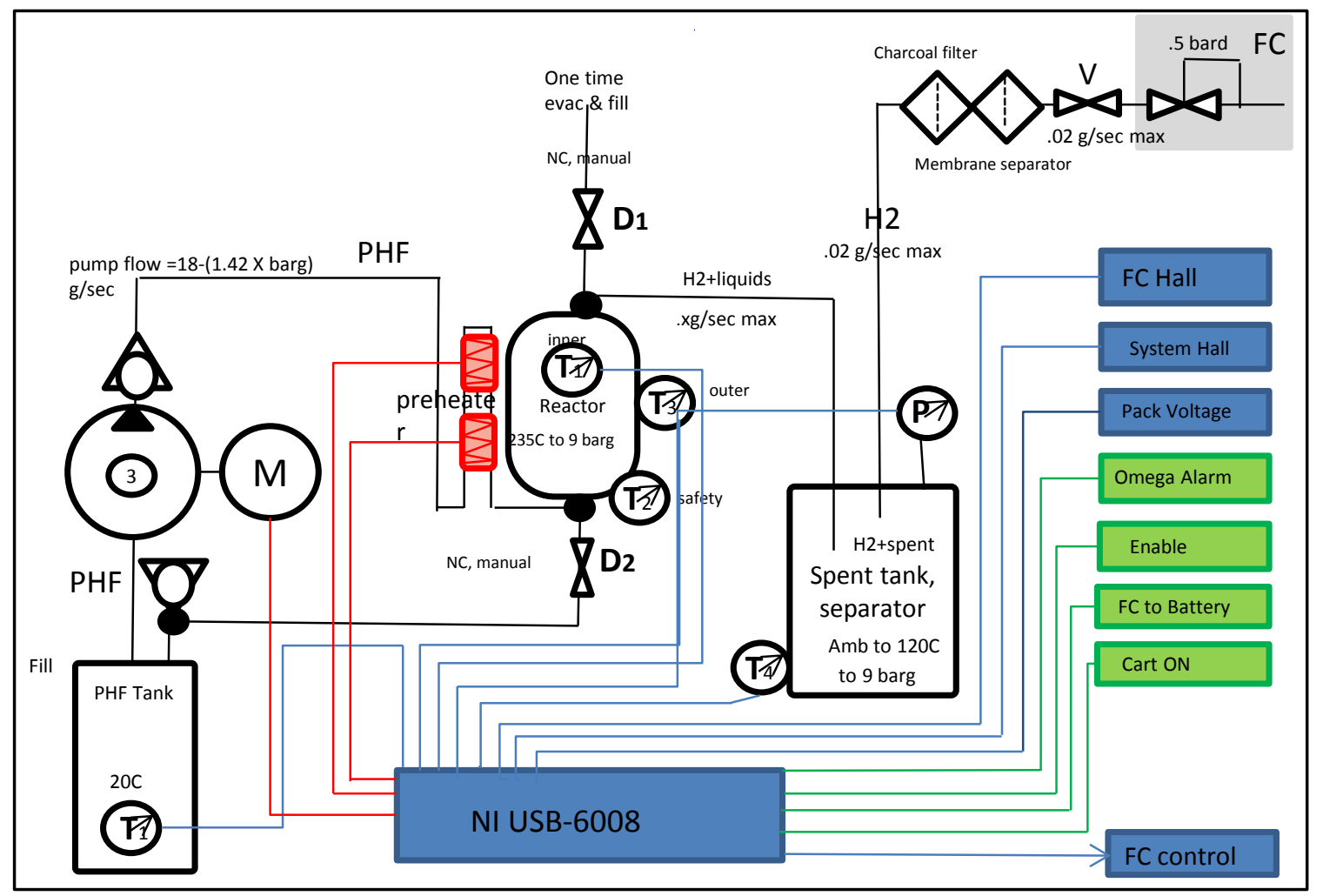

Figure 33 - Fuel System Controller Schematic

The control system processing is done in a standard laptop computer using Labview ${ }^{\circledR}$. The laptop is connected to the inputs and outputs via its USB port using a National Instruments IN USB-6008 interface. An Omega data logger is used as backup for data collection and alarms.

Data are acquired using the analog-in ports on the 6008 and include:

- Temperatures, using type $\mathrm{K}$ (chromel-alumel) thermocouples connected through a cold junction and linearizing chip. Temperature inputs are:

- Reactor outer wall lower

- Reactor outer wall upper

- Reactor inner wall

- Reactor monolith output

- Pressure in the spent tank is measured using a diaphragm-type pressure transducer. Pressure is not measured in the reactor since the low flow rate and lack of restrictions cause the spent tank and reactor pressures to be effectively the same.

- Battery pack voltage is measured using a simple locally built voltage divider.

- Current out of the fuel cell and into the batteries and out of the batteries and into the motor is measured with Hall-effect sensors.

- Battery state-of-charge at start-up is determined by an empirically determined relationship between state-of-charge and quiescent battery voltage, although in this design state-ofcharge would be $100 \%$ at start unless there was a premature shutdown. Battery state-ofcharge at start-up is then modified during operation via a coulomb counter that measures the difference between currents flowing into and out of the battery. 
Control is accomplished through the binary output ports on the 6008 which are power-amplified with a locally designed and built transistor pull-down circuit driving a 12 volt relay. They include:

- Fuel pump motor on/off. The gear pump motor was tested for flow versus pressure using neat fuel prior to final reactor tests with pulse widths of 0.5 and 1 second. Those curves were used to set the pulse frequency (run or idle frequency) to the pump motor to yield the desired flow rate. Only 0.5 second pulses were used in testing.

- User interface. The fuel system user interface is simply two switches fed directly to the 6008. The "on" switch to tell the system the vehicle is on and the "enable" switch to tell the system that all run conditions are met. The enable switch also acts as a single overriding emergency shut-down.

- Heaters. Three-zone heating is used to control the temperature in the reactor. The three heating zones are: (1) the lower half of the outer shell of the reactor, (2) the upper half of the outer shell, and (3) the inner shell of the reactor. All of these are external to the monolith and liquid, separated by the pipe walls which make up the reactor housing. The heaters are resistive heat cord driven by the pack batteries through the control relays. A proportional-integral-derivative (PID) control logic is used. The controller uses the external temperatures, rather than the internal liquid temperature, because of the substantial thermal lag that results from the thermal inertia of the thick stainless steel reactor walls. A thermal offset between the internal liquid temperature and the outer wall was experimentally derived and used successfully in the control algorithm.

The assembled demonstration fuel system is shown in Figure 34.

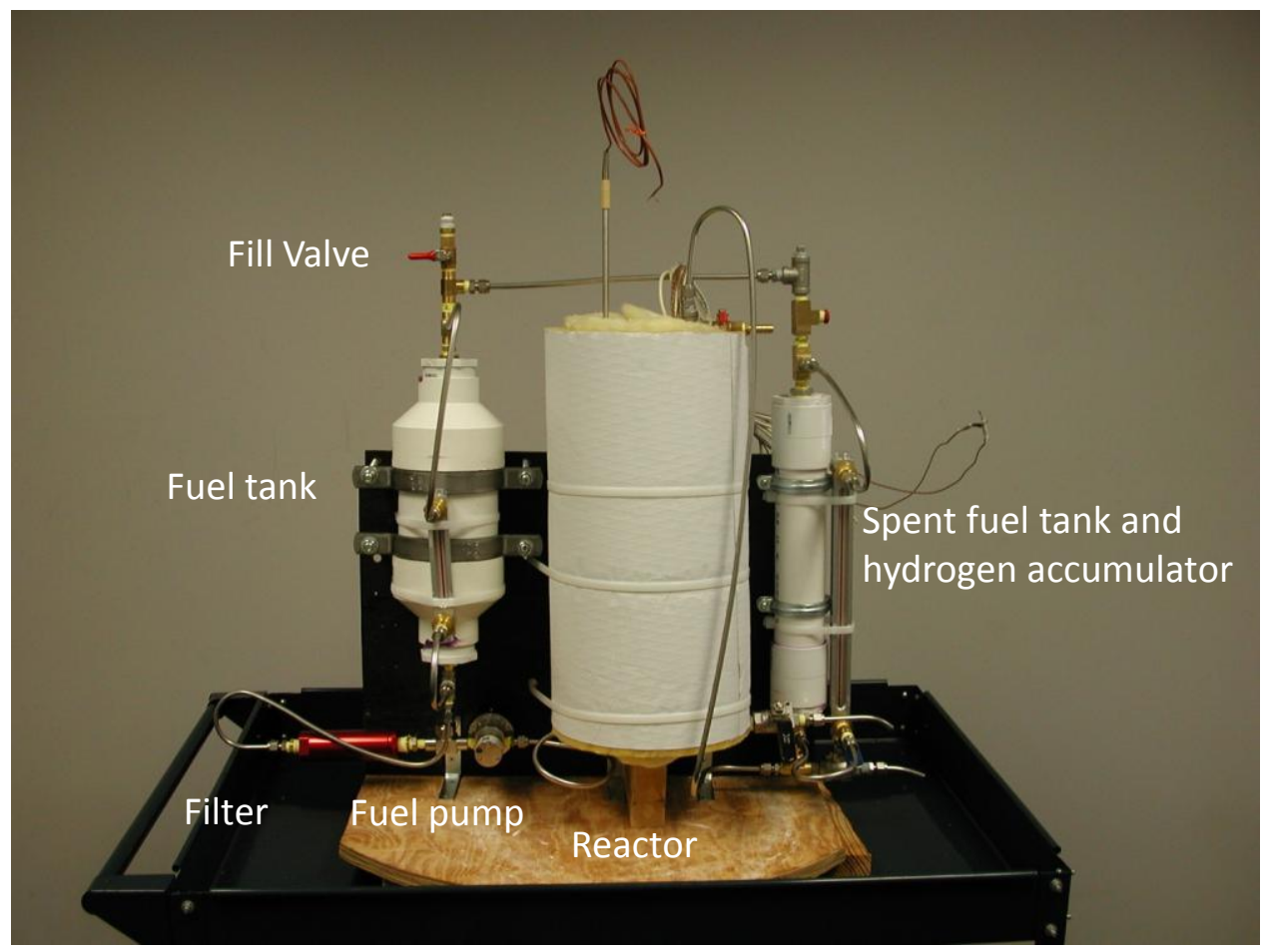

Figure 34 - Demonstration Fuel System

Figure 35 shows the system installed in the hood for testing, with the controller and data acquisition equipment connected. 


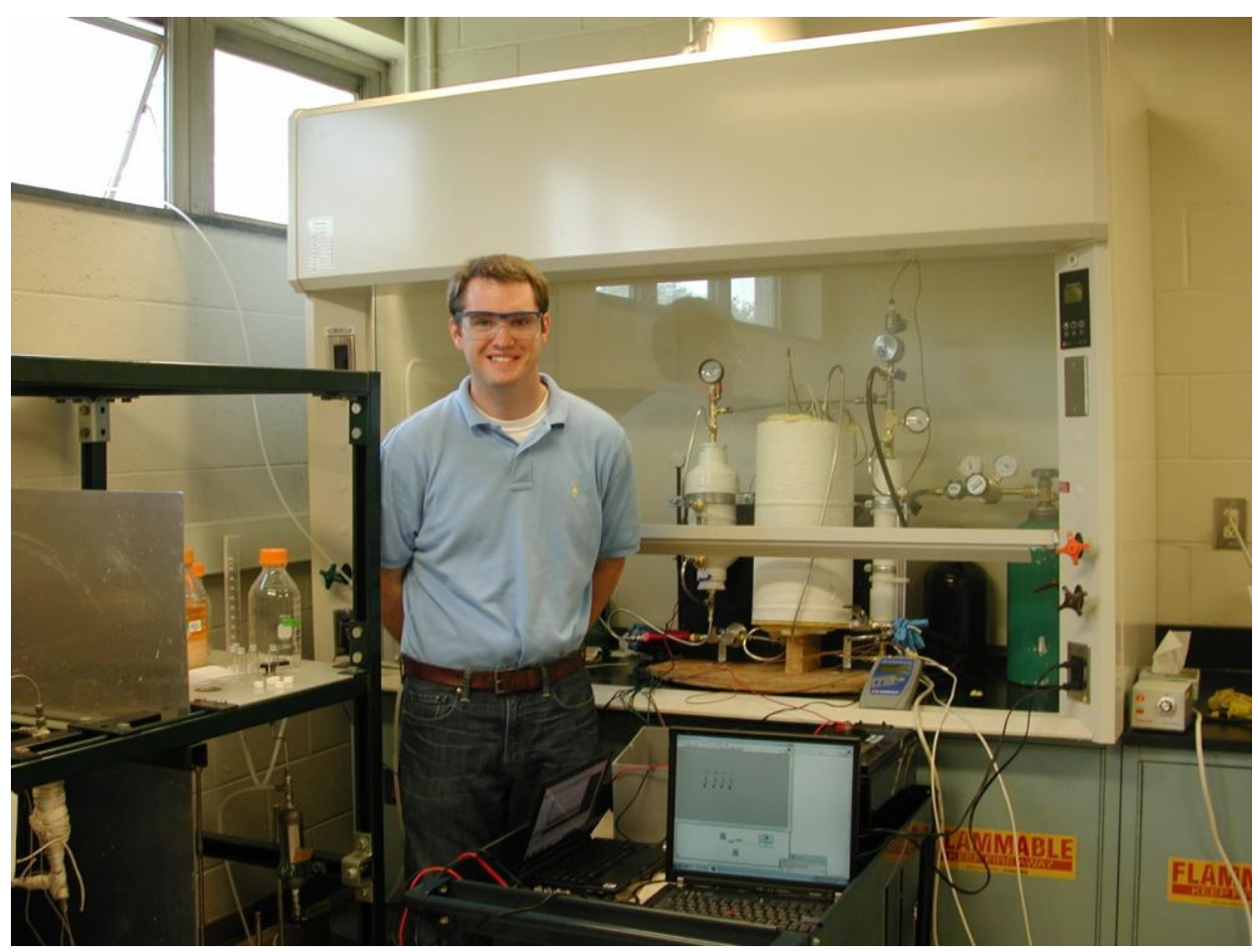

Figure 35 - Demonstration Fuel System Test Installation

Four tests were run with the demonstration fuel system - three with the corrugated monolith and one with the fanfold. During system set-up, the fuel system controller was inadvertently connected to 36 VDC rather than the design voltage of 12 VDC, damaging the control electronics. To prevent any delays in the test schedule, the system was reconfigured by plumbing the reactor to the positive displacement pump that was used for the experimental reactor tests, and the reactor heaters were rewired to manual thermostatic controllers. The reactor thermocouple temperatures were monitored via a portable data logger, and the thermostats were manually adjusted to maintain the correct internal reactor temperature. It was found that the reactor core temperature could be maintained within $\pm 2^{\circ} \mathrm{C}$ using this setup, which was within the desired tolerance. This reconfiguration allowed testing to proceed while the control electronics were repaired.

Initial testing of the corrugated monolith was done with a reactor temperature of $235^{\circ} \mathrm{C}$ to confirm system operation. The reactor temperature was slowly raised to $235^{\circ} \mathrm{C}$, and then neat fuel was introduced at a flow rate of $400 \mathrm{ml} / \mathrm{hr}$. The system was run for approximately 90 minutes under these conditions, with six samples of the liquid reactor products being taken during that time. The results for these six samples are shown in Figure 36. The amount of fluorene produced was fairly consistent throughout the test, averaging $9.7 \%$ of the liquid reaction products. Similarly, the amount of unreacted PHF in the liquid products was fairly steady, averaging $74.5 \%$. More importantly, the demonstration reactor performed without problems under these conditions, paving the way to higher temperature testing. 


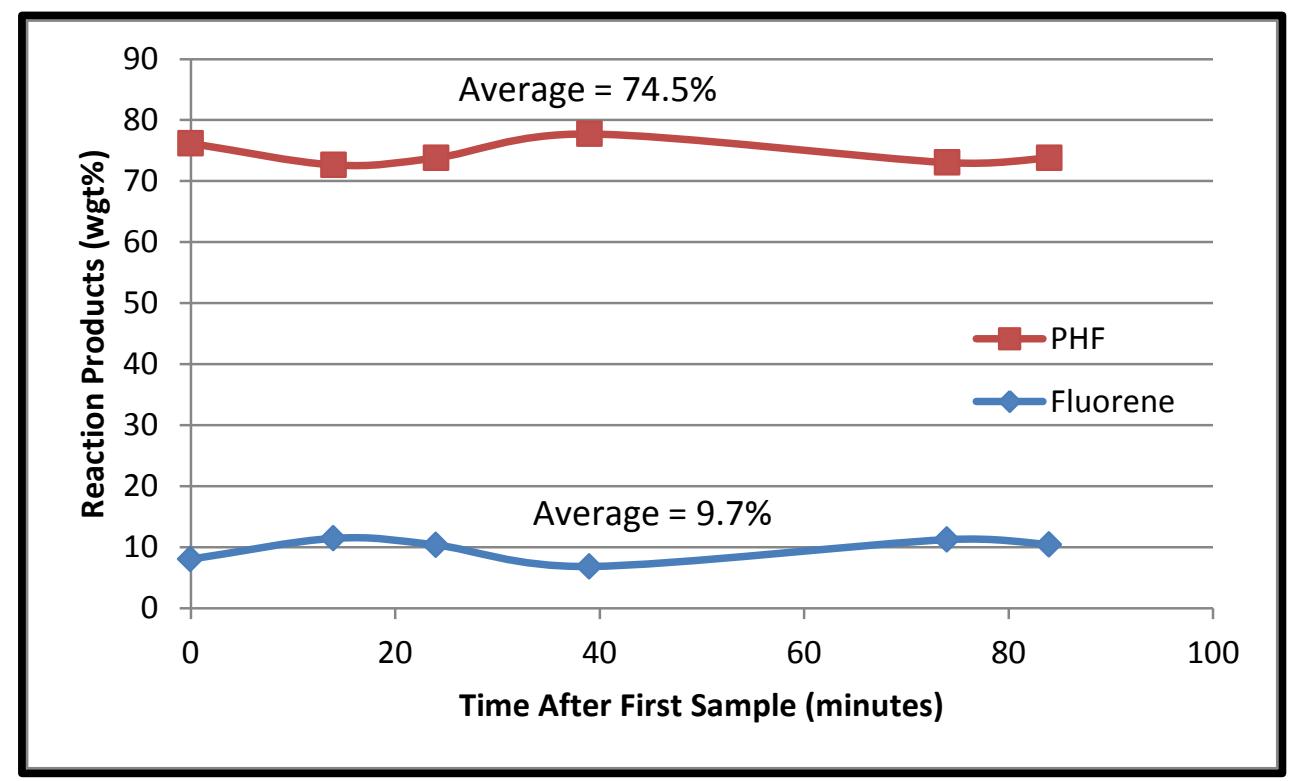

Figure 36 - Demonstration Fuel System Test Results - Test $1\left(T=235^{\circ} \mathrm{C}\right)$

The second test used the same fuel system configuration and test conditions as the first test, except the reactor temperature was increased to $250^{\circ} \mathrm{C}$, so that the results could be compared with the experimental reactor tests. The reactor temperature was slowly raised to $250^{\circ} \mathrm{C}$, and then neat fuel was introduced at a flow rate of $400 \mathrm{ml} / \mathrm{hr}$. The system was run for approximately 90 minutes under these conditions, with seven samples of the liquid reactor products being taken during that time. The results for these seven samples are shown in Figure 37. Again, the production of reaction products was fairly consistent throughout the test, with an average fluorene production level of $16.5 \%$ and an average remaining PHF of $67.4 \%$. However, for this test, the variability in remaining PHF is higher than the variability in fluorene, with early samples showing the lowest amounts of unreacted PHF. The amount of PHF increased with each sample, until a peak of $70 \%$ was reached.

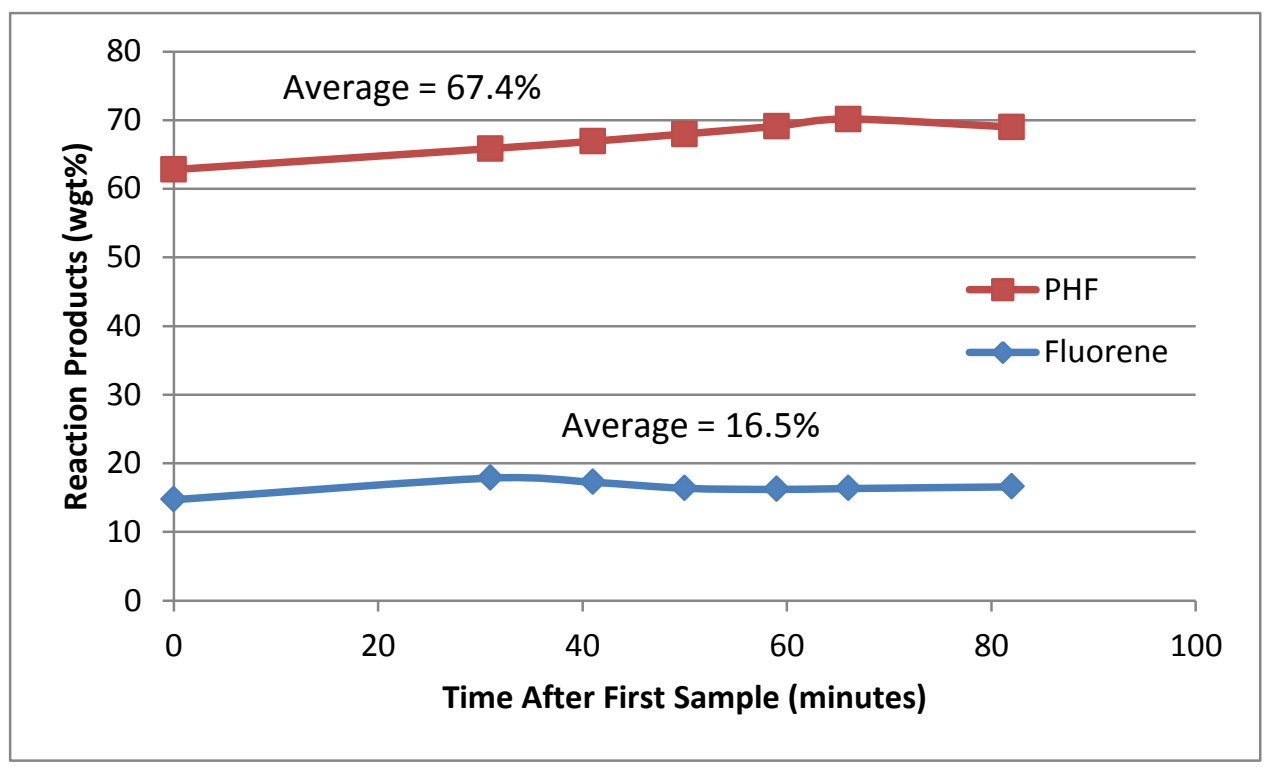

Figure 37 - Demonstration Fuel System Test Results - Test $2\left(\mathrm{~T}=250^{\circ} \mathrm{C}\right)$ 
A comparison of experimental reactor and demonstration fuel system test results is shown in Figure 38. Both reactors used neat fuel, a set point temperature of $250^{\circ} \mathrm{C}$, and a reactor pressure of $1 \mathrm{~atm}$. The flow rates were $50 \mathrm{ml} / \mathrm{hr}$ for the experimental reactor and $400 \mathrm{ml} / \mathrm{hr}$ for the demonstration reactor, resulting in a residence time approximately five times greater in the demonstration reactor, because of the much larger reactor volume. Therefore, the increase in fluorene produced and reduction in the amount of PHF in the product samples was not unexpected. However, the conversion levels were not as high as expected, suggesting that the effectiveness of the catalyst decreased with increasing monolith length, perhaps due to formation of a hydrogen gas film on the surface, however, determining the exact reasons were beyond the scope of this study.

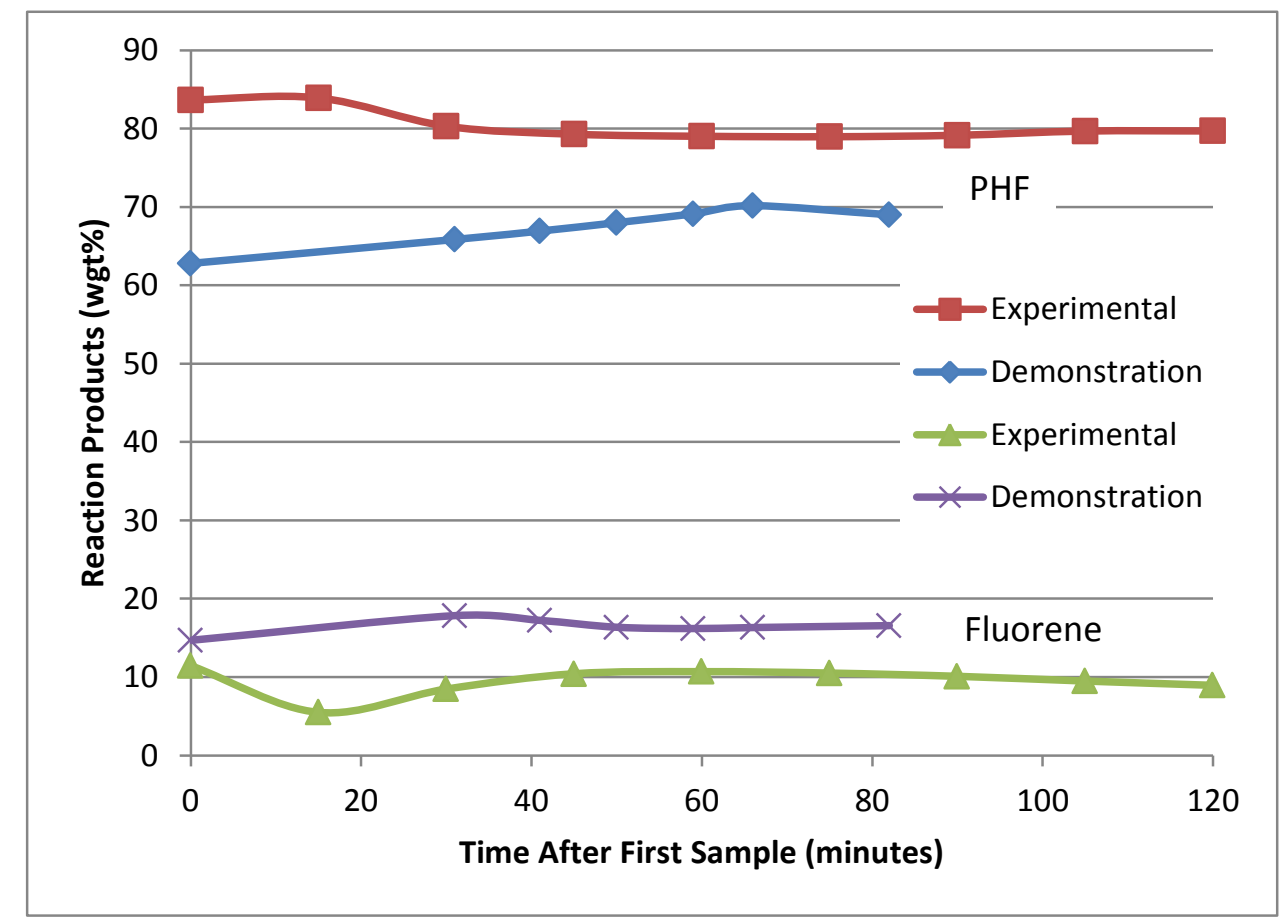

Figure 38 - Comparison of Experimental and Demonstration Reactor Test Results $\left(\mathrm{T}=\mathbf{2 5 0}{ }^{\circ} \mathrm{C}\right)$

To determine the limits of reactor performance, the final test with the corrugated monolith was performed at a reactor core temperature of $270^{\circ} \mathrm{C}$. Repairs of the pump controller circuitry had been completed by this time, so for this test the vehicle fuel pump and controller were used instead of the positive displacement lab pump. The controller was set to deliver fuel in 0.5 second pulses (36.8 $\mathrm{ml} /$ pulse) every 264 seconds, for an average flow rate of $500 \mathrm{ml} / \mathrm{hr}$. The reactor temperature was slowly raised to $270^{\circ} \mathrm{C}$, and then neat fuel flow was started. The system was run for approximately 75 minutes under these conditions, with nine samples of the liquid reactor products being taken during that time. The results for these nine samples are shown in Figure 39. Again, test results were fairly consistent, with average fluorene production of $17.2 \%$ and average unreacted PHF remaining of $72.2 \%$. 


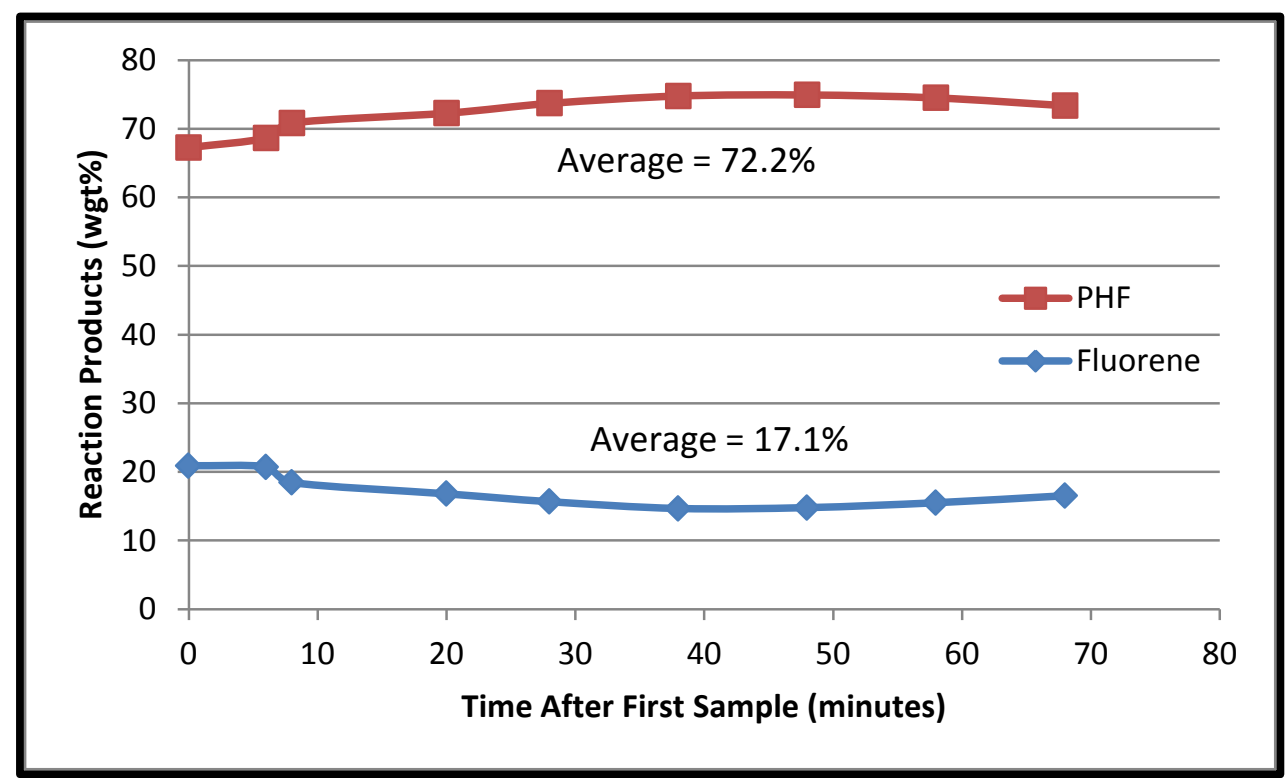

Figure 39 - Demonstration Fuel System Test Results - Test $3\left(T=270^{\circ} \mathrm{C}\right)$

The results for the experimental reactor at $270^{\circ} \mathrm{C}$ using neat fuel are compared with the demonstration system results at the same reactor temperature in Figure 40. The flow rate in the experimental reactor is $50 \mathrm{ml} / \mathrm{hr}$ and $500 \mathrm{ml} / \mathrm{hr}$ in the demonstration reactor, resulting in a residence time in the demonstration reactor that is approximately four times longer than in the experimental reactor. However, the performance of the demonstration reactor is only slightly better, again suggesting that the longer monolith in the demonstration system is not contributing substantially to overall conversion rates.

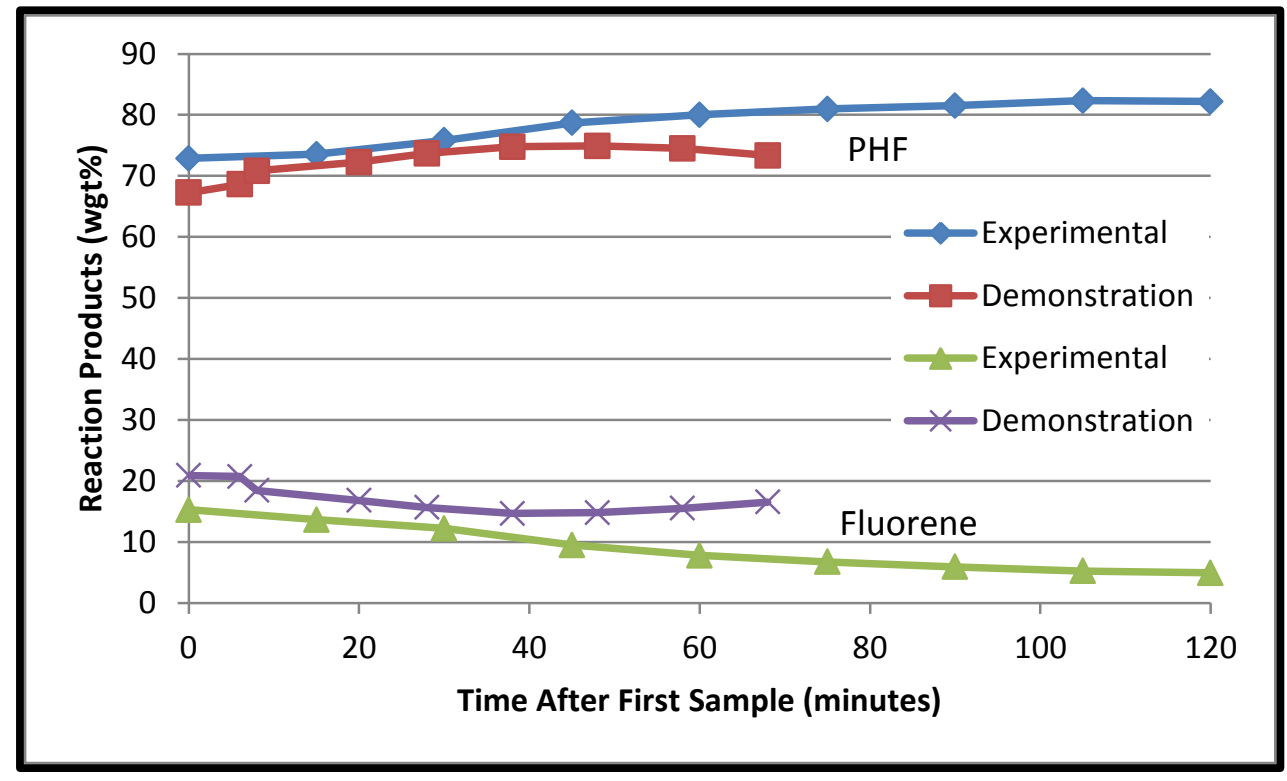

Figure 40 - Comparison of Experimental and Demonstration Reactor Test Results $\left(\mathrm{T}=\mathbf{2 7 0 ^ { \circ } \mathrm { C } )}\right.$

Since it had been postulated that one reason for the reduction in catalyst effectiveness with length might be due to formation of hydrogen gas film in the tiny triangular corrugations of the monolith, an 
alternate monolith design was constructed using a fan fold rather than corrugations. While this monolith had a much smaller surface area to volume ratio (about $1 / 5$ that of the corrugated monolith), it eliminated the small channels and corners. Testing of this monolith was performed at a set point temperature of $250^{\circ} \mathrm{C}$ and two flow rates $-400 \mathrm{ml} / \mathrm{hr}$ and $200 \mathrm{ml} / \mathrm{hr}$. Test results, shown in Figure 41 , were fairly constant, as with the corrugated monolith, with average fluorene production of $10.6 \%$ and $74.7 \%$ of the reaction products consisting of unreacted PHF (for the $200 \mathrm{ml} / \mathrm{hr}$ flow rate).

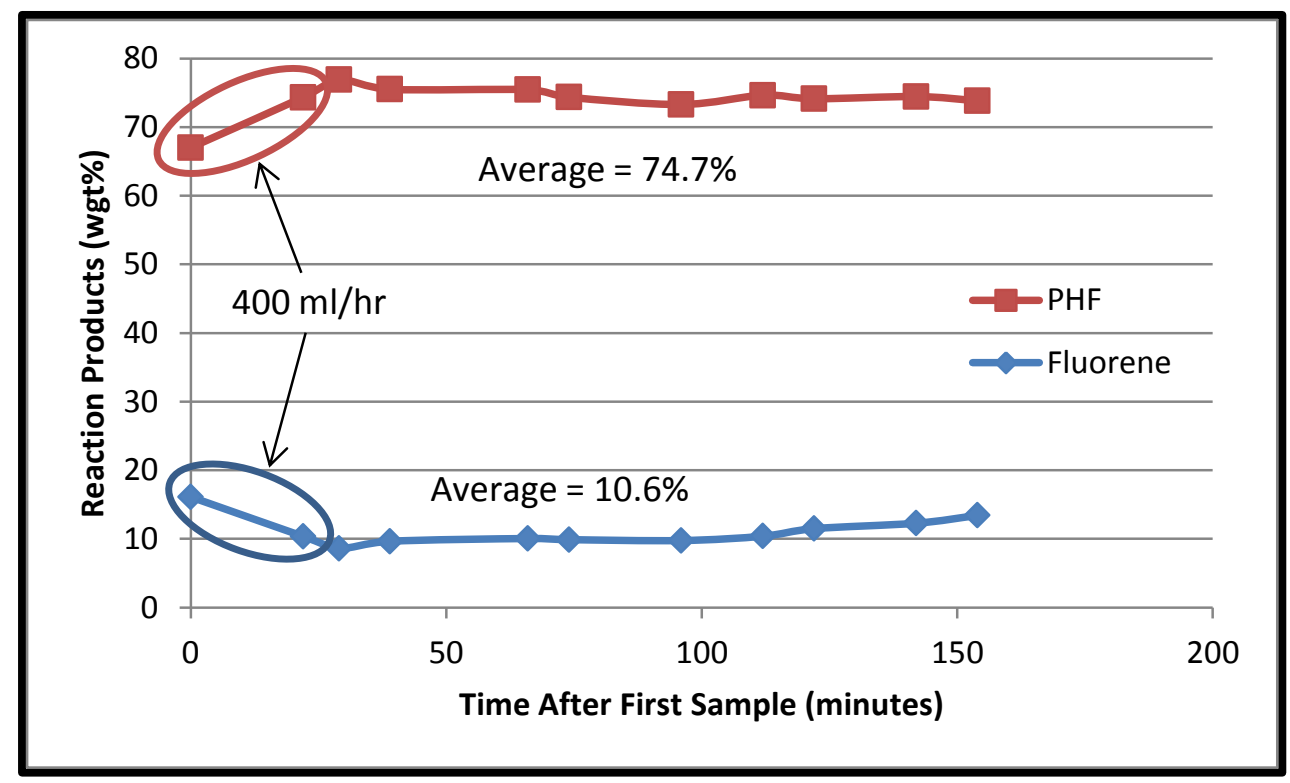

Figure 41 - Demonstration Fuel System Test Results - Test 4 (Fanfold)

A comparison of the four demonstration reactor tests is shown in Figure 42. The corrugated reactor is clearly superior to the fanfold, producing about $70 \%$ more fluorene under similar test conditions. Of the three test conditions used with the corrugated monolith, the $250^{\circ} \mathrm{C}$ reactor showed the best performance based on the amount of fluorene produced and the least amount of unreacted PHF remaining. Results for the $270^{\circ} \mathrm{C}$ test suggest that some of the fluorene was produced from intermediates in the fuel, rather than PHF (the fuels were about $85 \%$ PHF with the remainder consisting of intermediate reactants). 


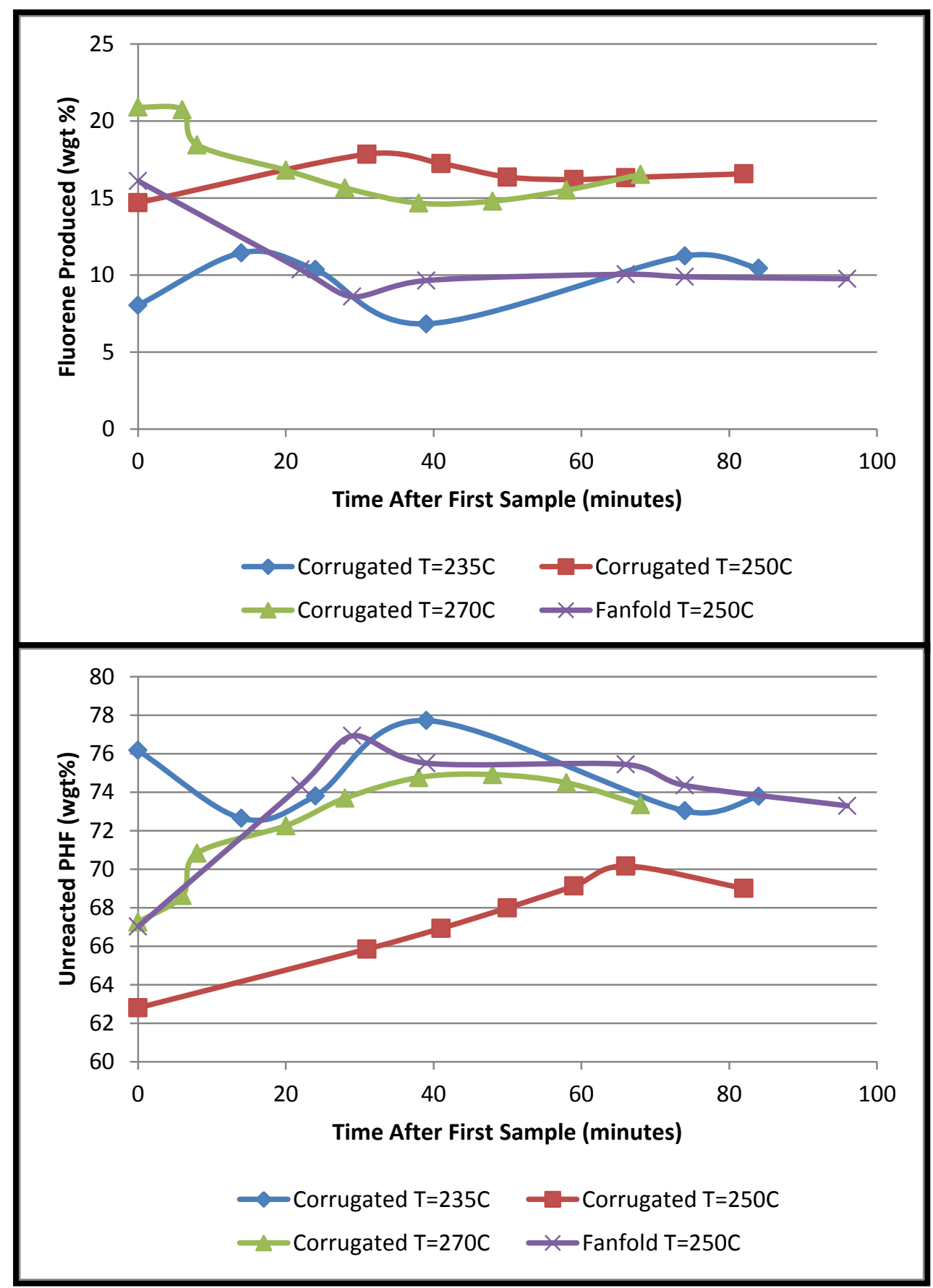

Figure 42 - Comparison of Demonstration Fuel System Test Results

None of the reactor configurations tested produced adequate performance to operate the fuel system in the test vehicle. The test flow rate of $400 \mathrm{ml} /$ hour was only about $1 / 4$ the flow rate needed to produce the amount of hydrogen required to run the fuel cell at full power, assuming an $80 \%$ conversion efficiency. The $20 \%$ conversion efficiency actually achieved was too low to produce adequate hydrogen for fuel cell operation. Therefore, no on-vehicle testing was performed. However, a fit check of the fuel system was conducted to confirm proper system installation. The fuel system installed on the test vehicle is shown in Figure 43. 


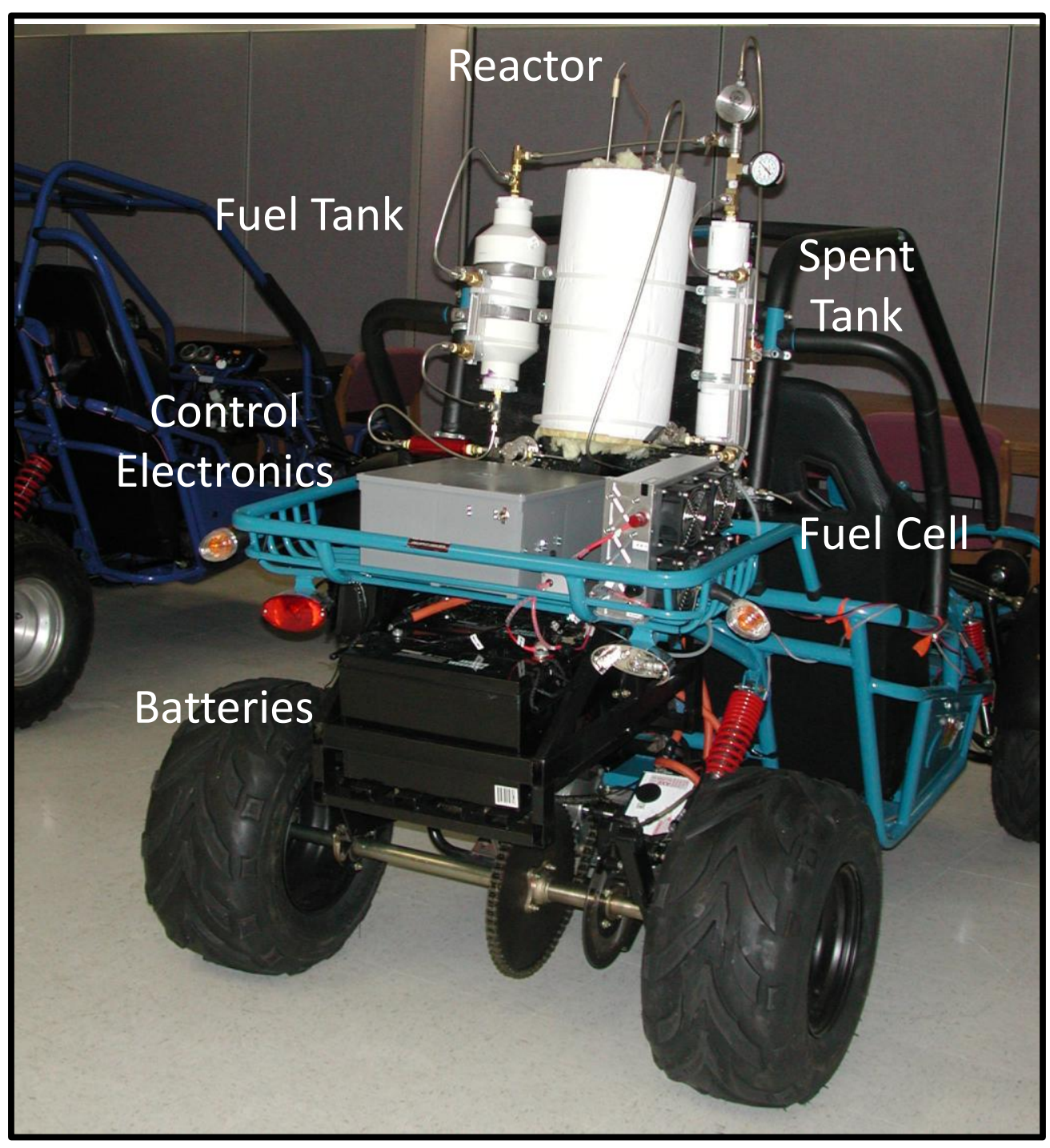

Figure 43 - Fuel System Installation

\subsubsection{Conclusions and Recommendations}

\section{Overall Conclusion and Recommendation}

Conclusion - The concept of performing prototype demonstration and validation in a university innovation center environment proved to be successful. We successfully demonstrated the ability to use existing university faculty, staff, students and laboratory equipment, normally used for basic research, to conduct rapid, low cost prototype demonstration and validation efforts. This capability is particularly useful to small companies with limited resources (e.g. technical experts, specialized equipment, and funding) or larger companies that are exploring product opportunities outside of their core business. Key to this success was having innovation center personnel with product development experience to serve as the project managers and intermediaries between the technology company and the university researchers. 
Recommendation - Universities with research capabilities should consider adding a small staff of personnel with product development expertise to allow the university to assist small businesses with the prototype development and validation phase of product commercialization.

\section{Specific Conclusions and Recommendations for Hydrogen Storage Technologies}

The data collected on the two prototype hydrogen fuel storage technologies was adequate to determine that neither was ready to proceed to the commercialization phase of product development without further research. However, the prototype work that was performed did result in the following specific conclusions and recommendations for each technology.

\section{Propylamine Liquid Carrier}

Conclusion - The basic dehydrogenation reaction, using the three catalysts tested, occurred at a fairly high rate and to a relatively high percentage completion given the short residence time in the reactor, however, the reaction was not highly selective. The best performance achieved was $38.9 \%$ propylamine reacted, but only $9.0 \%$ propionitrile produced; the remainder was unwanted byproducts, including some potentially hazardous byproducts, such as cyanide gas.

Recommendation - A catalyst screening effort should be performed to determine whether a catalyst with high selectivity and high rate can be found.

\section{Perhydrofluorene Liquid Carrier}

Of the two technologies evaluated, the most promising was the perhydrofluorene liquid carrier technology. The test results showed a hydrogenation/dehydrogenation process that occurred with repeatability and reliability. While the level of performance achieved did not reach the level needed to move to the commercialization phase of product development, several promising conclusions were reached, resulting in recommendations for future research.

Conclusion - The basic perhydrofluorene-fluorene reaction is a viable approach to a liquid carrier. The reaction, performed at $250^{\circ} \mathrm{C}$ and 1 atmosphere using a $\mathrm{Pd}$ catalyst, is highly selective. Where byproducts are produced, either during hydrogenation or dehydrogenation, they are intermediates that are readily transformed to the final state with additional reaction time. The production of gaseous hydrogen from liquid fuel greatly simplifies the separation process. Necessary improvements for commercial applications include increasing the overall rate of reaction and the completeness of the reaction. In addition, for some applications, a lower reaction temperature would be beneficial, as would a lower melting point for the fuel and product.

Recommendation - Near term commercial use is possible, with improved reactor/catalyst design. Reactor design approaches that more effectively use the catalyst or that allow longer total residence times (such as multi-chamber, quasi-batch designs) should be explored.

Recommendation - Near term designs should also explore the use of a carrier liquid or gas. The test results showed large improvements in performance (i.e. reaction rate and reaction completion), when toluene was mixed with the PHF fuel. This may have been due to the toluene gas expelling the hydrogen gas from the monolith, preventing it from forming a film on the catalyst surface. Small 
volumes of an inert carrier gas or liquid could be incorporated into the fuel system design with minimal penalty. Designs that utilize this approach should be explored.

Recommendation - Further studies of catalysts should be performed to determine if a higher rate and higher reaction completion can be achieved.

Recommendation - Variations of the PHF and fluorene molecules should be explored that would result in lower melting point temperatures and lower reaction temperatures. 


\section{Works Cited}

1. California Plug-In Electric Vehicle Coooperative. Taking Charge. 2010.

2. A. Brown, L. Rusin and H. Rakouth. Open Innovation: An Automotive Supplier's Perspective. s.I. : SAE Convergence, 2010.

3. L. Huston and N. Sakkab. Connect and develop: Inside Procter \& Gamble's new model of innovation. Harvard Business Review. Vol. 84, 3.

4. Chesbrough, H. W. Open Business Models: How to Thrive in the New Innovation Landscape. 2007.

5. SBA-1. Small Serial Innovators: The Small Firm Contribution to Technical Change. s.l. : Small Business Administration, 2003.

6. SBA-2. Small Firms and Technology: Acquisitions, Inventor Movement, and Technology Transfer. s.I. : Small Business Administration, 2005.

7. Baumol, W. J. Toward Analysis of Capitalism's Unparalleled Growth: Sources and Mechanisms. Entrepreneurship, Innovation, and the Growth Mechanism of the Free Enterprise Economies. 2007.

8. J.P. MacDuffie and T. Fujimoto. Why Dinosaurs Will Keep Ruling the Auto Industry. Harvard Business Review. 2010, Vol. 88.

9. Utterback, J. M. Mastering the Dynamics of Innovation. s.I. : Harvard Business Press, 1994.

10. C.K. Prahalad and V. Ramaswamy. The New Frontier of Experience Innovation. MIT Sloan

Management Review. Vol. 44, 4.

11. A. Ipakchi and F. Albuyeh. Grid of the Future. Power and Energy Magazine. 2009, Vol. 7, 2.

12. Rasin, V. The New Wireless Frontier: Home and Vehicle Connectivity. Convergence International Congress \& Exposition on Transportation Electronics.

13. Grove, A. How America Can Create Jobs. Business Week. Jul 1, 2010.

14. E. Mills and J. Livingston. Traversing the Valley of Death. Forbes.com. [Online] Nov 05, 2005.

15. Lovell, M. Trekking Through That Valley of Death--Sandia Technology. Innovation. 2005, Vol. 3, 3.

16. DOE-1. Reversible Liquid Carriers for an Integrated Production, Storage and Delivery of Hydrogen.

DOE Hydrogen Program: FY2010 Annual Progress Report. III.14, 2010.

17. DOE-2. Reversible Liquid Carriers for an Integrated Production, Storage and Delivery of Hydrogen.

DOE Hydrogen Program: FY2009 Annual Progress Report. III.13, 2009.

18. DOE-3. Hydrogen Storage by Reversible Hydrogenation of Liquid-Phase Hydrogen Carriers. DOE

Hydrogen Program: FY2008 Annual Progress Report. IV.B.2, 2008.

19. G.P Pez, A.R. Scott, A.C. Cooper, and H. Cheng. US Patent 74293722008.

20. G.P. Pez, A.R. Scott, A.C. Cooper, H. Cheng, F.C. Wilhelm, and A.H. Abdourazak. US Patent 7351395 2008.

21. G.P. Pez, A.R. Scott, A.C. Cooper, and H. Cheng. US Patent 71015302006. 